NBSIR 80-2110

\title{
Recommended Testing and Calculation Procedures for Estimating the Seasonal Performance of Residential Condensing Furnaces and Boilers
}

George E. Kelly

Mark E. Kuklewicz

\author{
Building Equipment Division \\ Center for Building Technology \\ National Engineering Laboratory \\ U.S. Department of Commerce \\ National Bureau of Standards \\ Washington, DC 20234
}

April 1981

Sponsored by $Q C$ S. Department of Energy 100 'ashington, DC 20585 

RECOMMENDED TESTING AND

CALCULATION PROCEDURES FOR

ESTIMATING THE SEASONAL

PERFORMANCE OF RESIDENTIAL

CONDENSING FURNACES AND BOILERS

George E. Kelly

Mark E. Kuklewicz

Building Equipment Division

Center for Building Technology

National Engineering Laboratory

U.S. Department of Commerce

National Bureau of Standards

Washington, DC 20234

April 1981

Sponsored by

U.S. Department of Energy

Washington, DC 20585

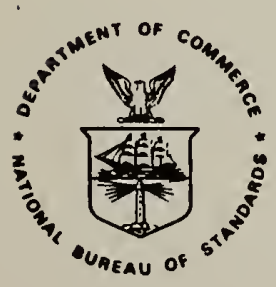

U.S. DEPARTMENT OF COMMERCE, Malcolm Baldrige, Secretary NATIONAL BUREAU OF STANDARDS, Ernest Ambler, Director 

Procedures are developed for testing and rating the performance of residential central furnaces and boilers of the condensing type. A condensing furnace or boiler is a unit designed to condense part of the water vapor generated by the burning of hydrogen in the fuel and equipped with a means of draining this condensate. The test procedure is similar to one developed by the National Bureau of Standards for the Department of Energy covering noncondensing central heating equipment, except that it requires slightly tighter control of the laboratory temperature, a return water temperature of $120^{\circ} \mathrm{F}\left(48.9^{\circ} \mathrm{C}\right)$ with a 20 degree Fahrenheit ( 11.1 degree celsius) water temperature rise for hot water bollers, and offers an optional test procedure for condensing units having no off-period losses. The rating procedure provides a method for estimating the steady-state, part-load and annual fuel utilization efficiencies of condensing furnaces and boilers. It accounts for the fact that the latent heat loss for a condensing unit is smaller than for a conventional furnace or boiler, since some of the water vapor generated from burning hydrogen in the fuel is condensed and thereby gives up part of its latent heat to the heat exchanger and jacket.

Key Words: Annual fuel utilization efficiency; annual operating costs; central heating equipment; condensing boilers; condensing furnaces; part-load performance; rating procedure; seasonal efficiency. 
The authors are indebted to the Department of Energy for funding this study. They also wish to acknowledge the valuable contribution of Mrs. Mary Reppert of the Center for Building Technology, National Bureau of Standards, for editing this report and for her many valuable suggestions for improving its readability.

Note: Based largely upon the recommendations in this report, the Department of Energy (DOE) published a "Final Rulemaking Regarding Amendments to Test Procedures for Furnaces" in the Federal Register; Volume 45, No. 157, August 12, 1980, page 53714 through 53728. This DOE rulemaking covers test procedures for condensing furnaces and boilers and is the official legally binding version of the test procedure which manufacturers of the covered products are required to follow. 


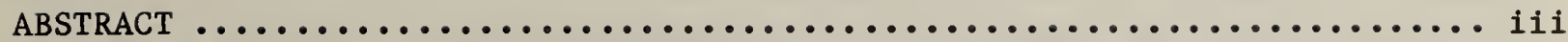

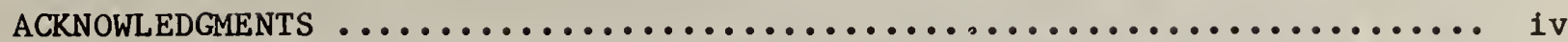

1. INTRODUCTION $\ldots \ldots \ldots \ldots \ldots \ldots \ldots \ldots \ldots \ldots \ldots \ldots \ldots \ldots \ldots \ldots \ldots \ldots \ldots \ldots \ldots \ldots \ldots \ldots$

1.1 Description of Recommended Test Procedures .................. 1

1.2 Description of Recommended Calculation Procedure for Determining the Fuel Utilization Efficiency and the Annual Operating Cost .. 2

2. TEST INSTALLATION AND INSTRUMENTATION $\ldots \ldots \ldots \ldots \ldots \ldots \ldots \ldots \ldots \ldots \ldots \ldots \ldots$

2.1 Installation of Test Plenum, Duct Work, and Piping ........... 3

2.2 Flue Requirements .................................. 4

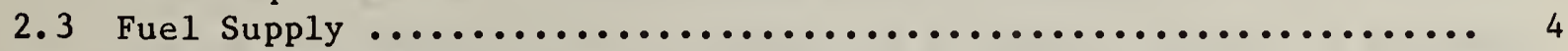

2.4 Burner Ad justments $\ldots \ldots \ldots \ldots \ldots \ldots \ldots \ldots \ldots \ldots \ldots \ldots \ldots \ldots \ldots \ldots \ldots \ldots \ldots \ldots$

2.5 Circulating Air and Water Flow Requirements .............. 5

2.6 Location of Temperature Measuring Instrumentation ............ 6

2.7 Combustion Measurement Instrumentation .................. 7

2.8 Energy Flow Instrumentation $\ldots \ldots \ldots \ldots \ldots \ldots \ldots \ldots \ldots \ldots \ldots \ldots \ldots \ldots \ldots$

2.9 Room Ambient Temperature ........................... 7

2.10 Equipment Used to Measure More Flow Rate Through the Furnace or Boiler ................................... 7

3. TESTING AND MEASUREMENT $\ldots \ldots \ldots \ldots \ldots \ldots \ldots \ldots \ldots \ldots \ldots \ldots \ldots \ldots \ldots \ldots \ldots \ldots$

3.1 Steady State Testing $1 \ldots \ldots \ldots \ldots \ldots \ldots \ldots \ldots \ldots \ldots \ldots \ldots \ldots \ldots \ldots \ldots \ldots$

3.2 Cool Down Test $\ldots \ldots \ldots \ldots \ldots \ldots \ldots \ldots \ldots \ldots \ldots \ldots \ldots \ldots \ldots \ldots \ldots \ldots \ldots$

3.3 Heat Up Test $\ldots \ldots \ldots \ldots \ldots \ldots \ldots \ldots \ldots \ldots \ldots \ldots \ldots \ldots \ldots \ldots \ldots \ldots \ldots \ldots \ldots \ldots$

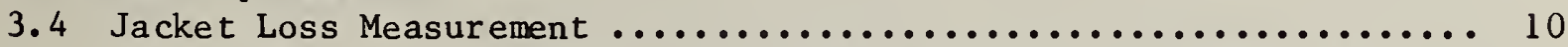

3.5 Measurement for Determining the Effectiveness of Automatic Flue

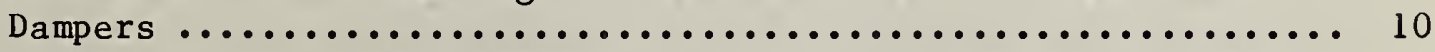

3.6 Optional Procedure for Determining $\mathrm{D}_{\mathrm{p}}$ and $\mathrm{D}_{\mathrm{F}}$ for Pulse Combustion

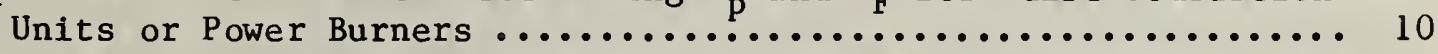

3.7 Optional Procedures for Condensing Furnaces and Boilers Which Have No Off-Period Flue Losses .......................... 11

4. CALCULATION OF DERIVED RESULTS FROM TEST MEASUREMENTS .......... 12

4.1 Recommended Procedure for Calculating the Annual Fuel Utilization Efficiency for Condensing Furnaces and Boilers .............

4.2 Recommended Procedures for Calculating the Annual Cost of Operation of a Condensing Furnace or Boiler Located in Different Climate Regions of the Country and in Buildings with Different

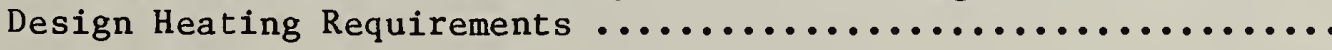


4.3 Additional Calculations for Condensing Furnaces or Boilers

Utilizing Automatic Flue Dampers ....................... 16

4.4 Additional Calculation Procedures for Furnaces or Boilers with

Power Burners ..................................... 16

REFERENCES

APPENDIX A: Calculation Procedures for Non-Condensing Furnaces and Boilers

APPENDIX B: Computerized Calculation Procedure for Condensing and NonCondensing Furnaces and Boilers

APPENDIX C: Using Condensate Measurement for Calculation of Annual

Fuel Utilization Efficiency of Condensing Furnaces

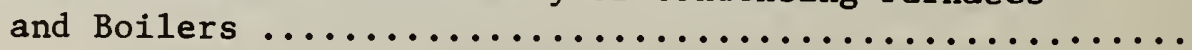


The test and calculation procedures recommended herein apply to residential central furnaces and boilers of the condensing type. A condensing furnace or boiler is a unit which is designed to condense part of the water vapor generated by the burning of hydrogen in the fuel and is equipped with a means of draining this condensate. For the purposes of this test procedure, a furnace or boiler shall be considered to be of the condensing type if the latent heat loss coefficient $C_{L}$, defined in step 68 of the calculation procedure, in section 4.1 is less than 1 when the unit is evaluated in a hypothetical test cycle having a percent on-time of $22.5 \%$ and, if the unit is a boiler, the return water temperature is $120^{\circ} \mathrm{F}\left(48.9^{\circ} \mathrm{C}\right)$.

\subsection{DESCRIPTION OF RECOMMENDED TEST PROCEDURES}

The testing procedure for condensing furnaces and boilers is almost identical to the procedure that has been developed for non-condensing units $[1,2]$. It consists of a steady-state performance test and cool-down and heat-up tests to determine the flue gas temperature vs. time profiles during the off-and on-periods. It differs from the conventional furnace and boiler test procedure in that it requires control of laboratory temperature between $65^{\circ} \mathrm{F}$ and $85^{\circ} \mathrm{F}$, a return water temperature of $120^{\circ} \mathrm{F}\left(48.9^{\circ} \mathrm{C}\right)$ with a 20 degree Fahrenheit (11.1 degree Celsius) water temperature rise for hot water boilers, and offers an optional test procedure (section 3.7) for condensing units whose design is such that there is absolutely no chance of air flow through the combustion chamber during the off-period. This optional procedure allows a manufacturer to test and rate his unit using only the steady-state test, thereby neglecting the slight gain in performance that his unit is likely to experience during the on-period when operating in a cyclic manner. This effect is not expected to be very large and allowing the manufacturer to eliminate the cool-down and heat-up test greatly simplifies the test and calculation procedures.

The requirements that the boiler be tested with a return water temperature of $120^{\circ} \mathrm{F}\left(48.9^{\circ} \mathrm{C}\right)$ and a water temperature rise of 20 degrees Fahrenheit (11.1 degrees (elsius) should result in an average distribution system water temperature, $\overline{\mathrm{T}_{\mathrm{AV}}}$, of approximately $130^{\circ} \mathrm{F}\left(54.4^{\circ} \mathrm{C}\right)$. This value was selected using the assumption that the average boiler. water temperature used to meet the building load at an outdoor design temperature of $5^{\circ} \mathrm{F}\left(-15^{\circ} \mathrm{C}\right)$ might typically be $190^{\circ} \mathrm{F}\left(87.8^{\circ} \mathrm{C}\right)$ and that the heat transfer from baseboard convectors to the room air was proportional to $\left(\mathrm{T}_{\mathrm{AV}}-\mathrm{T}_{\mathrm{A}}\right) 1.5$, where $\mathrm{T}_{\mathrm{A}}$ is the room air temperature [3]. Assuming a typical residential zero-load temperature of $65^{\circ} \mathrm{F}\left(18.3^{\circ} \mathrm{C}\right)$ and continuous water circulation, it can then be shown that an average boiler water temperature of approximately $130^{\circ} \mathrm{F}\left(54.4^{\circ} \mathrm{C}\right)$ would be required to meet the house's heating load at an outdoor temperature of $42^{\circ} \mathrm{F}\left(5.56^{\circ} \mathrm{C}\right)$, which is the average heating season temperature used to rate non-condensing furnaces and boilers in NBSIR 78-1543 [1]. While cyclic operation of the pump will tend to raise the temperature of the water required during the on-period to meet the building load, its exact effect depends on factors outside the control of the boiler manufacture (i.e. the mass of and water content in distribution system, the type of distribution 
system, the size of the house, etc.) and has been ignored in the present version of this test procedure. The average boiler water temperature rise of 20 degrees Fahrenheit ( 11.1 degrees Celsius) was selected because it is believed to be typical of temperature rises found in the field and results in uniform heating of a house without the designer of the distribution system having to be concerned about excessive temperature drops throughout the system.

\subsection{DESCRIPTION OF RECOMMENDED CALCULATION PROCEDURE FOR DETERM INING THE FUEL UTILIZATION EFFICIENCY AND THE ANNUAL OPERATING COST}

Condensing furnaces and boilers are extremely complex heating devices. Their efficiency, as measured by the input/output method, is dependent on the return water (or air) temperature, the temperature and moisture content of the incoming combustion air, and even the barometric pressure. These effects would tend to make it extremely difficult to devise a test and rating procedure which yielded consistent and repeatable results if it were not for the fact that a preliminary test of a pulse combustion, condensing boiler at the National Bureau of Standards tended to show that the flue gas temperature was primarily a function of the return water temperature. Large changes in the temperature and absolute humidity of the incoming combustion air (and also, by implication, the barometric pressure) had an almost negligible effect on the measured flue gas temperature. These findings indicated than an acceptable procedure for rating a condensing boiler/furnace would be to determine its flue gas temperature at a typical return water/air temperature and then to calculate its flue losses assuming dry combustion air having an average (heating season) temperature of $42^{\circ} \mathrm{F}\left(5.56^{\circ} \mathrm{C}\right)$. This assumes that most of these condensing units will be of the direct-vent type which uses outdoor air for combustion, and that this combustion air would typically have a very low water vapor content (be nearly dry). To keep the calculation procedure as close as possible to that given for non-condensing units in section 4.1 of NBSIR 78-1543 and to avoid confusion, it was decided that all condensing furnaces and boilers (including direct exhaust units using indoor combustion air) should be rated as direct-vent devices. This is expected to result in an insignificant error for condensing units using indoor combustion air for the following reasons: the combustion air must be heated up regardless of whether it comes from inside or outside the residence; direct vent and direct exhaust units do not use dilution air for draft control ( $/ F=1)$; and condensing furnaces and boilers have very low flue gas temperatures (and thus very low losses).

As a result of the observations and assumptions described above, the calculation procedure for determining the steady-state $\left(n_{S S}\right)$ and part-load $\left(\eta_{u}\right)$ efficiencies of condensing furnaces and boilers is only slightly changed from the procedure specified in section 4.1 of NBSIR 78-1543 for noncondensing units [1]. The major difference is that, for condensing boilers, the steady-state efficiency is the value measured in the steady-state test corrected to a return water temperature of $180^{\circ} \mathrm{F}\left(82.2^{\circ} \mathrm{C}\right)$, and, for condensing furnaces and boilers, a procedure is provided (in steps 68 and 69) to account for the fact that the latent heat loss, $L_{L, A}$, is reduced, since some of the water vapor (generated from the burning of hydrogen in the fuel) is condensed and gives up part of its latent heat to the heat exchanger and 
jacket. In addition, a procedure is given to calculate $n_{u}$ using only steady-state operating losses, if the optional test procedure in section 3.7 is employed for a pulse combustion unit whose design is such that there is absolutely no chance of air flow through the unit during the off-period.

As in the case of non-condensing units, the part-load efficiency, $\eta_{u}$, is found for a single cycle having a percent on-time of $22.5 \%$ and then corrected for the effect of the pilot light during the non-heating season, if applicable, to arrive at the annual fuel utilization efficiency, $\mathrm{EFFY}_{A}$ The $^{-}$ procedure for calculating the annual cost of operation of condensing furnaces and boilers is unchanged from that specified in section 4.2 of NBSIR 78-1543 [1].

\section{TEST INSTALLATION AND INSTRUMENTATION}

The test requirements for gas and oil-fired condensing furnaces and boilers are, in general, identical to those described in NBSIR 78-1543 for forced air furnaces and hot water boilers, except that:

a) tighter room temperature control is required during the condensing furnace test, and

b) different supply and return water temperatures are employed in testing condensing boilers, and a means must be provided to maintain these water temperatures within strict limits.

\subsection{INSTALLATION OF TEST PLENUM, DUCT WORK, AND PIPING}

\subsubsection{Condensing Furnaces}

For gas-fueled condensing furnaces, the plenum and test duct requirements are the same as those specified for gas-fueled, forced-air furnaces in sections 2.1.9 and 2.1.10 of ANSI Standard 221.47-1973. For oil-fueled condensing furnaces, the plenum and test duct requirements are identical to those specified in section 6.2 of ANSI Standard 291.1-1972.

\subsubsection{Condensing Boilers}

Piping requirements are identical to those described in section 2.9 of ANSI Standard 221.13-1974 for gas-fueled condensing boilers and those described in sections 7.0 and 8.1 .1 through 8.1 .3 of the Hydronic Institute's Testing and Rating for Cast Iron and Steel Heating Boilers, January 1977 edition, for oil-fueled condensing boilers, except that a means shall be provided to supply $120^{\circ} \mathrm{F}\left(48.9^{\circ} \mathrm{C}\right)$ return water, at a constant rate, to the test boiler during both the steady-state and heat-up tests described below. This will typically, although not necessarily, require the use of a large water tank, an auxiliary boiler, and two pumps. 


\subsection{FLUE REQURIEMENTS}

The exhaust/air intake system supplied by the manufacturer shall be in place during all tests. Units intended for installation with a variety of ventpipe lengths shall be tested with the minimum vent length recommended by the manufacturer. A furnace or boiler employing a direct-vent system shall not be connected to a chimney or induced draft source, but shall depend for venting of the combustion products solely on the provision for venting incorporated in the furnace and the exhaust/air intake system supplied with it. The first 18 inches of vent pipe downstream of the furnace outlet shall be covered with a layer of insulation having an $R$ value not less than $7\left({ }^{\circ} \mathrm{F}-\mathrm{h}-\mathrm{ft}^{2} / \mathrm{Btu}\right)$ and an outer layer of aluminum foil. Care should be taken to not block the air intake with insulation, where appropriate.

\subsection{FUEL SUPPLY}

\subsubsection{Natural Gas}

For a furnace or boiler utilizing natural gas, maintain the gas supply to the unit under test at a normal inlet test pressure immediately ahead of all controls at 7 to 10 inches water column. The regulator outlet pressure at normal test pressure shall be that recommended by the manufacturer. Use natural gas having a specific gravity of approximately 0.65 and a higher heating value within $+5 \%$ of 1025 Btu per standard cubic foot. Determine the actual higher heating value in Btu's per standard cubic foot for the natural gas to be used in the test with an error no greater than one percent.

\subsubsection{Propane Gas}

For a furnace or boiler utilizing propane gas, maintain the gas supply to the unit under test at a normal inlet pressure immediately ahead of all controls of 11 to 13 inches water column and a specific gravity of 1.53. The regulator outlet pressure, on units so equipped, shall be approximately that recommended by the manufacturer. Use propane HD-5 having a specific gravity of approximately 1.53 and a higher heating value within $\pm 5 \%$ of 2500 Btu's per standard cubic foot. Determine the actual higher heating value in Btu's per standard cubic foot for the propane to be. used in the test with an error no greater than one percent.

\subsubsection{Other Test Gas}

The specific gravity of other test gases shall approximate the values given in Table IX of ANSI Standard A21.47-1973. The test pressures immediately ahead of all controls shall be maintained between the "normal" and "increased" values of test pressures given in Table $X$ in the above ANSI Standard. The measured higher heating values shall be within $\pm 5 \%$ of the values specified in Table IX, in ANSI Standard 221.47-1973. The actual higher heating value of the gas used in the test shall be determined with an error no greater than one percent. 
For a furnace or boiler utilizing fuel oil, the fuel oil used shall be No. 1 or No. 2 fuel oil and shall conform to the specifications outlined in Tables 2 and 3 of ANSI Standard 291.1-1972. The higher heating value of the test fuel oil shall be measured with an error no greater than one percent.

\subsubsection{Electrical Supply}

For an electric furnace or boiler, or for an auxiliary electric component of the gas-and oil-fueled furnace or boiler, maintain the electrical supply to the test unit within one percent of the nameplate voltage for the entire portion of the test cycle. If a voltage range is used for nameplate voltage, maintain the electrical supply within one percent of the center of the nameplate voltage range.

\subsection{BURNER ADJUSTMENTS}

The burners on gas- or oil-fueled, condensing furnaces and boilers shall be adjusted to give, during the steady-state performance test described below, the $\mathrm{CO}_{2}$ reading recommended by the manufacturer (if applicable) and an hourly Btu input rate which is within $\pm 2 \%$ of the manufacturer's specified nominal hourly Btu input rating (nameplate rating). During the steady-state performance test, the concentration of carbon monoxide present in dry flue gas shall not exceed 0.04 percent by volume. For oil-fired condensing units, the smoke in the flue gases shall not exceed No. 1 smoke during the steady-state performance test as measured by the procedure in ANSI Standard Z11.182 - 1965 (R 1971) (ASTM D2156-65 (1970)). If the carbon monoxide or smoke exceeds these specified limits during the steady-state test, the burner shall be readjusted to give a lower $\mathrm{CO}_{2}$ reading and all tests shall be started over. Once the burner is properly adjusted, no additional adjustments shall be made to it during the required series of performance tests.

If a vent-limiting means is provided on a gas pressure regulator, it shall be in place during all tests.

\subsection{CIRCULATING AIR AND WATER FLOW REQUIREMENTS}

\subsubsection{Condensing Furnaces}

For gas-fueled, condensing furnaces, the external static pressure and air throughout shall be adjusted as specified in sections $2.1 .11,2.1 .12$ and 2.1.13 of ANSI Standard 221.47-1973, except that the temperature rise during the steady-state test described below shall be the maximum temperature rise specified by the manufacturer.

For oil-fueled, condensing furnaces, the external static pressure and air throughput shall be adjusted as specified in Table 5 and section 6.2 of ANSI Standard 291.1-1972, except that the temperature rise during the steadystate test described below shall be the maximum temperature rise specified by the manufacturer. 
During the steady-state and heat-up tests described below, the return air temperature to the gas-or oil-fueled, condensing furnace shall remain within \pm 5 degrees Fahrenheit ( +2.8 degrees Celsius) of the value of the room temperatures, $\mathrm{T}_{\mathrm{RA}}$ measured during the steady-state performance test.

\subsubsection{Condensing Boilers}

The water flow rate through the condensing boiler shall be adjusted to produce a water temperature rise, during the steady-state test described below, which is between 19.5 and 20.5 degrees Fahrenheit ( 10.8 and 11.4 degrees Celsius). During the steady-state test and the heat-up test, the condensing boiler shall be supplied with return water having a temperature of $120^{\circ} \mathrm{F}$ $\left(48.9^{\circ} \mathrm{C}\right)$. The maximum permissible variation of the return water temperature from the required value, during the steady-state and heat-up tests, shall not exceed plus or minus 2 degrees Fahrenheit ( 1.1 degrees Celsius), except during the first 30 seconds after start up it shall not exceed plus or minus 10 degrees Fahrenheit ( 5.56 degrees Celsius) and between 30 and 60 seconds after start up it shall not exceed plus or minus 5 degrees Fahrenheit (2.78 degrees Celsius).

\subsection{LOCATION OF TEMPERATURE MEASURING INSTRUMENTATION}

A grid of thermocouples shall be installed in a test plane parallel to and located within 12 inches $(30.5 \mathrm{~cm})$ of the furnace or boiler outlet. The grid shall consist of either 9 or 17 thermocouples (manufacturer's option) if the nominal inside diameter of the flue pipe is greater than 2 inches $(5.1 \mathrm{~cm})$ and 5 thermocouples if the nominal inside diameter of the flue pipe is less than or equal to 2 inches $(5.1 \mathrm{~cm})$. The thermocouples making up the grid shall be wired in pa:allel and the length of all thermocouple leads shall be equal before paralleling. Locate one thermocouple in the center of the vent pipe and eight (sixteen) [four] thermocouples along imaginary lines intersecting at right ( 45 degree) [right] angles in this test plane at points $1 / 3$ and $2 / 3(1 / 3$ and $2 / 3)$ [half] the distance between the center of the flue pipe and the pipe wall.

Bead-type thermocouples shall be used having wire size not greater than No. 24 American Wire Gauge (AWG). If there is a possibility that the thermocouples could recelve direct radiation from the fire, radiation shields shall be installed on the fire-side of the thermocouples only and the shields positioned so that they do not touch the thermocouple junctions.

The location of thermocouples used for measuring conditioned warm air are described in ANSI 221.47-1973, sections 2.1.9 and 2.9.1. The temperature of the inlet air shall be established by means of a single No. 24 AWG bead-type thermocouple, suitably shielded from direct radiation and location in the center of the plane of each inlet air opening.

The inlet and outlet water temperatures on both gas-fueled and oil-fueled hot water boilers shall be measured using sheathed thermocouples inserted through pipe plugs that are located within 12 inches $(30.5 \mathrm{~cm})$ of the inlet and outlet of the boiler. A minimum of 6 inches $(15.3 \mathrm{~cm}$ ) of thermocouple lead, 
immediately upstream of the thermocouple junction, shall be immersed in the water between the pipe plug and the boiler inlet/outlet. The remainder of the thermocouple lead shall be run along the surface of the pipe (and under any insulation) for a distance of not less than 3 feet $(183 \mathrm{~cm})$. The three feet of pipe immediately before the boiler inlet and the three feet immediately after the boiler outlet shall be covered with insulation having an $R$ value of not less than $7\left({ }^{\circ} \mathrm{F}-\mathrm{h}-\mathrm{ft} \mathrm{t}^{2} / \mathrm{Btu}\right)$ and an outer layer of aluminum foil.

\subsection{COMBUSTION MEASUREMENT INSTRUMENTATION}

The flue gases for condensing furnaces and boilers shall be analyzed to determine the concentration by volume of carbon dioxide $\left(\mathrm{CO}_{2}\right)$ present in the dry flue gas, with instrumentation which will result in a determination of the $\mathrm{CO}_{2}$ concentration with an error no larger than \pm 0.1 percentage points.

\subsection{ENERGY FLOW INSTRUMENTATION}

Install one or more instruments which measure the quantity of electrical energy and gas or fuel oil supplied to the furnace or boiler during the steady-state and heat-up tests with an error no larger than one percent.

\subsection{ROOM AMBIENT TEMPERATURE}

During the time period required to perform all the testing and measurement procedures specified in section 3 , the laboratory room temperature shall remain within \pm 5 degrees Fahrenheit $\left( \pm 2.8\right.$ degrees Celsius) of the value $\mathrm{T}_{\mathrm{RA}}$ measured during the steady-state performance test. At no time during these tests shall the room temperature exceed $85^{\circ} \mathrm{F}\left(37.8^{\circ} \mathrm{C}\right)$ or fall below $65^{\circ} \mathrm{F}\left(18.3^{\circ} \mathrm{C}\right)$. Use the procedure outlined in section 2.1 .14 of ANSI Standard 21.47-1973 to measure room temperature.

\subsection{EQUIPMENT USED TO MEASURE MASS FLOW RATE OF AIR THROUGH THE FURNACE OR BOILER DURING THE OFF-PERIOD}

The tracer gas chosen for this task should have a density which is less than or approximately equal to the density or air. It shall be of different chemical species or significantly larger concentration from the flue gas to be measured and shall be unreactive with the environment to be encountered. Instrumentation used to measure the concentration of tracer gas may be either the batch or continuous type which will result in a reading having an error no larger than $\pm 2 \%$ of the value of the concentration measured.

\section{TESTING AND MEASUREMENT}

\section{1 STEADY-STATE TESTING}

The furnace or boiler shall be set up as specified in sections $2.1,2.2,2.3$ and 2.6. Begin the test by operating the burner and circulating air blower or water pump, with the adjustments specified in 2.4 and 2.5 , until 
steady-state conditions are obtained, as indicated by a temperature variation in three successive readings taken 15 minutes apart of not more than 1 degree Fahrenheit ( 0.56 degrees Celsius) in the flue gas temperature and the supply (outlet) water temperature, for hot water boilers.

Measure the room temperature $\left(\mathrm{T}_{\mathrm{RA}}\right)$ as described in section 2.9, and measure the steady-state flue gas temperature ( $\mathrm{T} F, \mathrm{SS})$ using the thermocouple grid described in section 2.6. A sample of the flue gas shall be secured in the plane of temperature measurement or within $31 / 2 \mathrm{feet}(107 \mathrm{~cm})$ of this plane on the downstream side and analyzed to determine the concentration by volume of $\mathrm{CO}_{2}\left(\mathrm{X}_{\mathrm{CO}_{2}, \mathrm{~F}}\right)$ present in the dry flue gas. If the location of sampling the $\mathrm{CO}_{2}$ differs from the temperature measurement plane, care should be taken to assure that there are no air leaks in the flue pipe between these two locations.

The steady-state heat input rate $\left(Q_{i n}\right)$, including pilot light gas input if appropriate, shall be determined by multiplying the measured higher heating value of the test fuel by the measured steady-state input rate. If gas is the fuel used, correct the input rate to standard conditions of $60^{\circ} \mathrm{F}\left(15.6^{\circ} \mathrm{C}\right)$ and 30 inches of mercury ( $762 \mathrm{~mm}$ of measuring) using measured values of gas temperature and pressure at the meter and the measured barometric pressure.

Measure the steady-state electric power to the burner (PE), if appropriate. For furnaces, measure the steady-state electrical power to the conditioned air blower (BE). For hot water boilers, use a steady-state water pump power of $B E=0.13 \mathrm{~kW}$.

Record all measured values.

\subsection{COOL-DOWN TEST}

\subsubsection{Gas-and 011-Fueled Condensing Furnaces}

After steady-state testing is completed and all required measurements made, the burner shall be turned off and the flue gas temperature measured, ( $\mathrm{T}_{\mathrm{f}, \text { off }}$ ) by means of the thermocouple grid described in 2.6 , at 1.5 minutes $\left(t_{3}\right)$ and 9.0 minutes $\left(t_{4}\right)$ after the burner shuts off. Units employing flue dampers or a stack damper in conjunction with a barometric damper shall have their flue or stack dampers closed during the cool-down test. During this off-period, there shall be a time delay, $\mathrm{t}^{+}$, between burner shut-down and blower shut-down of either 1.5 minutes or until the supply air temperature drops to a value of 40 degrees Fahrenheit (22.2 degrees Celsius) above the inlet air temperature, whichever results in the longer blower on-time. An exception to this is that if the furnace employs a single motor drive a power burner and an indoor air circulating blower, the blower and the burner shall be shut off together. If the blower delay time exceeds 1.5 minutes, the time between burner shut-off and blower shut-off shall be measured using a stop watch and the quantity $t^{+}$shall be set equal to this measured delay time or 13.30 minutes, whichever is smaller. For units equipped with a continuously burning pilot light, the main burner(s) shall remain off until equilibrium conditions are attained, 
as indicated by variations in the flue gas temperature of not more than 0.5 degrees Fahrenheit ( 0.28 degrees Celsius) in three sucessive readings taken 15 minutes apart, and then a third flue gas temperature measurement shall be made to determine the off-period minimum flue gas temperature $\left(T_{F}\right.$ off $\left.(\infty)\right)$. For units not equipped with a continuously operating pilot light, $\mathrm{T}_{\mathrm{F}}$, off $(\infty)$ shall be set equal to the measured room temperature $\mathrm{T}_{\mathrm{RA}}$ and the unit shall remain off for a minimum time period of 20 minutes.

During the cool-down test, the energy input rate to the pilot light $\left(Q_{P}\right)$, if the unit is so equipped, shall be measured to within an accuracy of $\pm 3 \%$. Record all measured values.

\subsubsection{Gas- and 0il-Fueled Condensing Boilers}

After steady-state testing is completed, the main burner(s) shall be turned off and the flue gas temperature, $T_{F}$, off measured at $3.75\left(t_{3}\right)$ and 22.5 $\left(t_{4}\right)$ minutes after the burner(s) shuts off, using the thermocouple grid described in section 2.6. During this off-period, no water shall be allowed to circulate through the boiler. A third flue gas temperature shall be made 45 minutes after the burner(s) shuts off to determine the off-period minimum flue gas temperature $\left(\mathrm{T}_{\mathrm{f}}\right.$ off $\left.(\infty)\right)$. During this cool-down test, the energy input rate to the pilot light $\left(Q_{P}\right)$, if the unit is so equipped, shall be measured with an error no larger than $\pm 3 \%$. For units equipped with flue dampers, the damper shall be closed during the cool-down test. Record all measured values.

\subsection{HEAT-UP TEST}

\subsubsection{Gas- and 0i1-Fueled Condensing Furnaces}

After the cool-down test is completed, the furnace shall be turned on and the flue gas temperature measured, $\left(\mathrm{T}_{\mathrm{f}_{5} \text { on }}\right)$ using the thermocouple grid described in section 2.6 , at $0.5\left(t_{1}\right)$ and $2.5^{\circ}\left(t_{2}\right)$ minutes after the main burner $(s)$ comes on. During this on-period, there shall be a time delay, $t^{-}$, between the burner start-up and blower start-up of 1.5 minutes. Two exceptions to this are: if the furnace employs a single motor to drive a power burner and an indoor air circulating blower, both shall be started together; and if a 1.5 minute blower delay time results in the operation of the high limit control to shut the burner off, the fan control shall be permitted to automatically start the blower provided that, if it is adjustable, it is set to turn the blower on at the highest flue gas temperature. If the fan control is permitted to start the blower, the time delay, $t^{-}$, between burner and blower start-up shall be measured using a stop watch. Record the measured values.

\subsubsection{Gas- and 0il-Fueled Condensing Boilers}

Fifty minutes after the main burner(s) is turned off for the cool-down test, the condensing boiler shall be turned on and the flue gas temperature measured, $\left(\mathrm{T}_{\mathrm{f}, \mathrm{on}}\right)$ using the thermocouple grid described in section 2.6 at 1.0 minute $\left(t_{1}\right)$ 
and 5.5 minutes $\left(t_{2}\right)$ after the main burner comes on. The pump circulating the water through the boiler shall be started simultaneously with the main burner(s), the water flow rate shall be the same as that maintained during the steady state test described in 3.1 , and the return water temperature shall be within the limits specified in section 2.5 .2 .

\subsection{JACKET LOSS MEASUREMENT}

A jacket loss test is specified only for units intended to be installed out of doors. Measure the jacket loss $\left(L_{j}\right)$ in accordance with the following ANSI standards, and record the total loss and ambient room temperature during the test:

(a) Gas-fueled forced-air condensing furnaces - ANSI 221.47-1973, section 2.9.1 and Appendix F.

(b) Gas- or oil-fueled hot water condensing boilers - ANSI 221.47-1973, section 2.9.1 and Appendix F.

(c) 0i1-fueled forced-air condensing furnaces - 291.1-1972, Appendix B.

\subsection{MEASUREMENT FOR DETERMINING EFFECTIVENESS OF AUTOMATI; STACK DAMPER}

The effectiveness of an automatic stack damper $\left(D_{0}\right)$, on furnaces so equipped, shall be determined by measuring the cross-sectional area of the stack $\left(\mathrm{A}_{\mathrm{S}}\right)$, the net area of the damper plate $\left(A_{D}\right)$ (the area of the damper plate minus the area of any holes in the plate), and the angle which the damper plate makes when closed with a plane perpendicular to the axis of the stack. The equation in section 4.3 is then employed to calculate $D_{0}$.

\subsection{OPTIONAL PROCEDURE FOR DETERMINING $\mathrm{D}_{\mathrm{P}}$ AND $\mathrm{D}_{\mathrm{F}}$}

On furnaces or bollers where design is such that there is absolutely no chance of air flow through the combustion chamber and heat exchanger when the unit is off, $D_{F}$ and $D_{P}$ may be set equal to 0.0 .

For other units using pulse combustion or power burners, the values of $\mathrm{D}_{\mathrm{F}}$ and $\mathrm{D}_{\mathrm{P}}$ may be obtained as described below. On.systems not employing automatic stack dampers or power-burner systems with a stack damper and a draft diverter or draft hood, $\mathrm{D}_{\mathrm{F}}$ shall be measured during the cool-down test described in section 3.2. On systems for which the flue or stack damper is to be closed during the cool-down test described in section 3.2 , $D_{\mathrm{P}}$ shall be measured during a separate cool-down test. This separate cool-down test shall be conducted after the heat-up test described in section 3.3 is completed. It shall be conducted by letting the unit run after the heat-up test until steady-state conditions are reached, as indicated by temperature variation in three successive readings taken 15 minutes apart of not more than plus or minus $1^{\circ} \mathrm{F}\left(0.56^{\circ} \mathrm{C}\right)$ in the flue gas temperature and the outlet water temperature, for hot water boilers, and then shutting the unit off with the stack or flue damper controls by-passed or adjusted so that the stack or flue damper remains open during the resulting cool-down period. If a draft was maintained on 
oil-fueled units in the flue pipe during the steady-state performance test described in section 3.1, the same draft (within -0.001 and +0.005 inches of water gauge of the average steady-state draft) shall be maintained during this cool-down period.

The flue gas mass flow rate $\left(\dot{\mathrm{m}}_{\mathrm{F}, O F F}\right)$ during the cool-down test described above shall be measured at a specific off-period flue gas temperature and then corrected to obtain its value at the steady-state flue gas temperature $\left(\mathrm{T}_{\mathrm{F}, \mathrm{SS}}\right)$, using the procedure described in 4.4 .

Within one minute after the unit is shut off to start the cool-down test for determining $\mathrm{D}_{\mathrm{P}}$, begin feeding a tracer gas into the combustion chamber at a constant flow rate of $V_{\mathrm{T}}$, and at a point which will allow for the best possible mixing with the air flowing through the chamber. On units equipped with an oil-fired power burner, the best location for injecting this tracer gas appears to be through a hole drilled in the blast tube. The value of $V_{T}$ shall be periodically measured with an instantaneously reading flow meter which will result in a reading having an error no larger than $\pm 3 \%$ of the quantity measured and shall be less than $1 \%$ ot the air flow rate through the furnace. If a combustible tracer gas is used, there should be a delay period between the time the unit is shut off and the time the tracer gas is first injected, to prevent ignition of the tracer gas. Great care should be exercised when employing tracer gases which are combustible or dangerous, to prevent human injury.

Between 5 and 6 minutes after the unit is shut off to start the cool-down test, the flue gas temperature, $\mathrm{T}_{\mathrm{F}, \mathrm{OFF}}^{*}$, shall be measured using the nine the rmocouples described above. At the same instant the flue gas temperature is measured, the percent volumetric concentration of tracer gas, $\mathrm{C}_{\mathrm{T}}$, in the flue gas shall also be measured in the same plane where $\mathrm{T}_{\mathrm{F}}^{*}, \mathrm{OFF}$ is determined. The concentration of tracer gas shall be obtained using an instrument which will result in a reading having an error no larger thatn $\pm 2 \%$ of the value of $\mathrm{C}_{\mathrm{T}}$ measured and may be either a batch or continuous reading type instrument. If the sampling arrangement on a continuously reading instrument results in a delay time between drawing of a sample and its analysis, this delay should be taken into account so that the temperature measurement and the measurement of tracer gas concentration coincide. In addition, the temperature $\left(\mathrm{T}_{\mathrm{T}}\right)$ of the tracer gas entering the flow meter and the barometric pressure $\left(\mathrm{P}_{\mathrm{B}}\right)$ shall also be determined.

The rate of the flue gas mass flow through the furnace and the factors $D_{P}$, $\mathrm{D}_{\mathrm{F}}$, and $\mathrm{D}_{\mathrm{S}}$ are calculated by the equations in section 4.4 .

\subsection{OPTIONAL PROCEDURES FOR CONDENSING FURNACES AND BOILERS WHICH HAVE NO OFF-PERIOD FLUE LOSSES}

At the discretion of the manufacturer, the cool-down and heat-up tests specified in 3.2 and 3.3 may be omitted on condensing units whose design is such that there is absolutely no chance of air flow through the combustion chamber and heat exchanger when the burner(s) is off. This type of unit has no off-period heat losses up the flue and the above option (in conjunction 
with the calculation procedure in section 4.1) allows the manufacturer to give up the slight gain in efficiency that his unit would typically experience during the on-period (due to a lower average, on-period, flue gas temperature) and use the efficiency achieved during the steady state test described in 3.1 in place of the part-load efficiency $n_{u}$.

\section{CALCULATION OF DERIVED RESULTS FROM TEST MEASUREMENTS}

4.1 RECOMMENDED PROCEDURE FOR CALCULATING THE ANNUAL FUEL UTILIZATION EFFICIENCY FOR CONDENSING FURNACES AND BOILERS

The recommended procedure for calculating the annual fuel utilization efficiency, $\mathrm{EFFY}_{A}$, consists of two types of tasks, namely:

- Collecting measured quantities from the tests and the assignment of characterisitc constants associated with the system under evaluation.

- Calculation of losses (1.e., latent heat loss, $\mathrm{L}_{\mathrm{L}, \mathrm{A}}$, on-cycle sensible heat loss, $\mathrm{L}_{\mathrm{S}}$ on, and off-cycle sensible heat $10 \mathrm{ss}, \mathrm{L}_{\mathrm{S}, \text { off }}$ ) and the annual fuel utilization efficiency, $\mathrm{EFFY}_{\mathrm{A}^{*}}$

The calculation procedure involves carrying out each of the following numbered steps and entering the result, in the column having the same number, on the worksheet given in Figure 10 of NBSIR 78-1543 [1]. In order to facilitate a comparison with the calculation procedure for non-condensing furnaces and boilers, these steps are presented, whenever possible, as modifications to the corresponding steps in section 4 of NBSIR 78-1543 [1]. The list of nomenclature, section 4, the figures, and the tables from NBSIR 78-1543 [1] are reproduced in Appendix $A$ for the benefit of those readers who do not have a copy of $[1]$.

Numbered Steps and Columns in Figure 10 of NBSIR 78-1543 (Refer to Appendix A):

1. Select the appropriate system number SYS 非 from Table 2 of NBSIR 781543. This table shall apply to both direct vent and direct exhaust, condensing units.

2-7. Same as steps 2 through 7 in 4.1 of NBSIR $78-1543$.

8-9. Enter 0.0 .

10,11 . Same as steps 10 and 11 in 4.1 of NBSIR 78-1543.

12-16. Same as steps 12 through 16 in 4.1 of NBSIR $78-1543$ except enter 0.0 if optional procedure described in section 3.7 is employed.

17-18. Same as steps 17 and 18 in 4.1 of NBSIR $78-1543$. 
19. Enter $S / F=1.0$.

20. Enter the off-period flue gas factor, $D_{F}$, selected from Table 2 of NBSIR 78-1543 for SYS (column 1) under consideration or obtained in accordance with section 3.6 .

21. Enter $D_{S}=D_{F}(\operatorname{col} .20)$ in column 21 .

22-28. Same as steps 22 through 28 in 4.1 of NBSIR 78-1543.

29. Using the value of $R_{T, F}$ (column 28) and $\Delta T_{F, S S}=\left[T_{F, S S}\right.$ (column 11) $\mathrm{T}_{\mathrm{RA}}$ (column 17)] read from Figure 2 of NBSIR, 78-1543 the average sens-

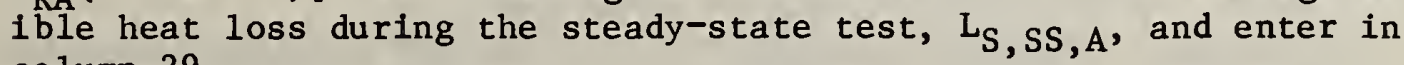
column 29.

30. Calculate and enter the steady-state efficiency (excluding jacket losses and corresponding to a return water temperature of $180^{\circ} \mathrm{F}$ $\left(82.2^{\circ} \mathrm{C}\right)$ for boilers) using:

$$
\begin{aligned}
n_{S S} & =100-C_{L}^{\prime} L_{L, A}(\operatorname{col} .26)-L_{S, S S, A}(\operatorname{col} .29)-L_{C}^{\prime} \text {, for furnaces } \\
n_{S S} & =100-L_{L, A}(\operatorname{col} 1.26)-L_{S, S S, A}(\operatorname{col} .29) \\
& -\frac{(100)(.24)(180-120)\left(1+\left(R_{T}, F(\operatorname{col} 1.28)\right)(A / F(\operatorname{col} 1.25))\right)}{\mathrm{HHV}_{A}(\operatorname{col} 1.24)} \text {, for boilers }
\end{aligned}
$$

where $C_{L}^{\prime}$ and $L_{c}^{\prime}$ are found in steps 68 and 69 respectively, and, if the optional procedure described in section 3.7 was employed, proceed directly to step 64 skipping all intermediate steps. If optional procedure in section 3.7 is not employed, continue with step 31 .

31-38. Same as steps 31 through 38 in 4.1 of NBSIR $78-1543$.

39. Enter $C_{S}=\frac{T_{F, S S}(\operatorname{col} 11)-42}{T_{F, S S}(\operatorname{col} 11)-70}$ in column 39

40-48. Same as steps 40 through 48 in 4.1 of. NBSIR $78-1543$.

49. Calculate and enter: $\theta_{F, 0}=C_{t, \text { on }} \times \theta_{F}, 0, X(\operatorname{col} .33)$ using the definition of $C_{t}$, on in step 49 of 4.1 , NBSIR 78-1543.

50-63. Same as steps 50 through 63 in 4.1 of NBSIR 78-1543.

64. If optional procedure described in 3.7 was employed, calculate and enter: 


$$
\begin{aligned}
& \eta_{\mathrm{u}}=100-\mathrm{c}_{\mathrm{L}} \mathrm{L}_{\mathrm{L}, \mathrm{A}}(\operatorname{col} \cdot 26)-\mathrm{L}_{\mathrm{C}}-\mathrm{C}_{\mathrm{J}}(\operatorname{col} \cdot 27) \mathrm{L}_{\mathrm{J}}(\operatorname{col} \cdot 18) \\
& -\frac{t_{\text {on }}(\operatorname{col} 145)}{t_{\text {on }}(\operatorname{col} 1.45)+P F(\operatorname{col} 1.23) t_{\text {of } f}(\operatorname{col} .46)} \times C_{s}(\operatorname{col} .39)
\end{aligned}
$$

$X \mathrm{~L}_{\mathrm{S}, \mathrm{SS}, \mathrm{A}}(\operatorname{col} \cdot 29)$

where $C_{L}$ is found using the procedure described in step $68, L_{C}$ is found in step 69 and $\mathrm{C}_{\mathrm{S}}=\frac{\mathrm{T}_{\mathrm{F}, \mathrm{SS}}(\operatorname{col} \cdot 11)-42}{\mathrm{~T}_{\mathrm{F}, \mathrm{SS}}(\operatorname{col} 11)-70}$

If optional procedure described in 3.7 was NOT employed, calculate and enter:

$$
\begin{aligned}
\eta_{\mathrm{u}} & =100-\mathrm{C}_{\mathrm{L}} \mathrm{L}_{\mathrm{L}, \mathrm{A}}(\operatorname{col} \cdot 26)-\mathrm{L}_{\mathrm{c}}-\mathrm{C}_{\mathrm{J}}(\operatorname{col} \cdot 27) \times \mathrm{L}_{\mathrm{J}}(\operatorname{col} \cdot 18) \\
& -\frac{\mathrm{t}_{\mathrm{on}}(\operatorname{col} \cdot 45)}{\mathrm{t}_{\text {on }}(\operatorname{col} 1.45)+\mathrm{PF}(\operatorname{col} .23) \mathrm{t}_{\text {off }}(\operatorname{col} \cdot 46)} \times\left[\mathrm{L}_{\mathrm{S}, \text { on }}(\operatorname{col} \cdot 60)\right. \\
& \left.+\mathrm{L}_{\mathrm{S}, \text { of } \mathrm{f}}(\operatorname{col} 161)\right],
\end{aligned}
$$

where $C_{L}$ is found using the procedure described in step 68 and $L_{C}$ is found in step 69.

65-67. Same as steps 65 through 67 in 4.1 of NBSIR 78-1543.

68. Calculate and enter the latent heat loss coefficient, $C_{L}$, using the following four-step procedure:

(a) Calculate what the partial pressure, $\mathrm{P}_{\mathrm{V}}$, of water vapor would be in the flue gases if there were no condensation and the atmospheric pressure was equal to 14.7 psia:

$\mathrm{p}_{\mathrm{v}}=\frac{\mathrm{m}_{\mathrm{v}}}{\mathrm{m}_{\mathrm{FG}}} \times \frac{\mathrm{M}_{\mathrm{FG}}}{\mathrm{M}_{\mathrm{v}}} \times(14.7)$

where $\mathrm{m}_{\mathrm{v}}=\frac{\mathrm{HHV}_{\mathrm{A}}(\operatorname{col} 1.24) \times \mathrm{L}_{\mathrm{L}, \mathrm{A}}(\operatorname{col} .26)}{(100) \times(1053.3)}$ is the weight of water vapor

generated per unit weight of fuel burnt.

$\mathrm{m}_{\mathrm{FG}}=1+\mathrm{A} / \mathrm{F}(\operatorname{col} .25) \times \mathrm{R}_{\mathrm{T}, \mathrm{F}}(\operatorname{col} .28)$ is the weight of flue gases generated per unit weight of fuel burnt.

$M_{v}=18$ is the approximate molecular weight of water 
$M_{F G}=\left\{\begin{array}{ll}29.0 & \text { No. } 1 \text { and No. } 2 \text { fuel oil } \\ 28.0 & \text { natural gas } \\ 27.5 & \text { manufactured gas } \\ 28.5 & \text { butane and propane }\end{array} \quad \begin{array}{l}\text { are the approximate apparent } \\ \text { molecular weights of flue } \\ \text { gases for different fuels. }\end{array}\right.$

1053.3 is the assumed latent heat/1b of water.

(b) Calculate the average flue gas temperature, $\overline{\mathrm{T}_{\mathrm{F}} \text { on, }}$, during the on-period using:

$\overline{T_{F, \text { on }}}=T_{F, S S}(\operatorname{col} \cdot 11)+\frac{\left({ }_{F, 0}(\operatorname{col} \cdot 49)\left(e^{-\left(\frac{t_{o n}}{\tau_{\text {on }}}\right)(\operatorname{col} \cdot 47)}-1\right.\right.}{\left(\frac{t_{\text {on }}}{\tau_{\text {on }}}\right)(\operatorname{col} 47)}$,

if the optional procedure described in 3.7 was NOT employed.

Use $\overline{\mathrm{T}_{\mathrm{F}} \text { on }}=\mathrm{T}_{\mathrm{F}, \mathrm{SS}}(\operatorname{col} .11)$, if optional procedure described in 3.7 was employed.

(c) From Table 1 find the saturated vapor pressure, $\mathrm{p}_{\mathrm{v}}{ }^{\mathrm{s}}$, at temperature $\overline{\mathrm{T}}_{\mathrm{F}, \text { on }}$ and the saturated vapor pressure $\mathrm{Pv}^{\mathrm{s}}$ at $\mathrm{T}_{\mathrm{F}, \mathrm{ss}}{ }^{\circ}$

(d) If $\mathrm{p}_{\mathrm{v}}<\mathrm{p}_{\mathrm{v}}{ }^{\mathrm{s}}, \mathrm{C}_{\mathrm{L}}=1$ and the unit does not meet the definition given in the Introduction for a condensing furnace or boiler and the furnace or boiler should be re-tested using the procedures specified in NBSIR 78-1543. If $\mathrm{Pv}<\mathrm{Pv}^{\text {s' }}, \mathrm{C}_{\mathrm{L}}=1$.

If $\mathrm{p}_{\mathrm{v}} \geq \mathrm{p}_{\mathrm{v}}{ }^{\mathrm{s}}$, calculate the latent heat loss coefficient, $\mathrm{C}_{\mathrm{L}}$, using:

$C_{L}=\left(\frac{p_{v}^{s}}{p_{v}}\right)\left(\frac{14.7-p_{v}}{14.7-p_{v}^{s}}\right)$

If $\mathrm{Pv} \geqslant \mathrm{Pv}^{\dot{S}}$, calculate the latent heat. loss coefficient, $C_{L}^{\prime}$, using:

$C_{L}^{\prime}=\left(\frac{P v^{\prime}}{P v}\right)\left(\frac{14.7-P v}{14.7-P_{v}^{s}}\right)$ 
69.

Calculate the loss $\mathrm{L}_{\mathrm{C}}$ and $\mathrm{L}_{\mathrm{C}}^{\prime}$, in percent, due to hot condensate going down the drain and correct for the fact that this condensate did not go up the flue as heated vapor (as was assumed in determining $\mathrm{L}_{\mathrm{S}, \mathrm{SS}, \mathrm{A}}$ ). $\mathrm{L}_{\mathrm{C}}=\frac{\mathrm{L}_{\mathrm{L}, \mathrm{A}}(\operatorname{col} \cdot 26)\left(1-\mathrm{C}_{\mathrm{L}}(\operatorname{col} \cdot 68 \mathrm{~d})\right)}{1053.3} \times$

$$
\begin{aligned}
\mathrm{L}_{C}^{\prime}= & \frac{\left(1.0\left(\mathrm{~T}_{\mathrm{F}, \mathrm{SS}}(\operatorname{col} 111)-70\right)-0.45\left(\mathrm{~T}_{\mathrm{F}, \mathrm{SS}}(\operatorname{col} \cdot 11)-42\right)\right)}{1053.3} \times \\
& \left(1.0\left(\mathrm{~T}_{\mathrm{F}, \mathrm{SS}}(\operatorname{col} 1.11)-70\right)-0.45\left(\mathrm{~T}_{\mathrm{F}, \mathrm{SS}}(\operatorname{col} 1.11)-42\right)\right)
\end{aligned}
$$

4.2 RECOMMENDED PROCEDURES FOR CALCULATING THE ANNUAL COST OF OPERATION OF A CONDENS ING FURNACE OR BOILER LOCATED IN DIFFERENT CLIMAT IC REGIONS OF THE COUNTRY AND IN BUILDINGS WITH DIFFERENT DESIGN HEAT ING REQUIREMENTS

These procedures are the same as those in section 4.2 of NBSIR 78-1543.

4.3 ADDITIONAL CALCULATIONS FOR CONDENSING FURNACES OR BOILERS UTILIZING AUTOMATIC FLUE DAMPERS

These calculations are identical to those given in section 4.3 of NBSIR $78-1543$.

\subsection{ADDITIONAL CALCULATION PROCEDURES FOR FURNACES OR BOILERS EQUIPPED WITH POWER BURNERS}

These procedures are the same as the procedures given in section 4.4 of NBSIR 78-1543.

\section{REFERENCES}

1. Kelly, G. E., CHI, J., and Kuklewicz, M. E., "Recommended Testing and Calculation Procedures for Determining the Seasonal Performance of Residential Central Furnaces and Boilers," NBSIR 78-1543, October 1978.

2. Department of Energy, "Test Procedure for Furnaces and Vented House Heating Equipment," Federal Register, Vol. 43, No. 91, Wednesday, May 10, 1978, pages 20108 through 20205.

3. American Society of Heating, Refrigerating and Air-Conditioning Engineers, ASHRAE Handbook and Product Directory - 1979 Equipment Volume, New York, New York, 1979, page 284. 
Table 1. Saturated Vapor Pressure of Water at Different Temperatures

Temp. $\left({ }^{\circ} \mathrm{F}\right) \quad$ Pressure (psia)

\begin{tabular}{|c|c|}
\hline 700.0 & 3094.3 \\
\hline 600.0 & 1543.2 \\
\hline 500.0 & 680.86 \\
\hline 400.0 & 247.26 \\
\hline 300.0 & 67.005 \\
\hline 200.0 & 11.526 \\
\hline 180.0 & 7.5110 \\
\hline 179.0 & 7.3460 \\
\hline 178.0 & 7.1840 \\
\hline 177.0 & 7.0250 \\
\hline 176.0 & 6.8690 \\
\hline 175.0 & 6.7159 \\
\hline 174.0 & 6.5656 \\
\hline 173.0 & 6.4182 \\
\hline 172.0 & 6.2736 \\
\hline 171.0 & 6.1318 \\
\hline 170.0 & 5.9926 \\
\hline 169.0 & 5.8562 \\
\hline 168.0 & 5.7223 \\
\hline 167.0 & 5.5911 \\
\hline 166.0 & 5.4623 \\
\hline 165.0 & 5.3361 \\
\hline 164.0 & 5.2124 \\
\hline 163.0 & 5.0911 \\
\hline 162.0 & 4.9722 \\
\hline 161.0 & 4.8556 \\
\hline 160.0 & 4.7414 \\
\hline 159.0 & 4.6294 \\
\hline 158.0 & 4.5197 \\
\hline 157.0 & 4.4122 \\
\hline 156.0 & 4.3068 \\
\hline 155.0 & 4.2036 \\
\hline 154.0 & 4.1025 \\
\hline 153.0 & 4.0035 \\
\hline 152.0 & 3.9065 \\
\hline 151.0 & 3.8114 \\
\hline 150.0 & 3.7184 \\
\hline 149.0 & 3.6273 \\
\hline 148.0 & 3.5381 \\
\hline 147.0 & 3.4508 \\
\hline 146.0 & 3.3653 \\
\hline 145.0 & 3.2816 \\
\hline 144.0 & 3.1997 \\
\hline 143.0 & 3.1195 \\
\hline 142.0 & 3.0411 \\
\hline 141.0 & 2.9642 \\
\hline
\end{tabular}

Temp. $\left({ }^{\circ} \mathrm{F}\right) \quad$ Pressure (psia)

$\begin{array}{ll}140.0 & 2.8892 \\ 139.0 & 2.8157 \\ 138.0 & 2.7438 \\ 137.0 & 2.6735 \\ 136.0 & 2.6047\end{array}$

$135.0 \quad 2.5375$

$134.0 \quad 2.4717$

$133.0 \quad 2.4074$

$132.0 \quad 2.3445$

$131.0 \quad 2.2830$

$130.0 \quad 2.2230$

$129.0 \quad 2.1642$

$128.0 \quad 2.1068$

$127.0 \quad 2.0507$

$126.0 \quad 1.9959$

$125.0 \quad 1.9424$

$124.0 \quad 1.8901$

$123.0 \quad 1.8390$

$122.0 \quad 1.7891$

$121.0 \quad 1.7403$

$120.0 \quad 1.6927$

$119.0 \quad 1.6463$

$118.0 \quad 1.6009$

$117.0 \quad 1.5566$

$116.0 \quad 1.5133$

$115.0 \quad 1.4711$

$114.0 \quad 1.4299$

$113.0 \quad 1.3898$

$112.0 \quad 1.3505$

$111.0 \quad 1.3123$

$110.0 \quad 1.2750$

$109.0 \quad 1.2385$

$108.0 \quad 1.2030$

$107.0 \quad 1.1684$

$106.0 \quad 1.1347$

$105.0 \quad 1.10174$

$104.0 \quad 1.06965$

$103.0 \quad 1.03838$

$102.0 \quad 1.00789$

$101.0 \quad 0.97818$

$100.0 \quad 0.94924$

$99.0 \quad 0.92103$

$98.0 \quad 0.89356$

$97.0 \quad 0.86679$

$96.0 \quad 0.84072$ 
Table 1. Saturated Vapor Pressure of Water at Different Temperatures (con't)

Temp. $\left({ }^{\circ} \mathrm{F}\right) \quad$ Pressure (psia)

\begin{tabular}{|c|c|}
\hline $\begin{array}{l}95.0 \\
94.0 \\
93.0 \\
92.0 \\
91.0\end{array}$ & $\begin{array}{l}0.81534 \\
0.79062 \\
0.76655 \\
0.74313 \\
0.72032\end{array}$ \\
\hline $\begin{array}{l}90.0 \\
89.0 \\
88.0 \\
87.0 \\
86.0\end{array}$ & $\begin{array}{l}0.69813 \\
0.67653 \\
0.65551 \\
0.63507 \\
0.61518\end{array}$ \\
\hline $\begin{array}{l}85.0 \\
84.0 \\
83.0 \\
82.0 \\
81.0\end{array}$ & $\begin{array}{l}0.59583 \\
0.57702 \\
0.55872 \\
0.54093 \\
0.52364\end{array}$ \\
\hline $\begin{array}{l}80.0 \\
79.0 \\
78.0 \\
77.0 \\
76.0\end{array}$ & $\begin{array}{l}0.50683 \\
0.49049 \\
0.47461 \\
0.45919 \\
0.44420\end{array}$ \\
\hline $\begin{array}{l}75.0 \\
74.0 \\
73.0 \\
72.0 \\
71.0\end{array}$ & $\begin{array}{l}0.42964 \\
0.41550 \\
0.40177 \\
0.38844 \\
0.37549\end{array}$ \\
\hline $\begin{array}{l}70.0 \\
69.0 \\
68.0 \\
67.0 \\
66.0\end{array}$ & $\begin{array}{l}0.36292 \\
0.35073 \\
0.33889 \\
0.32740 \\
0.31626\end{array}$ \\
\hline $\begin{array}{l}65.0 \\
64.0 \\
63.0 \\
62.0 \\
61.0\end{array}$ & $\begin{array}{l}0.30545 \\
0.29497 \\
0.28480 \\
0.27494 \\
0.26538\end{array}$ \\
\hline
\end{tabular}


APPENDIX A. CALCULATION PROCEDURE FOR NON-CONDENSING FURNACES AND BOILERS

In order to assist readers who do not have a copy of NBSIR 78-1543 [1], the following items from [1] are reproduced in this appendix: the list of nomenclature, section 4 (which gives the calculation procedure for noncondensing furnaces and bollers), Tables 1 through 5, and Figures 1 through 10. 
$A_{D} \quad$ net area of stack or flue damper plate

$\mathrm{A}_{\mathrm{S}} \quad$ cross sectional area of stack where flue or stack damper is located, in square inches

$\mathrm{A} / \mathrm{F} \quad$ mass ratio of stoichiometric air to fuel

$\mathrm{BE}$ electrical power to circulating air blower or water pump, in $\mathrm{kW}$

$\mathrm{C}_{\text {IID }}$ correction factors for units using intermittent devices or cycling pilots

$\mathrm{C}_{\mathrm{J}} \quad$ jacket loss factor

$\mathrm{C}_{\mathrm{S}}, \mathrm{C}_{\mathrm{S}}{ }^{\prime}$ on-period and off-period correction factors for outdoor units, units intended for installation in unheated spaces or units equipped with direct vent systems

$\mathrm{C}_{\mathrm{T}}$ concentration by volume of tracer gas present in flue gas

$C_{t, O F F}$ cool-down temperature profile correction factor for the effect of cycling

$C_{t, O N} \quad$ heat-up temperature profile correction factor for the effect of cycling

DD degree days

Do stack or flue damper effectiveness factor

$D_{F} \quad$ off-cycle draft factor for flue gas flow

$D_{P} \quad$ power burner effectiveness factor

$\mathrm{D}_{\mathrm{S}} \quad$ off-cycle draft factor for stack gas flow

EFFY $_{A} \quad$ Annual Fuel Utilization Efficiency

$E_{\text {IN }}$ measured electrical power input for electric furnaces and boilers, in watts

F3, F4,

F5, F6, functions defined by Figures 3 through 8

F7, F8

HHV measured higher heating value of test gas, in Btu/lb

$\mathrm{HHV}_{\mathrm{A}}$ average higher heating value of typical fuel, in Btu/1b 
HR

number of non-heating season hours that pilot light is assumed wasted

$\mathrm{K}_{\mathrm{I}, \mathrm{OFF}}$ multiplication factor for infiltration loss during off-period

$\mathrm{K}_{\mathrm{I}, \mathrm{ON}} \quad$ multiplication factor for infiltration loss during on-period

$\mathrm{K}_{\mathrm{S}, \text { OFF }}$ multiplication factor for sensible heat loss during off-period

$\mathrm{K}_{\mathrm{S}, \mathrm{ON}} \quad$ multiplication factor for sensible heat loss during on-period

$\mathrm{L}_{\mathrm{I}, \mathrm{OFF}}$ off-cycle infiltration loss, in \%

$\mathrm{L}_{\mathrm{I}, \mathrm{ON}} \quad$ on-cycle infiltration loss, in $\%$

$\mathrm{L}_{\mathrm{J}} \quad$ jacket loss, in $\%$

$\mathrm{L}_{\mathrm{L}, \mathrm{A}} \quad$ laten $\mathrm{i}$ heat loss, in $\%$

$\mathrm{L}_{\mathrm{S}, \mathrm{OFF}}$ off-cycle sensible heat loss, in $\%$

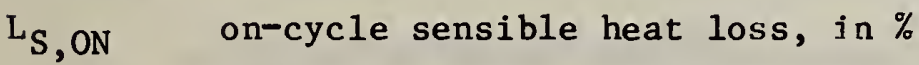

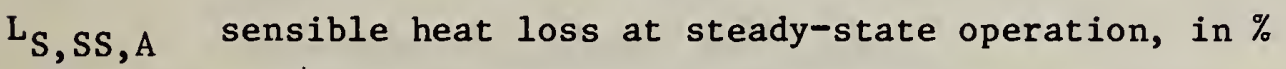

$\dot{\mathrm{m}}_{\mathrm{F}, \mathrm{OFF}}$ off-cycle flue gas flow rate, in $1 \mathrm{~b} / \mathrm{min}$

$\dot{\mathrm{m}}_{\mathrm{F}, \mathrm{SS}}$ flue gas flow rate at steady-state operation, in $1 \mathrm{~b} / \mathrm{min}$

$\mathrm{P}_{\mathrm{B}} \quad$ barometric pressure, in inches of $\mathrm{Hg}$

$\mathrm{PE} \quad$ electrical power to power burner, in $\mathrm{kW}$

PF ratio of $Q_{P}$ to $Q_{I N}, Q_{P} / Q_{I N}$

$\mathrm{Q}_{\mathrm{IN}} \quad$ fuel energy input rate at steady-state operation (including any pilot light input), in $\mathrm{Btu} / \mathrm{hr}$

$\mathrm{Q}_{\mathrm{P}}$

fuel energy input rate to pilot light in $\mathrm{Btu} / \mathrm{h}$

$\mathrm{R}_{\mathrm{T}, \mathrm{F}} \quad$ ratio of combustion air to stoichiometric air

$\mathrm{R}_{\mathrm{T}, \mathrm{S}} \quad$ ratio of combustion air and draft relief air to stoichiometric air

S/F ratio of stack gas mass flow rate to flue gas mass flow rate at steady-state operation and an average outdoor temperature equal to $42^{\circ} \mathrm{F}\left(5.6^{\circ} \mathrm{C}\right)$

t time, in minutes 
$\mathrm{t}_{\mathrm{OFF}}$ off-time per cycle, in minutes

$\mathrm{t}_{\mathrm{ON}} \quad$ on-time per cycle, in minutes

$t_{1}, t_{2}$, different times at which flue and/or stack gas temeprature are

$\mathrm{t}_{3}, \mathrm{t}_{4}$ measured, in minutes

$t^{+} \quad$ delay time between burner shut off and blower shut off, in minutes

$t^{-} \quad$ delay time between burner. start up and blower start up, in minutes

$T_{\text {FUEL }} \quad$ type of fuel defined in step 2 of section 4.2

$\mathrm{T}_{\mathrm{F}, \mathrm{OFF}}$ off-period flue gas temperature while the system is in cyclic operation, in ${ }^{\circ} \mathrm{F}$

$\mathrm{T}_{\mathrm{F}, \mathrm{OFF}}^{*}$ off-period flue gas temperature when tracer gas concentration is measured, in ${ }^{\circ} \mathrm{F}$

$T_{F, O F F, X}$ off-cycle flue gas temperature after shut down of the system from steady-state operation, in ${ }^{\circ} \mathrm{F}$

$\mathrm{T}_{\mathrm{F}, \mathrm{ON}}$ on-cycle flue gas temperature while the system is in cyclic operation, in ${ }^{\circ} \mathrm{F}$

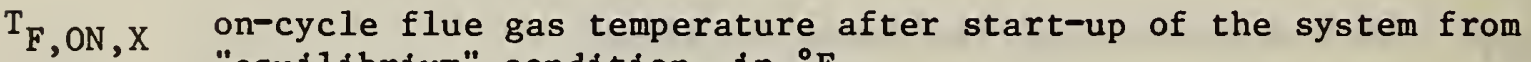
"equilibrium" condition, in ${ }^{\circ} \mathrm{F}$

$\mathrm{T}_{\mathrm{F}, \mathrm{SS}} \quad$ flue gas temperature at steady-state, in ${ }^{\circ} \mathrm{F}$

$\mathrm{T}_{\mathrm{F}, \mathrm{OFF}}{ }^{(\infty)}$ minimum flue gas temperature, in ${ }^{\circ} \mathrm{F}$

$\mathrm{T}_{\mathrm{OA}} \quad$ average outdoor air temperature assumed equal to $42^{\circ} \mathrm{F}\left(5.6^{\circ} \mathrm{C}\right)$

$\mathrm{T}_{\mathrm{RA}} \quad$ laboratory room temperature, in ${ }^{\circ} \mathrm{F}$

$\mathrm{T}_{\mathrm{S}, \mathrm{OFF}}$ off-cycle stack gas temperature while the system is in cyclic operation, in ${ }^{\circ} \mathrm{F}$

$\mathrm{T}_{\mathrm{S}, \text { OFF, }} \mathrm{X}$ off-cycle stack gas temperature after shut down of the system from steady-state operation, in ${ }^{\circ} \mathrm{F}$

$\mathrm{T}_{\mathrm{S}, \mathrm{ON}}$ on-cycle stack gas temperature while the system is in cyclic operation, in ${ }^{\circ} \mathrm{F}$

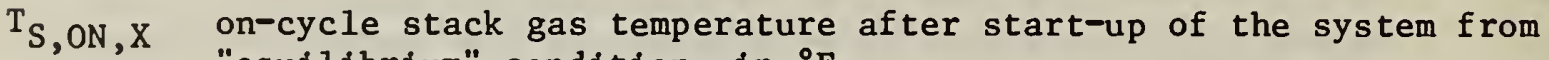
"equilibrium" condition, in ${ }^{\circ} \mathrm{F}$

$\mathrm{T}_{\mathrm{S}, \mathrm{SS}} \quad$ calculated stack gas temperature at steady-state, under typical field conditions, in ${ }^{\circ} \mathrm{F}$ 


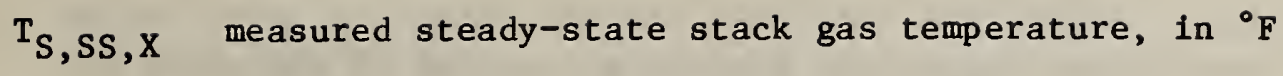

$\mathrm{T}_{\mathrm{S}, \text { OFF }}{ }^{(\infty)}$ minimum stack gas temperature, in ${ }^{\circ} \mathrm{F}$

$\mathrm{T}_{\mathrm{T}} \quad$ temperature of tracer gas entering flow meter

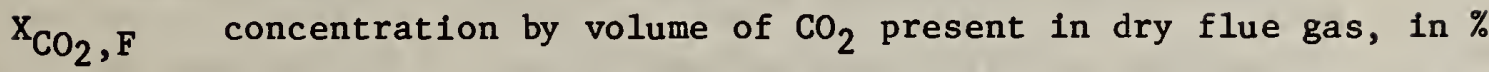

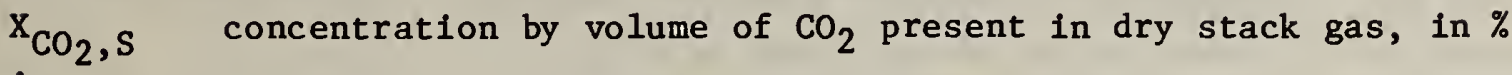

$\mathrm{V}_{\mathrm{T}} \quad$ flow rate of tracer gas in $\mathrm{cu} \mathrm{ft} / \mathrm{min}$

y

$\alpha$

ratio of blower on time to burner on time

oversizing factor

$\gamma \quad$ angle stack or flue damper plate makes when closed with plane perpendicular to axis of stack or flue

$\Delta \mathrm{T}_{\mathrm{F}, \mathrm{SS}} \quad$ temperature difference defined as $\mathrm{T}_{\mathrm{F}, \mathrm{SS}}-\mathrm{T}_{\mathrm{RA}}$

$\Delta \mathrm{T}_{\mathrm{S}, \mathrm{SS}} \quad$ temperature difference defined as $\mathrm{T}_{\mathrm{S}, \mathrm{SS}}-\mathrm{T}_{\mathrm{RA}}$

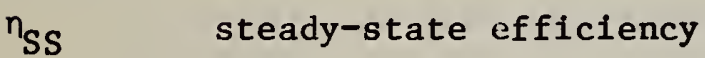

$\eta \mathbf{u}$

part-load utilization efficiency

$\theta_{\mathbf{F}}$

temperature difference defined as $\left(\mathrm{T}_{\mathrm{F}, \mathrm{SS}}-\mathrm{T}_{\mathrm{F}, \mathrm{ON}}\right)$

$\theta_{F, 0}$

temperature difference defined by step 49 in section 4.2

$\theta_{\mathrm{F}, 0, \mathrm{X}}$ temperature difference defined by step 33 in section 4.2

$\rho_{\mathbf{F}}$

density of flue gas, in $1 b / c u f t$

$\tau_{\text {ON }}$

heat-up time constant defined in step 32 of section 4.2 , in minutes

$\tau_{\text {OFF }}$

cool-down time constant defined in step 34 of section 4.2 , in minutes

$\phi$

infiltration parameter assumed equal to 0.7

$\psi_{\mathrm{F}}$

temperature difference defined as $\left(\mathrm{T}_{\mathrm{F}, \mathrm{OFF}}-\mathrm{T}_{\mathrm{F}, \mathrm{OFF}}{ }^{(\infty)}\right)$

$\psi_{\mathrm{F}, 0}$

temperature difference defined by step 50 in section 4.2

$\Psi_{\mathrm{F}, 0, \mathrm{X}}$ temperature difference defined by step 35 in section 4.2

$\psi_{\mathrm{F}, \infty} \quad$ temperature difference defined by step 51 in section 4.2

$\Psi_{\mathrm{F}, \infty, \mathrm{X}}$ temperature difference defined by $\left(\mathrm{T}_{\mathrm{F}, \mathrm{OFF}}{ }^{(\infty)}-\mathrm{T}_{\mathrm{RA}}\right)$ 


$\begin{array}{ll}\psi_{\mathrm{S}, 0} & \text { temperature difference defined by step } 52 \text { in section } 4.2 \\ \psi_{\mathrm{S}, 0, \mathrm{X}} & \text { temperature difference defined by step } 38 \text { in section } 4.2 \\ \psi_{\mathrm{S},} & \text { temperature difference defined by step } 52 \text { in section } 4.2 \\ \Psi_{\mathrm{S},}^{\infty}, \mathrm{X} & \text { temperature difference defined by step } 37 \text { in section } 4.2\end{array}$


4. CALCULATION OF DERIVED RESULTS FROM TEST MEASUREMENT (FOR NON-CONDENSING FURNACES AND BOILERS)

The test procedures for furnaces and boilers were outlined in sections 2 and 3 above.* A calculation procedure is described below, in subsection 4.1, for determining the annual fuel utilization efficiency, EFFY ${ }_{A}$, for gas- and oilfired central heating equipment. The fuel utilization efficiency for electric furnaces and boilers is assumed to be $100 \%$ for indoor units, and is given by $\mathrm{EFFY}_{\mathrm{A}}=\left(100-3.3 \mathrm{~L}_{\mathrm{J}}\right)$ and $\mathrm{EFFY}_{\mathrm{A}}=\left(100-4.7 \mathrm{~L}_{\mathrm{J}}\right)$ for electric furnaces and boilers, respectively, intended for installation out of doors or in unheated spaces (such as an attic or a crawl space). In subsection 4.2, recommended procedures for calculating the annual cost of operation in different climate regions of the country and an average operating cost for the continental United States are described. Sections 4.3 and 4.4 provide additional calculations relating to gas- or oil-fueled furnaces and boilers equipped with stack dampers and/or power burners.

4.1 RECOMMENDED PROCEDURE FOR CALCULATING THE ANNUAL FUEL UTILIZATION EFFICIENCY FOR FOSSIL-FUEL HEATING SYSTEMS

The recommended procedure for calculating the annual fuel utilization efficiency, ${ }^{E F F Y}$, consists of these types of tasks, namely:

- Collection of measured quantities from the tests and characteristic constants (see tables 2 and 3 ) associated with the system under evaluation.

- Calculation of losses (i.e., latent heat loss, $\mathrm{L}_{\mathrm{L}, \mathrm{A}}$, on-cycle sensible heat loss, $\mathrm{L}_{\mathrm{S}, \mathrm{ON}}$, off-cycle sensible heat loss, $\mathrm{L}_{\mathrm{S}, \mathrm{OFF}}$, on-cycle infiltration loss, $\mathrm{L}_{\mathrm{I}, \mathrm{ON}}$ off-cycle infiltration loss, $\mathrm{L}_{\mathrm{I}, \mathrm{OFF}}$ ) and the annual fuel utilization efficiency, EFFY ${ }_{A}$. These tasks are performed by carrying out each of the following numbered steps and entering the result in the column having the same number on the worksheet (Figure $10)$.

Numbered Steps and Columns in Figure 10 are as follows:

1. Enter in column 1 the system number SYS (see tables 1 and 2) for type of system under evaluation.

2. Enter type of fuel used, TFUEL. Use "1" for No. 1 oil, "2" for No. 2 oil, "3" for natural gas, "4" for manufactured gas, "5" for propane, and "6" for butane.

3. Enter measured higher heating value of fuel used, HHV, in Btu/lb.

4. Enter fuel input rate (including fuel supply to pilot flame) at full-

* i.e., sections 2 and 3 of NBSIR78-1543 [1]. 
load steady-state operation, $Q_{I N}$, in $B t u / h$.

5. Enter fuel input rate to pilot flame, $Q_{P}$, in $B t u / h$.

6. Enter power burner electric energy input rate at full-load steady-state operation, $\mathrm{PE}$, in $\mathrm{kW}$.

7. Enter circulating-air blower (or circulating-water pump) electric energy input rate at full-load steady-state operation, $B E$, in $\mathrm{kW}$.

8. For furnaces or boilers with draft diverters: Enter the $\mathrm{CO}_{2}$ concentra-

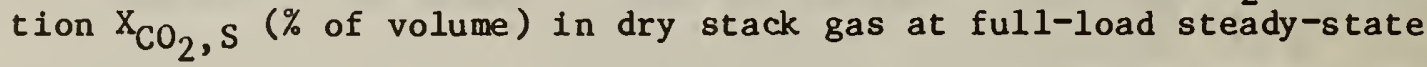

operation measured in accordance with section 2. For units employing draft hoods, barometric damper or direct vent systems: Enter 0.0 in column 8 .

9. For furnaces or bollers with draft diverters: Enter the stack gas temperature at ful1-1oad steady-state operation, $\mathrm{T}_{\mathrm{S}, \mathrm{SS}, \mathrm{X}}$, measured in accordance with section 2 .

For units employing draft hood, barometric dampers or direct vent systems: Enter 0.0 in column 9.

10. Enter the $\mathrm{CO}_{2}$ concentration $\mathrm{X}_{\mathrm{CO}_{2}, \mathrm{~F}}$ (\% by volume) in dry flue gas at ful1-load steady-state operation measured in accordance with section 2 .

11. Enter the flue gas temperature at full-load steady-state operation, $\mathrm{T}_{\mathrm{F}, \mathrm{SS}}$ measured in accordance with section 2.

12., 13. Enter the flue gas temperatures in ${ }^{\circ} \mathrm{F}$ at the start-up of the system burner from equilibrium, $T_{F, O N}\left(t_{1}\right)$ and $T_{F, O N}\left(t_{2}\right)$ in columns 12 and 13 , respectively.

For furnace: $t_{1}=0.5$ minute, $t_{2}=2.5$ minutes.

For boiler: $t_{1}=1$ minute, $t_{2}=5.5$ minutes.

14., 15. Enter the flue gas temperature in ${ }^{\circ} \mathrm{F}$ after the shut-down of the system burner from steady-state operation, $T_{F, O F F}\left(t_{3}\right)$ and $t_{F, O F F}\left(t_{4}\right)$ in colums 14 and 15 , respectively.

For furnace: $t_{3}=1.5$ minutes, $t_{4}=9$ mi nutes.

For boiler: $t_{3}=3.75$ minutes, $t_{4}=22.5$ minutes.

16. Enter the minimum flue gas temperature in ${ }^{\circ} \mathrm{F}$ as measured in accordance with section 3.2 while the burner is of, $\mathrm{T}_{F, O F F}(\infty)$. For furnaces not employing a continuously operating pilot light, $\mathrm{T}_{F, O F F}{ }^{(\infty)}$ equals the room temperture.

17. Enter the laboratory room temperature, $T_{R A}$, in ${ }^{\circ} \mathrm{F}$. 
18. For indoor unit: Enter 0.0 in column 18.

For outdoor unit or units intended for installation in unheated spaces (such as an attic or a crawl space): Enter jacket loss $\mathrm{L}_{\mathrm{J}}$, measured in accordance with section 2 .

19. Enter the average ratio of stack-gas mass flow rate to flue-gas mass flow rate at full-load steady-state operation, $S / F . S / F$ is selected from tables 1 and 2 for the SYS⿰三丨 (column 1) under consideration.

20. Enter the off-cycle flue gas draft factor, $D_{F}$, selected from tables 1 and 2 for the SYS非 (column 1) under consideration or measured in accordance with section 3.6 .

21. For SYS非 (column 1) equal to 9 through 12: Enter 0.0 in column 20.

For SYS作 (column 1) equal to 1 through 8: Enter off-cycle stack gas draft factor, $D_{S}$. $D_{S}$ may either be selected from table 1 for the SYS (column 1) under consideration or determined in accordance with section 3.6 .

22. Enter value of y equal to $1+\left(\frac{t^{+}-t^{-}}{3.87}\right)$ for furnaces, and y equal to 1.00 for boilers or furnaces employing a single motor to drive a power burner and an indoor-air circulating blower.

23. Calculate and enter the ratio of pilot flame fuel input rate to the system full-load fuel (including pilot flame fuel) input rate:

$$
\mathrm{PF}=\frac{\mathrm{Q}_{\mathrm{P}}(\operatorname{col} 15)}{\mathrm{O}_{\text {IN }}(\operatorname{col} 1.4)}
$$

24. For the type of fuel used, obtain the average higher heating value, $\mathrm{HHV}_{\mathrm{A}}$, in Btu/1b from table 3 and enter in column 24. Calculate

$\frac{\mathrm{HHV}}{\mathrm{HHV}_{\mathrm{A}}(\operatorname{col} 1.3)}$ 24) and proceed to step 25 only if $0.95 \leq \frac{\mathrm{HHV}}{\mathrm{HHV}_{\mathrm{A}}(\operatorname{col} 1.3)} \leq 1.05$

25., 26. Read average values of stoichiometric air-to-fuel ratio, A/F, and latent heat loss $\mathrm{L}_{\mathrm{L}}$ from table 3 for TFUEL (column 2) under consideration, and enter thése values in columns 25 and 26 , respectively.

27. Enter $C_{J}$ equal to 3.3 for furnaces and 4.7 for boilers.

28. Using TFUEL (column '2) and $\mathrm{X}_{\mathrm{CO}_{2}, \mathrm{~F}}$ (column 10), read from figure 1 the ratio of combustion air to stoichiometric air, $\mathrm{R}_{\mathrm{T}, \mathrm{F}}$ and enter this value.

29. For furnaces or boilers with draft diverters: Using TFUEL (column 2) and $\mathrm{X}_{\mathrm{CO}_{2}, \mathrm{~S}}$ (column 8 ), read from figure 1 the ratio of the sum of 
combustion and relief air to stoichiometric air, $R_{T, S}$. Then using this $R_{T, S}$ value and

$\Delta \mathrm{T}_{\mathrm{S}, \mathrm{SS}}=\left[\mathrm{T}_{\mathrm{S}, \mathrm{SS}, \mathrm{X}}\right.$ (column 9) $-\mathrm{T}_{\mathrm{RA}}($ column 17)] read from figure 2 for the'TFUEL (column 2) under consideration the average sensible heat loss at full-load steady-state operation $\mathrm{L}_{\mathrm{S}, \mathrm{SS}, \mathrm{A}}$ and enter this value in column 29.

For units equipped with draft hoods, barometric dampers or direct-vent systems: Using value of $\mathrm{R}_{\mathrm{T}, \mathrm{F}}$ (column 28) and $\angle \mathrm{T}_{\mathrm{F}, \mathrm{SS}}=\left[\mathrm{T}_{\mathrm{F}, \mathrm{SS}}\right.$ (column 11) $-T_{R A}$ (column 17)] read'from figure 2 the average sensible heat loss at steady-state operation, $\mathrm{L}_{S, S S, A}$ and enter this value in column 29.

30. Calculate and enter the steady-state efficiency (excluding jacket 1oss).

$$
n_{S S}=100-L_{L, A}(\operatorname{col} \cdot 26)-L_{S, S S, A}(\operatorname{col} .29) \text {. }
$$

31. Calculate and enter in column 31.

$\mathrm{T}_{\mathrm{S}, \mathrm{SS}}=\frac{1}{(\mathrm{~S} / \mathrm{F})(\mathrm{Col} \cdot 19)} \times\left[\mathrm{T}_{\mathrm{F}, \mathrm{SS}}(\operatorname{col} \cdot 11)-\mathrm{T}_{\mathrm{RA}}(\operatorname{col} \cdot 17)\right]+\mathrm{T}_{\mathrm{RA}}(\operatorname{col} 1.17)$

32. Calculate and enter on-cycle time constant

$\tau_{\mathrm{ON}}=\frac{\left(t_{2}-t_{1}\right)}{\ln \left[\frac{\mathrm{T}_{\mathrm{F}, \mathrm{SS}}(\operatorname{col} \cdot 11)-\mathrm{T}_{\mathrm{F}, \mathrm{NN}}\left(\mathrm{t}_{1}\right)(\operatorname{col} 112)}{\mathrm{T}_{\mathrm{F}, \mathrm{SS}}(\operatorname{col} 11)-\mathrm{T}_{\mathrm{F}, \mathrm{ON}}\left(\mathrm{t}_{2}\right)(\operatorname{col} 113)}\right]}$

where $\left(t_{2}-t_{1}\right)=2$ for furnace, and $\left(t_{2}-t_{1}\right)=4.5$ for boiler.

33. Calculate and enter effective flue gas temperature difference at startup under test conditions:

$$
\theta_{F, 0, X}=\left[T_{F, S S}(\operatorname{col} \cdot 11)-T_{F, O N}\left(t_{1}\right)(\operatorname{col} 112)\right] \times e^{\frac{t_{1}}{\tau_{O N}(\operatorname{col} 132)}}
$$

where $t_{1}=0.5$ for furnace and $t_{1}=1$ for boiler.

34. Calculate and enter off-cycle time constant:

$$
\tau_{\mathrm{OFF}}=\frac{\left(t_{4}-t_{3}\right)}{\ln \left[\frac{\mathrm{T}_{F, O F F}\left(t_{3}\right)(\operatorname{col} 114)-T_{F,}(\infty)(\operatorname{col} 116)}{T_{F, O F F}\left(t_{4}\right)(\operatorname{col} 115)-T_{F, O F F}(\infty)(\operatorname{col} 116)}\right]}
$$

where $\left(t_{4}-t_{3}\right)=7.5$ for furnace and $\left(t_{4}-t_{3}\right)=18.75$ for boiler.

35. Calculate and enter effective flue gas temperature difference at shut down under test conditions:

$$
\psi_{F, O, X}=\left[T_{F, O F F}\left(t_{3}\right)(\operatorname{col} \cdot 14)-T_{F, O F F}(\infty)(\operatorname{col} \cdot 16)\right] e^{\frac{t_{3}}{\tau_{0 F F}(\operatorname{col} 1.34)}}
$$

Where $t_{3}=1.5$ for furnace and $t_{3}=3.75$ for boller. 
36. Calculate and enter minimum flue gas temperature difference above the room temperature:

$$
\Psi_{\mathrm{F}, \infty, \mathrm{X}}=\mathrm{T}_{\mathrm{F}, \text { OFF }}(\infty)(\operatorname{col} 1.16)-\mathrm{T}_{\mathrm{RA}}(\operatorname{col} 117)
$$

37. For SYS⿰ (col. 1) equal to 1 through 4 and systems 5 through 8 for which $(S / F)(c o l .19) \times D_{S}(\operatorname{col} .21)>D_{F}(\operatorname{col} .20)$, calculate and enter in colum 37 :

$\psi_{S, \infty, X}=\frac{D_{F}(\operatorname{col} \cdot 20) \times \psi_{F, \infty, X}(\operatorname{col} \cdot 36)}{(S / F)(\operatorname{col} \cdot 19) \times D_{S}(\operatorname{col} 121)}$

For SYS $(c o l$. 1) equal to 5 through 8 for which $(S / F)(\operatorname{col} 119) \mathbf{x}$ $\mathrm{D}_{\mathrm{S}}(\operatorname{col} .21) \leq \mathrm{D}_{\mathrm{F}}(\operatorname{col} .20)$, calculate and enter in column 37:

$\Psi_{S, \infty, X}=\psi_{F, \infty, X}(\operatorname{col}, 36)$.

For SYS $(c o l .1)$ equal to 9 through 12: Leave column 37 blank.

38. For SYS\# (col. 1) equal to 1 through 4 and systems 5 through 8 for which $(\mathrm{S} / \mathrm{F})(\operatorname{col} .19) \times \mathrm{D}_{\mathrm{S}}(\operatorname{col} \cdot 21)>\mathrm{D}_{\mathrm{F}}(\mathrm{col}, 20)$, calculate and enter in column 38:

$$
\psi_{S, 0, X}=\frac{D_{F}(\operatorname{col} \cdot 20) \times \psi_{F, 0, X}(\operatorname{col} \cdot 35)}{(S / F)(\operatorname{col} \cdot 19) \times D_{S}(\operatorname{col} \cdot 21)}
$$

For SYS 非 (col. 1) equal to 5 through 8 for which $(S / F)(\operatorname{col} 1$ 19) $\mathrm{x}$ $\mathrm{D}_{\mathrm{S}}(\operatorname{col} .21) \leq \mathrm{D}_{\mathrm{F}}(\operatorname{col} .20)$, calculate and enter in column 38:

$$
\psi_{\mathrm{S}, 0, \mathrm{X}}=\psi_{\mathrm{F}, 0, \mathrm{X}}(\operatorname{col} \cdot 35) \text {. }
$$

For SYS ( $c 01.1$ ) equal to 9 through 12): Leave column 38 blank.

39. For SYS非 (col. 1) equal to 1 through 8: Leave column 39 blank.

For SYS (col. 1) equal to 9 through 12: Calculate and enter a correction factor for the use of outdoor air instead of indoor air for combustion:

$$
\mathrm{C}_{\mathrm{S}}=1+\frac{28 \times \eta_{\mathrm{ss}}(\operatorname{col} \cdot 30)}{\left[\mathrm{T}_{\mathrm{F}, \mathrm{SS}}(\operatorname{col} \cdot 11)-\mathrm{T}_{\mathrm{RA}}(\operatorname{col} \cdot 17)\right](100)}
$$

40. Calculate and enter multiplication factor for sensible heat loss during the on-period, $\mathrm{K}_{\mathrm{S}, \mathrm{ON}}$ :

$$
\mathrm{K}_{\mathrm{S}, \mathrm{ON}}=\frac{24 \times\left[1+\mathrm{R}_{\mathrm{T}, \mathrm{F}}(\operatorname{col} 128) \times(\mathrm{A} / \mathrm{F})(\operatorname{col} 125)\right]}{\mathrm{HHV}_{\mathrm{A}}(\operatorname{col} 124)}
$$


41. Calculate and enter multiplication factor for sensible heat loss during the off-period, $\mathrm{K}_{\mathrm{S}, \mathrm{OFF}}$.

For SYS\# (col. 1) equal to 1 through 4:

$$
\begin{aligned}
\mathrm{K}_{\mathrm{S}, \text { OFF }}= & \frac{\left(\mathrm{T}_{\mathrm{F}, \mathrm{SS}}(\operatorname{col} 11)-\mathrm{T}_{\mathrm{RA}}(\operatorname{col} 111)+530\right)^{1.19}}{\left(\mathrm{~T}_{\mathrm{F}, \mathrm{SS}}(\operatorname{col} 111)-\mathrm{T}_{\mathrm{RA}}(\operatorname{col} 1 \cdot 17)\right)^{0.56}} \\
& \times \mathrm{D}_{\mathrm{F}}(\operatorname{col} 1.20) \times \mathrm{K}_{\mathrm{S}, \mathrm{ON}}(\operatorname{col} 140)
\end{aligned}
$$

For SYS $(\operatorname{col} 1.1)$ equal to 5 through 8 :

$$
\begin{aligned}
& \mathrm{K}_{\mathrm{S}, \text { OFF }}=\frac{\left(\mathrm{T}_{\mathrm{S}, \mathrm{SS}}(\operatorname{col} \cdot 31)-\mathrm{T}_{\mathrm{RA}}(\operatorname{col} \cdot 17)+530\right)^{1.19}}{\left(\mathrm{~T}_{\mathrm{S}, \mathrm{SS}}(\operatorname{col} \cdot 31)-\mathrm{T}_{\mathrm{RA}}(\operatorname{col} \cdot 17)+28\right)^{0.56}} \times \mathrm{D}_{\mathrm{S}}(\operatorname{col} 1 \cdot 21) \\
& x(S / F)(\operatorname{col} 119) \times K_{S, Q N}(\operatorname{col} .40)
\end{aligned}
$$

For SYS (col. 1) equal to 9 through 12:

$$
\begin{aligned}
\mathrm{K}_{\mathrm{S}, \text { OFF }} & =\frac{\left(\mathrm{T}_{\mathrm{F}, \mathrm{SS}}(\operatorname{col} \cdot 11)-\mathrm{T}_{\mathrm{RA}}(\operatorname{col} 117)+530\right)^{1.19}}{\left(\mathrm{~T}_{\mathrm{F}, \mathrm{SS}}(\operatorname{col} 1.11)-\mathrm{T}_{\mathrm{RA}}(\operatorname{col} 117)+28\right)^{0.56}} \times \mathrm{D}_{\mathrm{F}}(\operatorname{col} 1.20) \\
& \times \mathrm{K}_{\mathrm{S}, \mathrm{ON}}(\operatorname{col} \cdot 40)
\end{aligned}
$$

42. For SYS\# (col. 1) equal to 1 through 8: Calculate and enter multiplication factor for infiltration loss during the on-period:

$$
\mathrm{K}_{\mathrm{I}, \mathrm{ON}}=(0.7) \times(\mathrm{S} / \mathrm{F})(\operatorname{col} \cdot 19) \times \mathrm{K}_{\mathrm{S}, \mathrm{ON}}(\operatorname{col} \cdot 40)
$$

For SYS ( $\operatorname{col}, 1)$ equal to 9 through 12: Leave column 42 blank.

43. For SYS\# (col.1) equal to 1 through 8: Calculate and enter in column 43 the multiplication factor for infiltration loss during the off-period:

$$
\begin{aligned}
\mathrm{K}= & \frac{\left(\mathrm{T}_{\mathrm{S}, \mathrm{SS}}(\operatorname{col} \cdot 31)-\mathrm{T}_{\mathrm{RA}}(\operatorname{col} \cdot 17)+530\right)^{1.19}}{\mathrm{I,OFF}} \times \mathrm{K}_{\mathrm{I}, \mathrm{ON}}(\operatorname{col} 1.42) \\
& \left(\mathrm{T}_{\mathrm{S}, \mathrm{SS}}(\operatorname{col} 1.31)-\mathrm{T}_{\mathrm{RA}}(\operatorname{col} \cdot 17)+28\right)^{0.56} \\
& \times \mathrm{D}_{\mathrm{S}}(\operatorname{col} 1.21)
\end{aligned}
$$

For SYS (col. 1) equal to 9 through 12: Leave column 43 blank.

44. Enter the value of the average outdoor temperature, $\mathrm{T}_{\mathrm{OA}}$ equal to $42^{\circ} \mathrm{F}$. 
45. For furnace: Enter colum 45 the average on-time per cycle, $t_{O N}$, equal to 3.87 minutes.

For boller: Enter column 45 the average on-time per cycle, $t_{O N}$, equal to 9.68 minutes.

46. For furnace: Enter column 46 the average off-time per cycle, $t_{O F F}$, equal to 13.30 minutes.

For boiler: Enter column 46 the average off-time per cycle, $t_{O F F}$, equal to 33.26 minutes.

47., 48. Calculate $t_{O N}(\operatorname{col} .45) / \tau_{O N}(\operatorname{col} .32)$ and $t_{O F F}(\operatorname{col} .46) / \tau_{O F F}(\operatorname{col} .34)$ and enter columns 47 and 48 , respectively.

49., 50., 51., 52., 53. Correct the heat-up and cool-down temperature profiles for the effect of cycling:

For SYS \# (col. 1) equal to 1 through 8 , calculate and enter:

$$
\begin{aligned}
& \theta_{F, O}(\operatorname{col} \cdot 49)=C_{t, O N}{ }_{F, O, X}(\operatorname{col} \cdot 33) \\
& \psi_{\mathrm{F}, 0}(\operatorname{col} .50)=c_{\mathrm{t}, \mathrm{OFF}} \psi_{\mathrm{F}, 0, \mathrm{X}}(\operatorname{col} .35) \\
& \psi_{\mathrm{F} \infty}(\operatorname{col} \cdot 51)=\psi_{\mathrm{F}, \infty, \mathrm{X}}(\operatorname{col} \cdot 36) \\
& \psi_{S, 0}(\operatorname{col} .52)=C_{t, \text { OFF }} \psi_{S, 0, X}(\operatorname{col} \cdot 38) \\
& \psi_{S, \infty}(\operatorname{col} \cdot 53)=\psi_{S, \infty, X}(\operatorname{col} \cdot 37)
\end{aligned}
$$

For SYS (col, 1) equal to 9 through 12, leave columns 52 and 53 blank, calculate and enter:

$$
\begin{aligned}
& \theta_{\mathrm{F}, 0}(\operatorname{col} .49)=\mathrm{C}_{\mathrm{t}, \text { ON }} \times \mathrm{C}_{\mathrm{S}}(\operatorname{col} .39) \times \theta_{\mathrm{F}, 0, \mathrm{X}}(\operatorname{col} .33) \\
& \psi_{\mathrm{F}, 0}(\operatorname{col} .50)=\mathrm{C}_{\mathrm{t}, \text { OFF }} \times \mathrm{C}_{\mathrm{S}}^{\prime} \times \psi_{\mathrm{F}, 0, \mathrm{X}}(\operatorname{col} .35) \\
& \Psi_{\mathrm{F}, \infty}(\operatorname{col} .51)=\mathrm{C}_{\mathrm{S}}^{\prime} \times \psi_{\mathrm{F}, \infty, \mathrm{X}}(\operatorname{col} 136) \\
& \text { where } \mathrm{C}_{\mathrm{S}}^{\prime}=1.22
\end{aligned}
$$




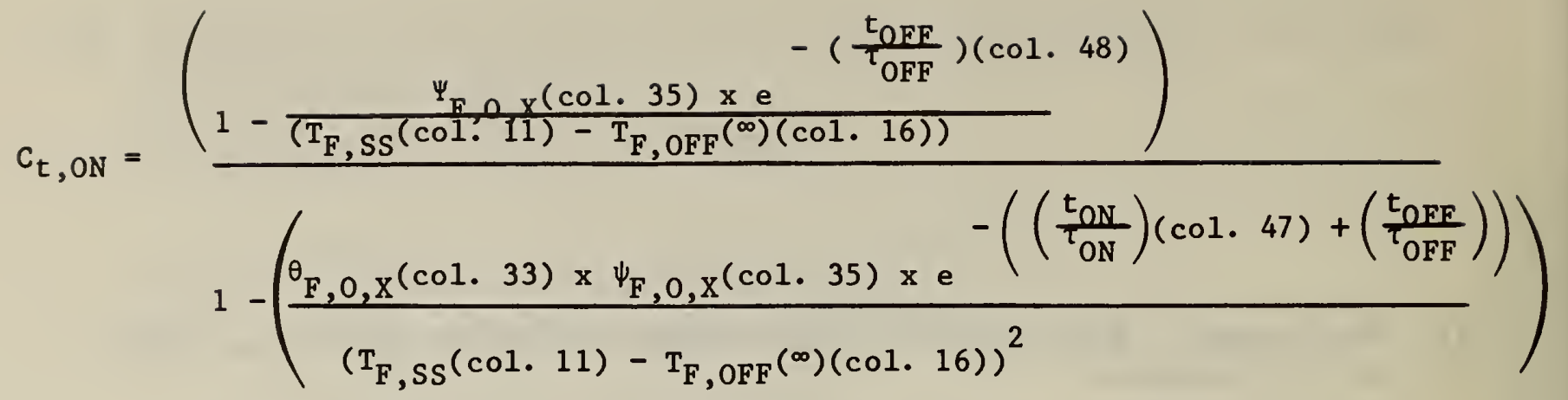

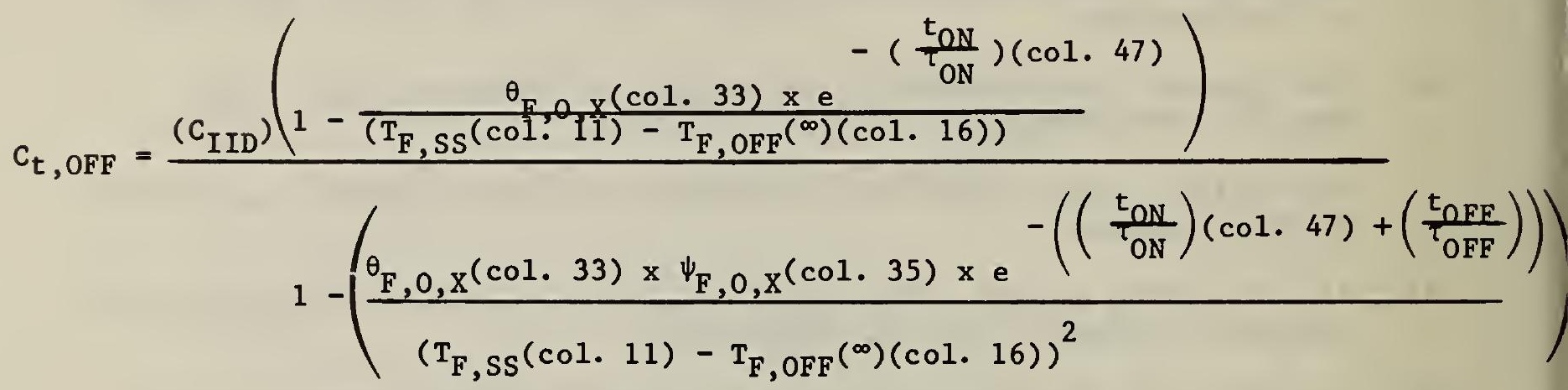

$C_{\text {IID }}=\left\{\begin{array}{l}1 \text { for units with continuously operating pilot lights } \\ 0.90 \text { for units with intermittent ignition devices or cycling pilots }\end{array}\right.$

54. For SYS作 (col. 1) equal to 1 through 4: Read from figure 3 and enter column 54: F3 $\left[\psi_{\mathrm{F}, 0}(\mathrm{col} .50),\left(\mathrm{t}_{\mathrm{OFF}} / \tau_{\mathrm{OFF}}\right)(\mathrm{col} .48)\right]$ :

For SYS⿰ (col. 1) equal to 5 through 12: Leave column 54 blank.

55. For SYS⿰ (col. 1) equal to 1 through 4: Kead from figure 4 and enter column 55: $\mathrm{F} 4\left[\psi_{\mathrm{F}, 0}(\mathrm{col} .50),\left(\mathrm{t}_{\mathrm{OFF}} / \tau_{\mathrm{OFF}}\right)(\mathrm{col} .48)\right] \cdot$

For SYS (col. 1) equal to 5 through 12:- Leave column 55 blank.

56. For SYS⿰ (col. 1) equal to 1 through 4: Leave column 56 blank.

For SYS非 (col. 1) equal to 5 through 8: Read from figure 5 and enter column 56: F5 $\left[\psi_{\mathrm{S}, 0}(\mathrm{col} .52),\left(\mathrm{t}_{\mathrm{OFF}} / \tau_{\mathrm{OFF}}\right)(\operatorname{col} .48)\right]$.

For SYS⿰ ( $c 01.1$ ) equal to 9 through 12: Read from figure 5 and enter column 56: F5 $\left[\psi_{\mathrm{F}, 0}(\mathrm{col} .50),\left(\mathrm{t}_{\mathrm{OFF}} / \tau_{\mathrm{OFF}}\right)(\operatorname{col} .48)\right]$.

57. For SYS非 (col. 1) equal to 1 through 4: Leave column 57 blank.

For SYS\# (col. 1) equal to 5 through 8: Read from figure 6 and enter column 57: F6 [ $\left.\psi_{\mathrm{S}, 0}(\operatorname{col} .52),\left(\mathrm{t}_{\mathrm{OFF}} / \tau_{\mathrm{OFF}}\right)(\operatorname{col} .48)\right]$. 
For SYS (col. 1) equal to 9 through 12: Read from figure 6 and enter in column 57: $\mathrm{F} 6\left[\psi_{\mathrm{F}, 0}(\operatorname{col} .50),\left(\mathrm{t}_{\mathrm{OFF}} / \tau_{\mathrm{OFF}}\right)(\operatorname{col} .48)\right]$.

58. For SYS\# (col. 1) equal to 1 through 8: Read from figure 7 and enter column 58: F7 $\left[\Psi_{\mathrm{S}, 0}(\operatorname{col} .52),\left(\mathrm{t}_{\mathrm{OFF}} / \tau_{\mathrm{OFF}}\right)(\operatorname{col} \cdot 48)\right]$.

For SYS\# (col. 1) equal to 9 through 12: Leave column 58 blank.

59. For SYS column 59: F8 $\left[\psi_{\mathrm{S}, 0}(\operatorname{col} .52),\left(\mathrm{t}_{\mathrm{OFF}} / \tau_{\mathrm{OFF}}\right)(\operatorname{col} .48)\right]$.

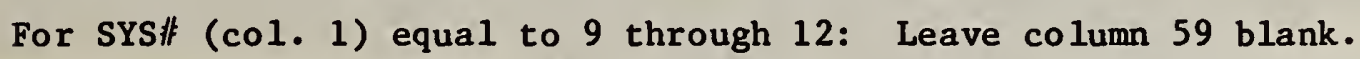

60. For SYS 非 (col. 1) equal to 1 through 8: Calculate and enter on-cycle sensible heat loss:

$$
\begin{aligned}
\mathrm{L}_{\mathrm{S}, \mathrm{ON}}= & \mathrm{L}_{\mathrm{S}, \mathrm{SS}, \mathrm{A}}(\operatorname{col} \cdot 29)-\mathrm{K}_{\mathrm{S}, \mathrm{ON}}(\operatorname{col} \cdot 40) \times \theta_{\mathrm{F}, 0}(\operatorname{col} \cdot 49) \times \frac{1}{\left(\mathrm{t}_{\mathrm{ON}} / \tau_{\mathrm{ON}}\right)(\operatorname{col} 1.47)} \\
& \quad \mathrm{x}\left(1-\mathrm{e}^{-\frac{\mathrm{t}_{\mathrm{ON}}}{{ }^{\mathrm{T}} \mathrm{ON}}(\operatorname{col} 1.47)}\right.
\end{aligned}
$$

For SYS\# (col. 1) equal to 9 through 12: Calculate and enter on-cycle sensible heat loss:

$$
\begin{aligned}
\mathrm{L}_{\mathrm{S}, \mathrm{ON}} & =\mathrm{C}_{\mathrm{S}}(\operatorname{col} .39) \times \mathrm{L}_{\mathrm{S}, \mathrm{SS}, \mathrm{A}}(\operatorname{col} \cdot 29)-\mathrm{K}_{\mathrm{S}, \mathrm{ON}}(\operatorname{col} 1.40) \times \theta_{\mathrm{F}, 0}(\operatorname{col} .49) \\
& \times \frac{1}{\left(\mathrm{t}_{\mathrm{ON}} / \tau_{\mathrm{ON}}\right)(\operatorname{col} .47)} \times\left(1-\mathrm{e}^{-\frac{\mathrm{t}_{\mathrm{ON}}}{\tau_{\mathrm{ON}}}(\operatorname{col} \cdot 47)}\right) .
\end{aligned}
$$

61. For SYS (col. 1) equal to 1 through 4, calculate and enter the offperiod sensible heat loss:

$$
\begin{aligned}
\mathrm{L}_{\mathrm{S}, \text { OFF }} & =\mathrm{K}_{\mathrm{S}, \text { OFF }}(\operatorname{col} 141) \times \frac{\mathrm{t}_{\mathrm{OFF}}(\operatorname{col} 1.46)}{\mathrm{t}_{\mathrm{ON}}(\operatorname{col} 1.45)} \times\left[\mathrm{F3}(\operatorname{col} .54)+\psi_{\mathrm{F}, \infty}(\operatorname{col} 1.51)\right. \\
& \times \mathrm{F} 4(\operatorname{col} 1.55)] .
\end{aligned}
$$

For SYS (col. 1) equal to 5 through 8, calulate and enter the offperiod sensible heat loss:

$$
\begin{aligned}
\mathrm{L}_{\mathrm{S}, \text { OFF }} & =\mathrm{K}_{\mathrm{S}, \text { OFF }}(\operatorname{col} .41) \times \frac{\mathrm{t}_{\mathrm{OFF}}(\operatorname{col} \cdot 46)}{\mathrm{t}_{\mathrm{ON}}(\operatorname{col} \cdot 45)} \times\left[\mathrm{F5}(\operatorname{col} .56)+\psi_{\mathrm{S}, \infty}(\operatorname{col} .53)\right. \\
& \times \mathrm{F} 6(\operatorname{col} 1.57)] .
\end{aligned}
$$


For SYS\# (col. 1) equal to 9 through 12, calculate and enter the off-period sensible heat loss:

$$
\begin{aligned}
\mathrm{L}_{\mathrm{S}, \text { OFF }} & =\mathrm{K}_{\mathrm{S}, \text { OFF }}(\operatorname{col} .41) \times \frac{\mathrm{t}_{\mathrm{OFF}}(\operatorname{col} \cdot 46)}{\mathrm{t}_{\mathrm{ON}}(\operatorname{col} \cdot 45)} \times\left[\mathrm{F5}(\operatorname{col} \cdot 56)+\psi_{\mathrm{F}, \infty}(\operatorname{col} .51)\right. \\
& \times \mathrm{F} 6(\operatorname{col} .57)] \cdot
\end{aligned}
$$

62. For SYS $(\operatorname{col}, 1)$ equal to 1 through 8: Calculate and enter on-cycle infiltration heat loss:

$\mathrm{L}_{\mathrm{I}, \mathrm{ON}}=\mathrm{K}_{\mathrm{I}, \mathrm{ON}}(\operatorname{col} \cdot 42) \times\left[70-\mathrm{T}_{\mathrm{OA}}(\operatorname{col} \cdot 44)\right]$

For SYS (col. 1) equal to 9 through 12: Enter on-cycle infiltration heat loss, $\mathrm{L}_{\mathrm{I}, \mathrm{ON}}=0$.

63. For SYS (col. 1) equal to 1 through 8: Calculate and enter off-cycle infiltration loss:

$$
\begin{aligned}
\mathrm{L}_{\mathrm{I}, \mathrm{OFF}} & =\mathrm{K}_{\mathrm{I}, \mathrm{OFF}}(\operatorname{col} 143) \times\left[70-\mathrm{T}_{\mathrm{OA}}(\operatorname{col} \cdot 44)\right] \times \frac{\mathrm{t}_{\mathrm{OFF}}(\operatorname{col} \cdot 46)}{\mathrm{t}_{\mathrm{ON}}(\operatorname{col} \cdot 45)} \\
& \times\left[\mathrm{F} 7(\operatorname{col} .58)+\Psi_{\mathrm{S}, \infty}(\operatorname{col} 153) \times \mathrm{F} 8(\operatorname{col} .59)\right]
\end{aligned}
$$

For SYS $(\operatorname{col} 1.1)$ equal to 9 through 12: Enter off-cycle infiltration heat loss, $\mathrm{L}_{\mathrm{I}, \mathrm{OFF}}=0$.

64. Calculate and enter part-load fuel utilization efficiency, for indoor unit:

$$
\begin{aligned}
& \eta_{\mathrm{u}}=100-\mathrm{L}_{\mathrm{L}, \mathrm{A}}(\operatorname{col} \cdot 26)-\frac{\mathrm{t}_{\mathrm{ON}}(\operatorname{col} \cdot 45)}{\mathrm{t}_{\mathrm{ON}}(\operatorname{col} \cdot 45)+\mathrm{PF}(\operatorname{col} \cdot 23) \mathrm{t}_{\mathrm{OFF}}(\operatorname{col} \cdot 46)} \\
& x\left[\mathrm{~L}_{\mathrm{S}, \text { ON }}(\operatorname{col} \cdot 60)+\mathrm{L}_{\mathrm{S}, \text { OFF }}(\operatorname{col} \cdot 61)+\mathrm{L}_{\mathrm{I}, \text { ON }}(\operatorname{col} \cdot 62)+\mathrm{L}_{\mathrm{I}, \text { OFF }}(\operatorname{col} \cdot 63)\right] \cdot \\
& \eta_{\mathrm{u}}=100-\mathrm{L}_{\mathrm{L}, \mathrm{A}}(\operatorname{col} \cdot 26)-\mathrm{C}_{\mathrm{J}}(\operatorname{col} 1 \cdot 27) \times \mathrm{L}_{\mathrm{J}}(\operatorname{col} \cdot 18) \\
& -\frac{\mathrm{t}_{\mathrm{ON}}(\operatorname{col} \cdot 45)}{\mathrm{t}_{\mathrm{ON}}(\operatorname{col} \cdot 45)+\mathrm{PF}(\operatorname{col} \cdot 23) \mathrm{t}_{\mathrm{OFF}}(\operatorname{col} \cdot 46)} \times\left[\mathrm{L}_{\mathrm{S}, \mathrm{ON}}(\operatorname{col} \cdot 60)\right. \\
& \left.+\mathrm{L}_{\mathrm{S}, \mathrm{OFF}}(\operatorname{col} \cdot 61)\right] \text {. }
\end{aligned}
$$

65. Enter the value of the average annual heating degree days for the U.S., DD, equal to 5200 . 
66. Enter the average total number of non-heating season hours per year that the energy to the pilot light is assumed wasted, HR, equal to 4600 .

67. Calculate and enter annual fuel utilization efficiency:

$$
\mathrm{EFFY}_{\mathrm{A}}=
$$$$
n_{\mathrm{SS}}(\operatorname{col} .30) \times \eta_{\mathrm{u}}(\operatorname{col} .64) \times \mathrm{DD}(\operatorname{col} \cdot 65)
$$

$\overline{n_{\mathrm{SS}}(\operatorname{col} .30) \times \mathrm{DD}(\operatorname{col} .65)+(2.5) \times n_{\mathrm{u}}(\operatorname{col} .64) \times \mathrm{PF}(\operatorname{col} .23)(1.7)(\mathrm{HR}(\operatorname{col} .66))}$

4.2 RECOMMENDED PROCEDURE FOR CALCULATING THE ANNUAL COST OF OPERATION OF A FURNACE OR BOILER LOCATED IN DIFFERENT CLIMATIC REGIONS OF THE COUNTRY AND IN BUILDINGS WITH DIFFERENT DESIGN HEATING REQUIREMENTS

The annual cost of operating a gas- or oil-fired furnace or boiler located in various geographic locations of the United States and in buildings with different design heating requirements shall be determined using the following three-step procedure:

Step 1. Determine the number of burner operating hours using the equation:

Burner Operating Hours $=A(H L H)(C)$ (design heating requirement) $-B(H L H)$

where the number of heating load hours, HLH, may be obtained from Figure 9 for the region of interest, the "design heating requirement" is the heating requirement to be met by the furnace or boiler in kBtu per hour at the $971 / 2$ percent outdoor design temperature, and $C=0.77$ is an "experience factor" which tends to improve the agreement between the average calculated burner operating hours and the average burner operating hours found in the field. It is strongly recommended that this "experience factor" be eliminated as soon as an improved method is available to more accurately estimate residential heating requirements. Typical values for the design heating requirement are given in Table 4 for different furnace or boiler output capacities $Q_{O U T}$, where $Q_{\text {OUT }} \equiv n_{\text {SS }}(\operatorname{col} .30) \times Q_{I N}$ (col. 30) $\times Q_{I N}$ (col. 4) rounded off to the nearest $1000 \mathrm{Btu} / \mathrm{h}$ for units intended for installation in a heated space and $Q_{\text {OUT }} \equiv\left(\frac{Q_{\text {IN }}(\operatorname{col} 14)}{100}\right)\left(n_{S S}(\operatorname{col} .30)-3.3 \mathrm{~L}_{J}(\operatorname{col} .18)\right)$ rounded off to the nearest $1000 \mathrm{Btu} / \mathrm{h}$ for units intended for installation out of doors or in an unheated space. The constants $A$ and $B$ are unique to the unit under tests and may be calculated using information contained in the work sheet and the following expressions: 


$$
\begin{aligned}
A & =\frac{100,000}{341,300(P E+y B E)+\left(Q_{I N}-Q_{p}\right) n_{u}} \\
B & =\frac{(2)(A)\left(Q_{p}\right)\left(n_{u}\right)}{100,000}
\end{aligned}
$$

where $y=\left\{\begin{array}{l}1+\left(\frac{t^{+}-t^{-}}{3.87}\right) \text { for furnace } \\ 1.00 \text { for boilers or furnaces employing a single motor to } \\ \text { drive a power burner and an indoor-air circulating blower. }\end{array}\right.$

Step 2. Determine the annual fuel consumption (in Btu) and the annual electricity consumption (in $\mathrm{kWh}$ ) using:

Annual Fuel Consumption $=\left(Q_{I N}-Q_{p}\right)($ Burner Operating Hours $)+8760 Q_{p}$

Annual Electricity Consumption $=(P E+y B E)$ (Burner Operating Hours)

Step 3. The annual cost of operation is then:

Annual Cost of Operation $=($ Annual Fuel Consumption $)\left(\frac{1}{k}\right)(\$$ per unit of fue 1$)$

$$
+ \text { (Annual Electricity Consumption)( } \$ \text { per } \mathrm{kWh} \text { ), }
$$

where $K$ is the Btu content per unit of fuel that the fuel cost is given in terms of $(\mathrm{e} . \mathrm{g} . \mathrm{K}=100,000 \mathrm{Btu} /$ therm if cost is given in dollars per therm; $\mathrm{K}=140,000 \mathrm{Btu} / \mathrm{gallon}$ if cost is expressed as dollars per gallon of No. 2 fuel oil). The annual cost of operation should be rounded off to the nearest five dollars.

The annual cost of operating an electric furnace or boiler in various geographic locations of the United States and in buildings with different design heating requirements shall be determined using the equation:

Annual Cost of Operation $=\frac{100(\mathrm{HLH})(\mathrm{C})(\text { design heating requirement })}{\mathrm{EFFY}_{\mathrm{A}}}$

$$
\mathrm{x} \frac{1}{3.413}(\$ \text { per } \mathrm{kWh})
$$

where $E_{\mathrm{A}}=n_{\mathrm{SS}}=\left\{\begin{aligned} & 100 \text { for units intended for installation in a heated space } \\ &\left(100-3.3 \mathrm{~L}_{\mathrm{J}}\right) \begin{array}{r}\text { for electric furnaces intended for } \\ \text { installation out of doors or in unheated } \\ \text { spaces (such as an attic or a craw1 space) }\end{array} \\ &\left(100-4.7 \mathrm{~L}_{\mathrm{J}}\right) \begin{array}{l}\text { for electric boilers intended for insta1- } \\ \text { lation out of doors or in unheated space } \\ \text { (such as an attic or a crawl space) }\end{array}\end{aligned}\right.$

and $C \equiv 0.77$ is the "experience factor" mentioned above. 
The number of heating load hours, HLH, for different geographical regions is given in Figure 10, and the "design heating requirement" is the building heating requirement in $\mathrm{kBtu}$ per hour at the $971 / 2$ percent outdoor design temperature. Typical value for the design heating requirement are given in Table 4 for electric furnaces and boilers having different output capacities $Q_{O U T}$, where $Q_{\text {OUT }}=\left(E_{I N}\right)(3.413)$ rounded off to the nearest $1000 \mathrm{Btu} / \mathrm{h}$ for units intended for installation in a heated space and $Q_{\text {OUT }} \equiv \frac{\left(E_{I N}\right)(3.413)}{100}$ $\mathrm{x}\left(100-3.3 \mathrm{~L}_{\mathrm{J}}\right)$ for units intended for installation out of doors or in an unheated space. The annual cost of operation should be rounded off to the nearest five dollars.

In order to facilitate performance comparison by the user of furnaces, boilers and heat pumps, it is recommended that the annual cost of operation be calculated for all of the appropriate typical design heating requirements shown in Table 4 and for a variety of heating load hours, HLH. For example, a furnace with an output capacity of $80 \mathrm{kBtu} / \mathrm{h}$ could have its annual cost of operation calculated at design heating requirements of 40, 45, 50 and 60 $\mathrm{kBtu} / \mathrm{h}$, and heating load hours of $750,1250,1750,2250$ and 2750 hours. This approach has the advantage of being able to handle different sizing relationships between the furnace or boiler and a residence's design heating requirement in different geographical locations and could be incorporated, along with the effect of different fuel costs, in a table having the following form:

\begin{tabular}{|c|c|c|c|c|c|c|c|}
\hline REGION & $\begin{array}{l}\text { DESIGN HEATING } \\
\text { REQUIREMENT } \\
(\mathrm{kBtu} / \mathrm{h}) \\
\end{array}$ & $\mathrm{EFFY}_{\mathrm{A}}$ & $\begin{array}{r}c \\
.20\end{array}$ & $\begin{array}{l}\text { OF } \\
.25\end{array}$ & $\begin{array}{r}(\$ / \\
.30\end{array}$ & $\begin{array}{l}\text { 1) } \\
.35\end{array}$ & .40 \\
\hline$\left(750^{\mathrm{I}} \mathrm{HLH}\right)$ & $\begin{array}{l}40 \\
45 \\
50 \\
60\end{array}$ & & & & & & \\
\hline $\begin{array}{c}\text { II } \\
(1250 \mathrm{HLH})\end{array}$ & $\begin{array}{l}40 \\
45 \\
50 \\
60\end{array}$ & & & & & & \\
\hline $\begin{array}{c}\text { III } \\
\text { (1750 HLH) }\end{array}$ & $\begin{array}{l}40 \\
45 \\
50 \\
60\end{array}$ & & & & & & \\
\hline $\begin{array}{c}\text { IV } \\
(2250 \mathrm{HLH})\end{array}$ & $\begin{array}{l}40 \\
45 \\
50 \\
60\end{array}$ & & & & & & \\
\hline $\begin{array}{c}V \\
(2750 \mathrm{HLH})\end{array}$ & $\begin{array}{l}40 \\
45 \\
50 \\
60\end{array}$ & & & & & & \\
\hline
\end{tabular}


If a single operating cost figure is required for a furnace or boiler that represents the national average, it is recommended that the preceding appropriate equations be used with HLH set equal to 2.080 hours and the design heating requirement set equal to the average design heating requirement given in Table 4 for the approprlate value of furnace or boller output capacity Q OUT

\subsection{ADDITIONAL CALCULATIONS FOR FURNACES OR BOILERS UTILIZING AN AUTOMATIC STACK (OR FLUE) DAMPER}

Calculate the automatic stack (or flue) damper effectiveness, $D_{0}$, defined as:

$$
\mathrm{D}_{0}=\sqrt{\left.\frac{\left[(2.6)\left(\frac{\mathrm{A}_{\mathrm{D}}{ }^{\prime}}{\mathrm{A}_{S}}\right)^{1.58}\right]}{\left(1-\left(\frac{\mathrm{A}_{\mathrm{D}}^{\prime}}{\mathrm{A}_{S}}\right)\right)^{2}}\right]}
$$

where $A_{D}^{\prime}=A_{D} \cos (\gamma)$

$A_{S}=$ cross sectional area of the stack determined in accordance with section 3.5 of this appendix, in square inches

$A_{D}=$ net area of the damper plate determined in accordance with section 3.5 of this appendix, in square inches

$\gamma=$ the angle the damper makes when closed with a plane perpendicular to the axis of the stack determined in accordance with section 3.5 .

4.4 ADDITIONAL CALCULATION PROCEDURES FOR FURNACES OR BOILERS EQUIPPED WITH POWER BURNERS

4.4.1 Optional Procedure for Determination of $D_{p}$ for Furnaces or Bollers Employing a Power Burner

Calculate the ratio $\left(D_{p}\right)$ of the rate of flue-gas mass flow through the furnace or boller during the off-period, ${ }_{F, O F F}\left(T_{F}, S S\right)$, to the rate of flue-gas mass flow during the on-period, $\stackrel{\mathrm{m}}{\mathrm{F}, S S}_{\mathrm{S}}\left(\mathrm{T}_{\mathrm{F}, \mathrm{SS}}\right)$, and defined as:

$$
\mathrm{D}_{\mathrm{p}}=\frac{\dot{\mathrm{m}}_{\mathrm{F}, \mathrm{OFF}}\left(\mathrm{T}_{\mathrm{F}, \mathrm{SS}}\right)}{\dot{\mathrm{m}}_{\mathrm{F}, S S}\left(\mathrm{~T}_{\mathrm{F}, \mathrm{SS}}\right)}=\frac{\left[\dot{\mathrm{m}}_{\mathrm{F}, \text { OFF }}\left(\mathrm{T}_{\mathrm{F}, \mathrm{OFF}}^{*}\right)\right] \mathrm{K}^{\prime}}{\dot{\mathrm{m}}_{\mathrm{F}, S S}\left(\mathrm{~T}_{\mathrm{F}, \mathrm{SS}}\right)}=\frac{\left[\frac{\left(\dot{\mathrm{V}}_{\mathrm{T}}\right)\left(\mathrm{o}_{\mathrm{F}}\right)\left(100-\mathrm{C}_{\mathrm{T}}\right)}{\mathrm{C}_{\mathrm{T}}}\right] \mathrm{K}^{\prime}}{\left[\left(\mathrm{R}_{\mathrm{T}, \mathrm{F}}\right) \mathrm{A} / \mathrm{F}+1\right] \frac{\mathrm{Q}_{\mathrm{IN}}}{\left(\mathrm{HHV}_{\mathrm{A}}\right)(60)}}
$$


$\int\left[\frac{\mathrm{T}_{F, S S}-\mathrm{T}_{\mathrm{RA}}}{\mathrm{T}_{\mathrm{F}, \mathrm{OFF}}-\mathrm{T}_{\mathrm{RA}}}\right]^{0.56}\left[\frac{\mathrm{T}_{\mathrm{F}, \mathrm{OFF}}^{*}+460}{\mathrm{~T}_{\mathrm{F}, \mathrm{SS}}+460}\right]^{1.19}$, for gas-fueled units or oil-fueled units for which no draft is maintained during the steady-state tests or cool down test.

1, for oil-fueled units tested with an imposed draft as described in section 3.6 .

$\dot{v}_{T}=\quad$ flow rate of tracer gas through the furnace measured in accordance with section 3.6 , in cubic feet per minute.

$\mathrm{C}_{\mathrm{T}}=\quad$ concentration by volume of tracer gas present in the flue gas sample measured in accordance with section 3.6, in percent.

$\rho_{F}=\quad$ the density the flue gas would have at the measured barometric pressure, $P_{B}$, and the measured temperature, $T_{T}$, in $1 \mathrm{~b}$. per cu. ft. It may be approximated by the equation:

$p_{F} \simeq 1.325 \frac{P_{B}}{T_{T}+460}$

$\mathrm{T}_{\mathrm{T}}=\quad$ temperature of tracer gas entering the flow meter measured in accordance with section 3.6 , in degrees Fahrenheit.

$\mathrm{P}_{\mathrm{B}}=\quad$ barometric pressure measured in accordance with section 3.6 , in inches of mercury.

4.4.2 Optional Procedure for Determination of Off-Cycle Draft Factor for Flue-Gas Flow for Furnaces or Boilers Employing a Power Burner

Calculate the off-cycle draft factor for flue gas flow, $D_{F}$, defined as:

for systems numbered $2,4,6,8$ or $10: D_{F}=D_{P}$

for system number $12: D_{F}=\left(D_{P}\right)\left(D_{0}\right)$

4.4.3 Optional procedure for Determination of Off-Cycle Draft Factor for Stack-Gas Flow for Furnaces or Boilers Employing a Power Burner

Calculate the off-cycle draft factor for stack-gas flow, $\mathrm{D}_{\mathrm{S}}$, defined as:

for system number $2: \quad D_{S}=1.0$

for system number $4: D_{S}=\left(0.79+D_{p}\right) / 1.4$

for system number $6: D_{S}=D_{0}$

for system number 8: 


$$
D_{S}=\left\{\begin{array}{l}
\left(D_{0}\right)\left(D_{p}\right), \text { if } D_{0} \leq \frac{1}{(S / F)} \\
\left(D_{0}\right)\left(D_{P}\right)+\frac{\left(0.85-\left(D_{0}\right)\left(D_{P}\right)\right)\left(D_{0}-\frac{1}{(S / F)}\right)}{\left(1-\frac{1}{(S / F)}\right)} \text { if } D_{0}>\frac{1}{(S / F)}
\end{array}\right.
$$




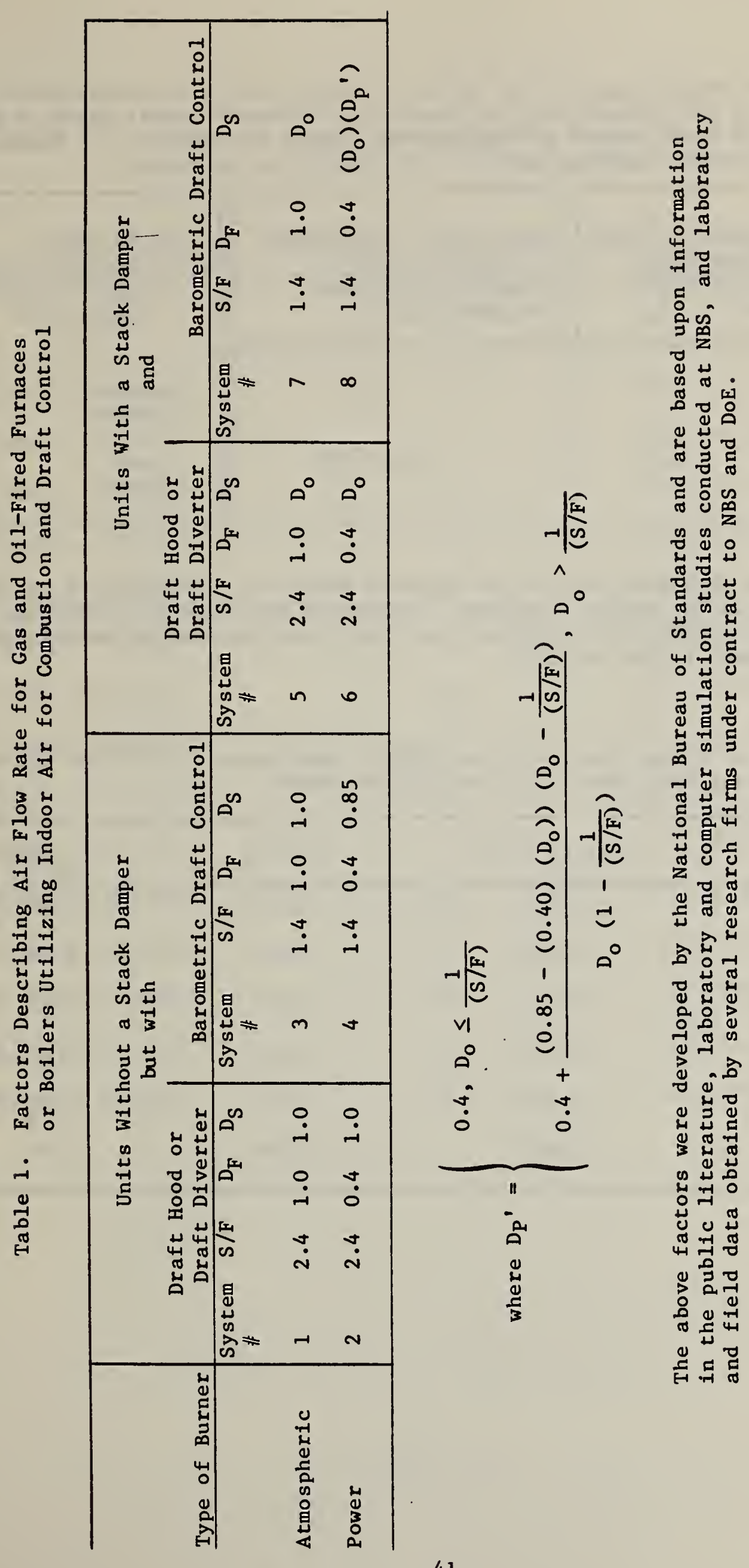


Table 2. Factors Describing Air Flow Rates for Gas or 0il-Fired Furnaces/Boilers Intended for Installation Out Doors or in Unheated Spaces (such as an attic or crawl space) or Intended for Indoor Installation but Equipped With a Direct Vent System

\begin{tabular}{|c|c|c|c|c|c|c|}
\hline \multirow[t]{2}{*}{$\begin{array}{l}\text { Type of } \\
\text { Burner } \\
\end{array}$} & \multicolumn{2}{|c|}{$\begin{array}{c}\text { Units Without a Stack } \\
\text { or Flue Damper }\end{array}$} & \multicolumn{2}{|c|}{ Units with a Flue Damper } & Type of Draft & $S / F$ \\
\hline & System \# & $\mathrm{D}_{\mathrm{F}}$ & System 非 & $\mathrm{D}_{\mathrm{F}}$ & None & 1 \\
\hline Atmosphere & 9 & 1.00 & 11 & $D_{0}$ & $\begin{array}{l}\text { barometric } \\
\text { damper }\end{array}$ & 1.4 \\
\hline Power & 10 & 0.40 & 12 & $0.40 \times \mathrm{D}_{0}$ & $\begin{array}{l}\text { draft } \\
\text { diverter }\end{array}$ & 2.4 \\
\hline
\end{tabular}

The above factors we re developed by the National Bureau of Standards and are based upon information in the public literature, laboratory and computer simulation studies conducted at NBS, and laboratory and field data obtained by several research firms under contract to NBS and DoE.

Table 3. Values of Higher Heating Value $\left(\mathrm{HHV}_{\mathrm{A}}\right)$, Stoichiometric Air/Fuel Ratio (A/F), and Latent Heat Loss $\left(\mathrm{L}_{\mathrm{L}, \mathrm{A}}\right.$ ) for Typical Fuels

\begin{tabular}{lccc}
\hline Fuels & $\mathrm{HHV}_{\mathrm{A}}(\mathrm{Btu} / 1 \mathrm{~b})$ & $\mathrm{A} / \mathrm{F}(--)$ & $\mathrm{L}_{\mathrm{L}, \mathrm{A}}(\%)$ \\
\hline No. 1 Oil & 19,800 & 14.56 & 6.55 \\
No. 2 Oil & 19,500 & 14.49 & 6.50 \\
Natural Gas & 20,120 & 14.45 & 9.55 \\
Manufactured Gas & 18,500 & 11.81 & 10.14 \\
Propane & 21,500 & 15.58 & 7.99 \\
Butane & 20,890 & 15.36 & 7.79 \\
\hline
\end{tabular}


Table 4. Average and Typical Design Heating Requirements for Furnaces and Boilers with Different Output Capacities

\begin{tabular}{ccl}
\hline $\begin{array}{c}\text { Furnace or Boiler Output } \\
\text { Capacity, } \\
(\text { Btu } / \mathrm{h})\end{array}$ & $\begin{array}{c}\text { Average Design } \\
\text { Heating Requirements } \\
(\mathrm{kBtu} / \mathrm{h})\end{array}$ & $\begin{array}{c}\text { Typical Design } \\
\text { Heating Requirements } \\
(\mathrm{kBtu} / \mathrm{h})\end{array}$ \\
\hline $26,000-34,000$ & 20 & 15,20 \\
$35,000-42,000$ & 25 & $20,25,30$ \\
$43,000-51,000$ & 30 & $25,30,35$ \\
$52,000-59,000$ & 35 & $30,35,40,45$ \\
$60,000-76,000$ & 40 & $35,40,45,50$ \\
$77,000-93,000$ & 50 & $40,45,50,60$ \\
$94,000-110,000$ & 60 & $50,60,70,80$ \\
$111,000-127,000$ & 70 & $60,70,80,90$ \\
$128,000-144,000$ & 80 & $70,80,90,100$ \\
$145,000-161,000$ & 90 & $80,90,100,110,120$ \\
$162,000-178,000$ & 100 & $90,100,110,120,130$ \\
$179,000-195,000$ & 110 & $100,110,120,130,140$ \\
$196,000-237,000$ & 130 & $120,130,140,150,160$ \\
$238,000-271,000$ & 150 & $120,140,160,180,200$ \\
$272,000-305,000$ & 170 & $140,160,180,200,220$
\end{tabular}




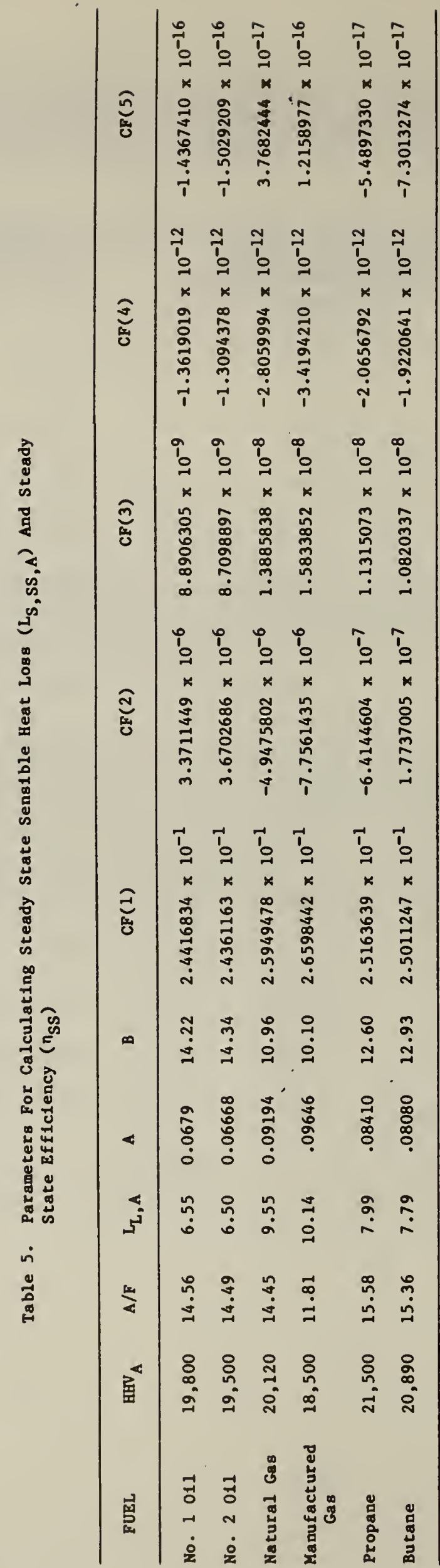

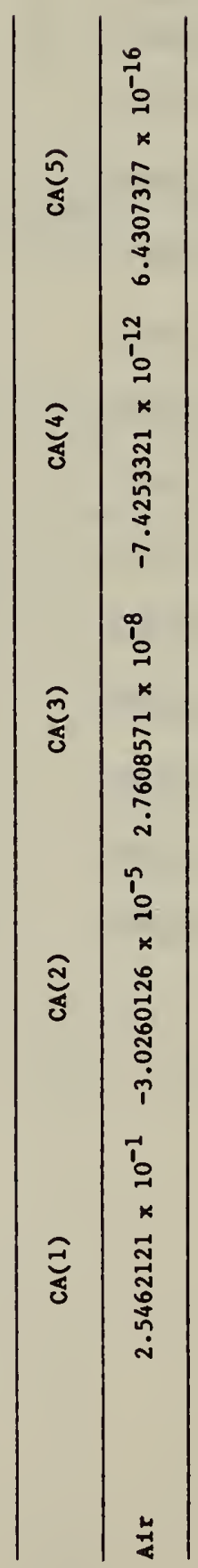




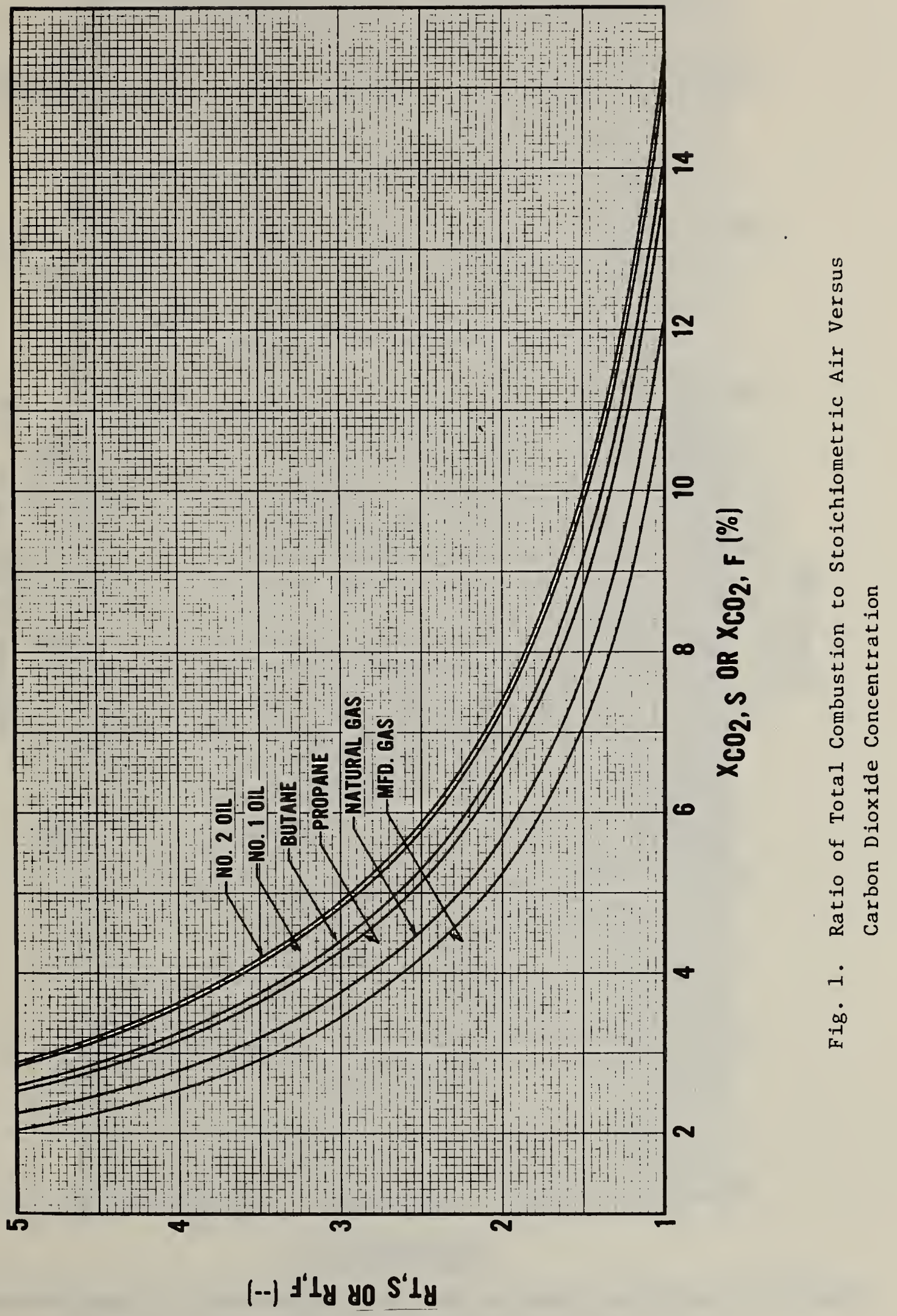




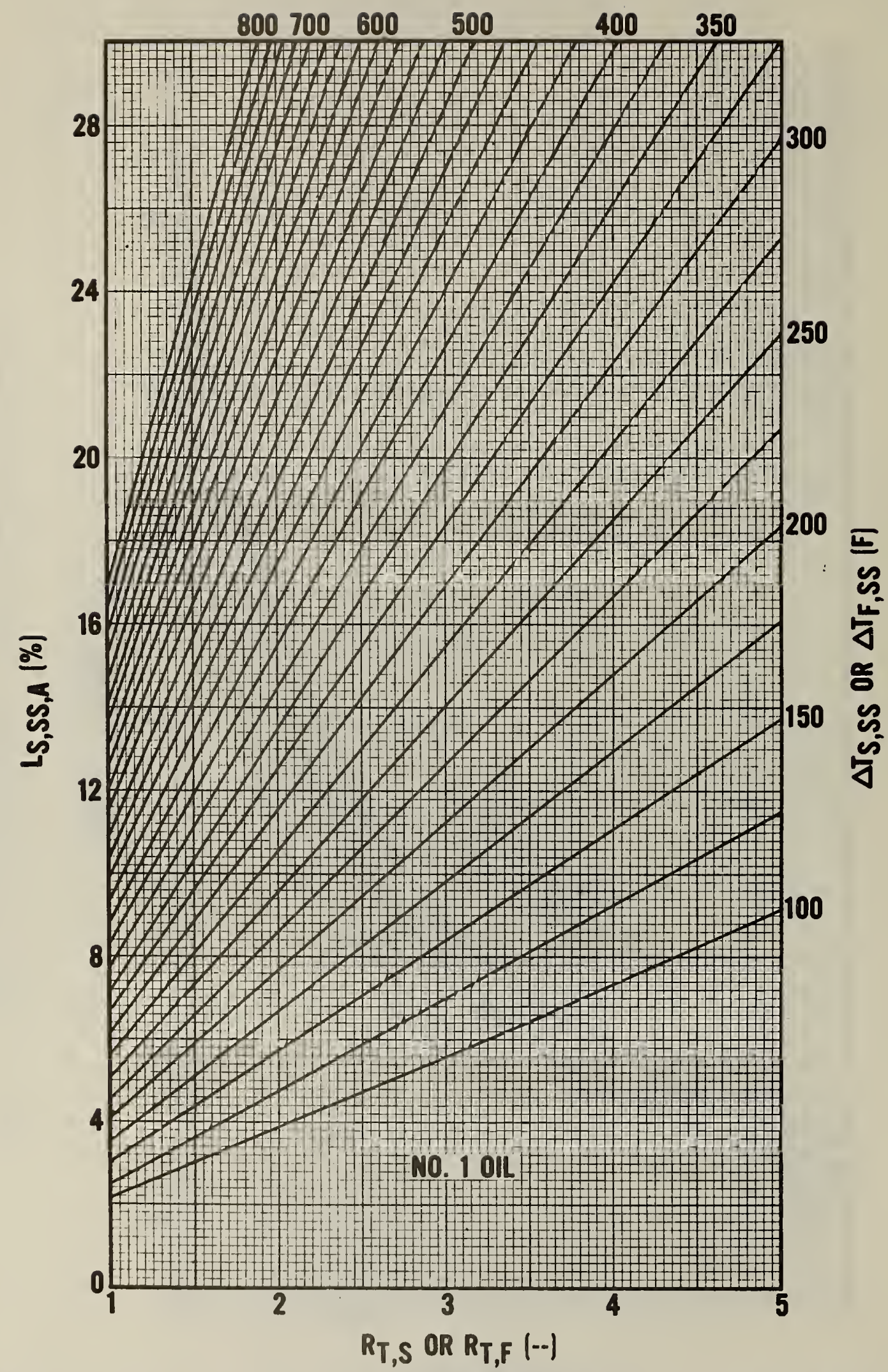

Fig. 2A. Steady-State Sensible Heat Loss Versus Ratio of Total Combustion to Stoichiometric Air (For No. 1 0i1) 


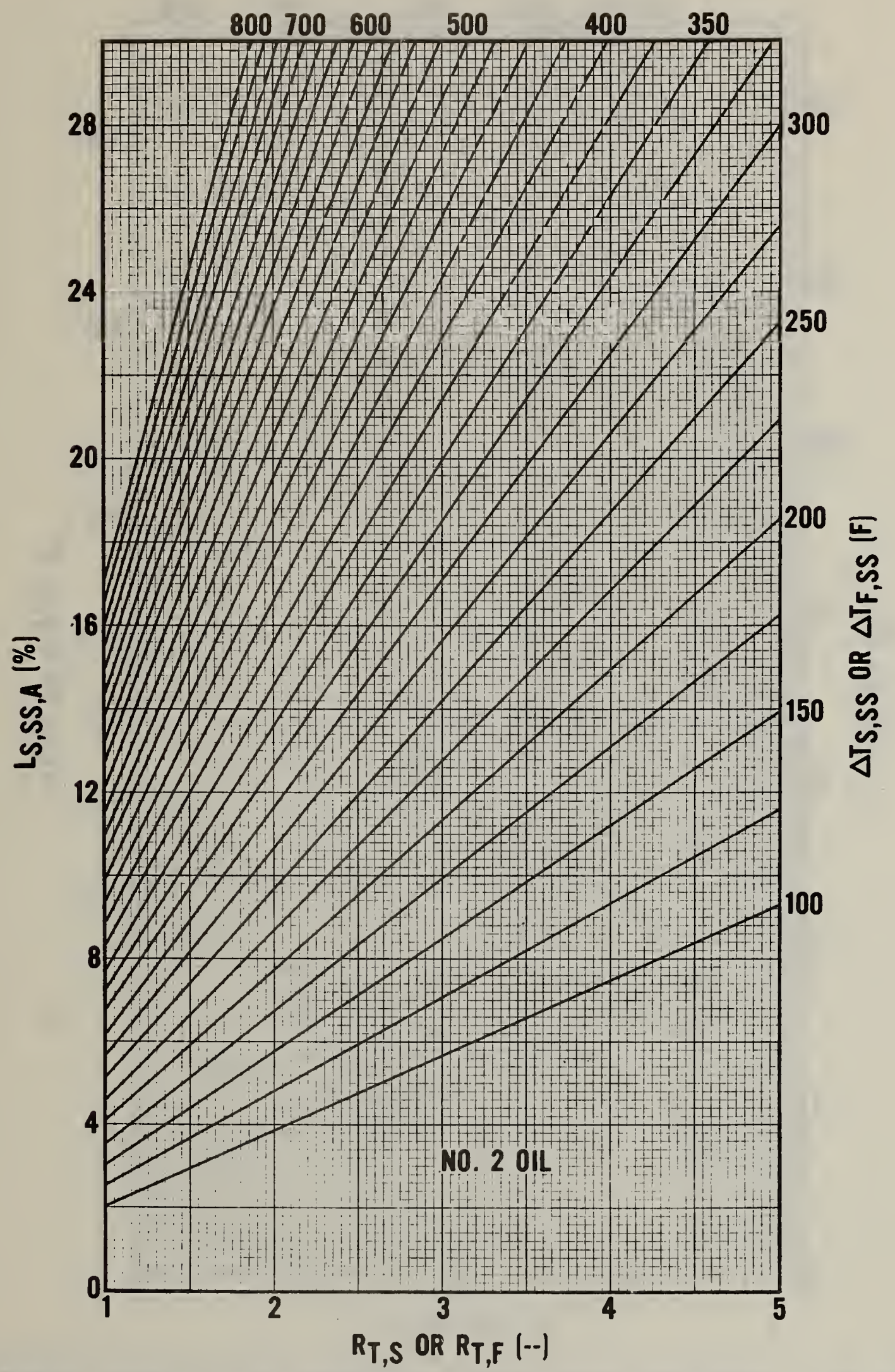

Fig. 2B. Steady-State Sensible Heat Loss Versus Ratio of Total Combustion to Stoichiometric Air (For No. 2 0i1) 


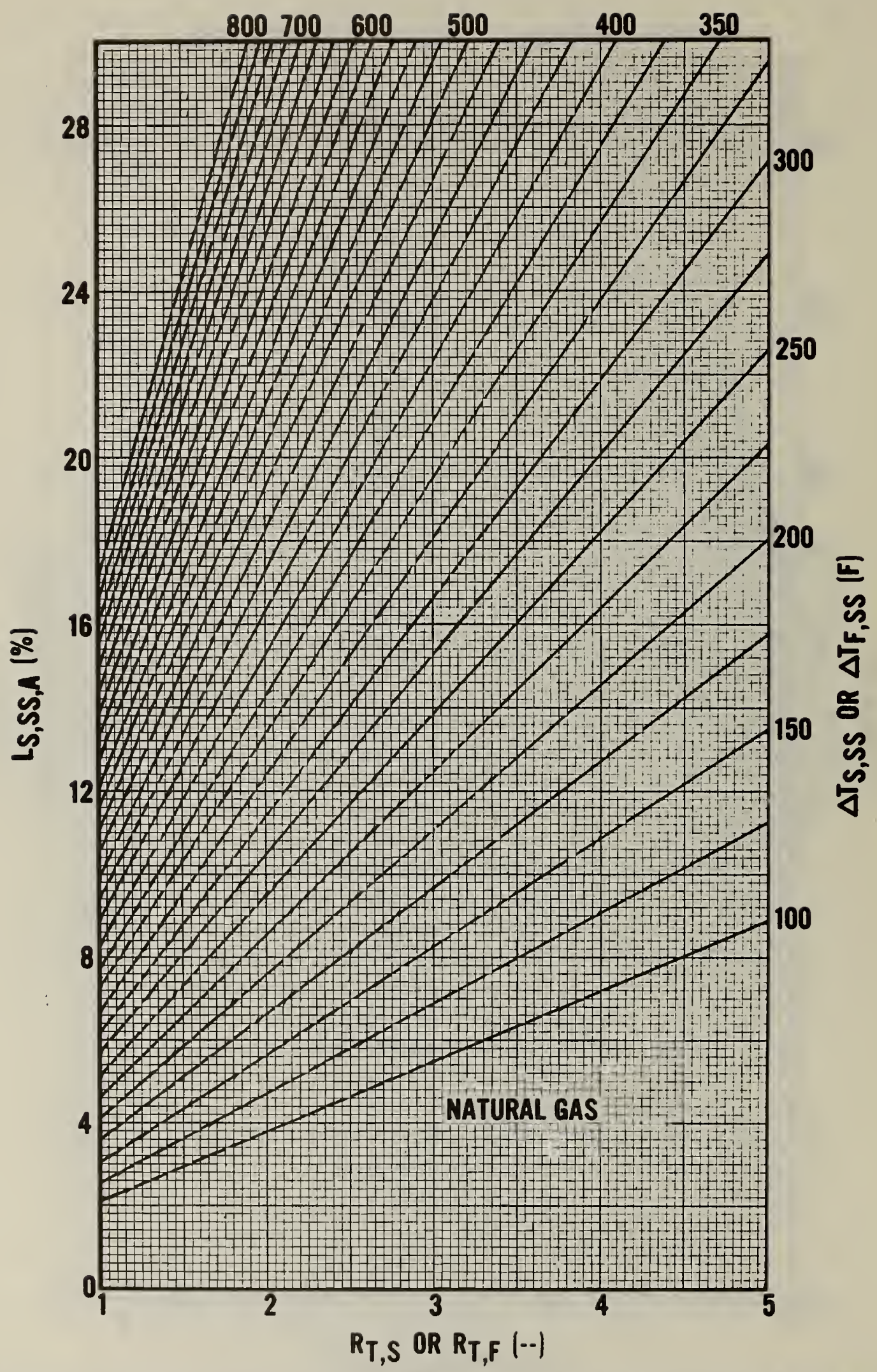

F1g. 2C. Steady-State Sensible Heat Loss Versus Ratio of Total Combustion to Stoichiometric Air (For Natural Gas) 


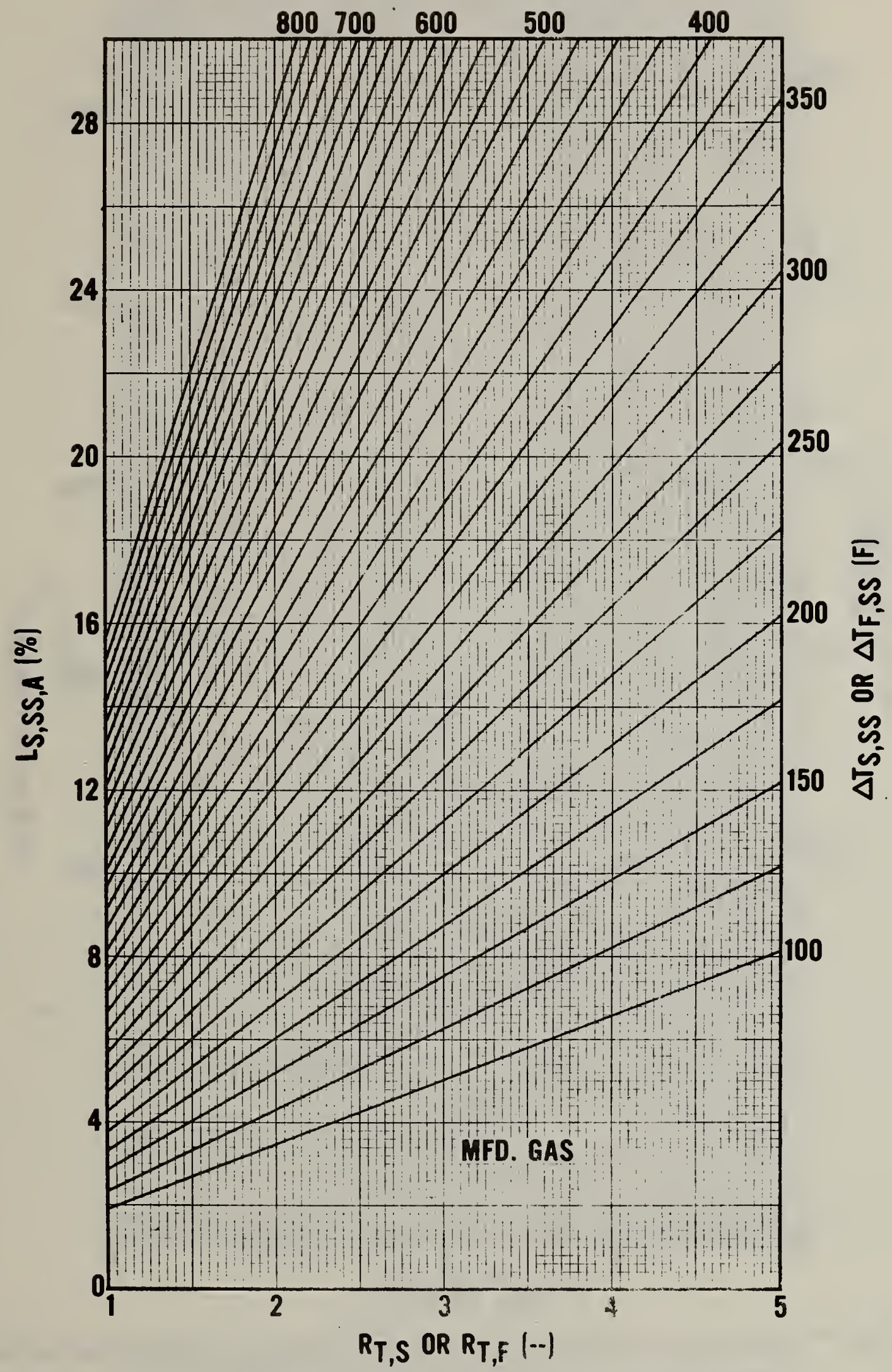

Fig. 2D. Steady-State Sensible Heat Loss Versus Ratio of Total Combustion to Stoichiometric Air (For Manufactured Gas) 


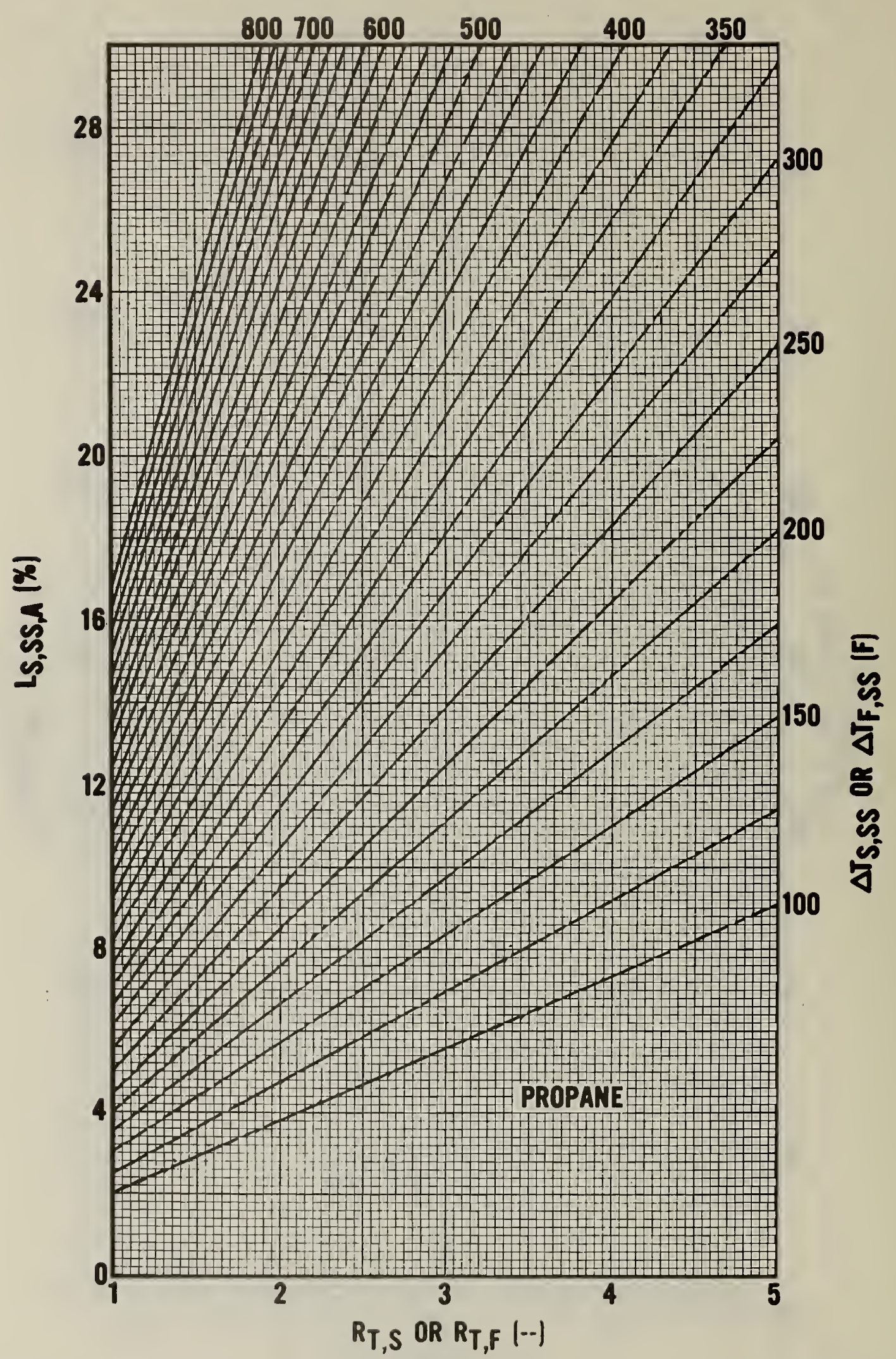

F18. 2E. Steady-State Sensible Heat Loss Versus Ratio of Total Combustion to Stolchlometric Air (For Propane) 


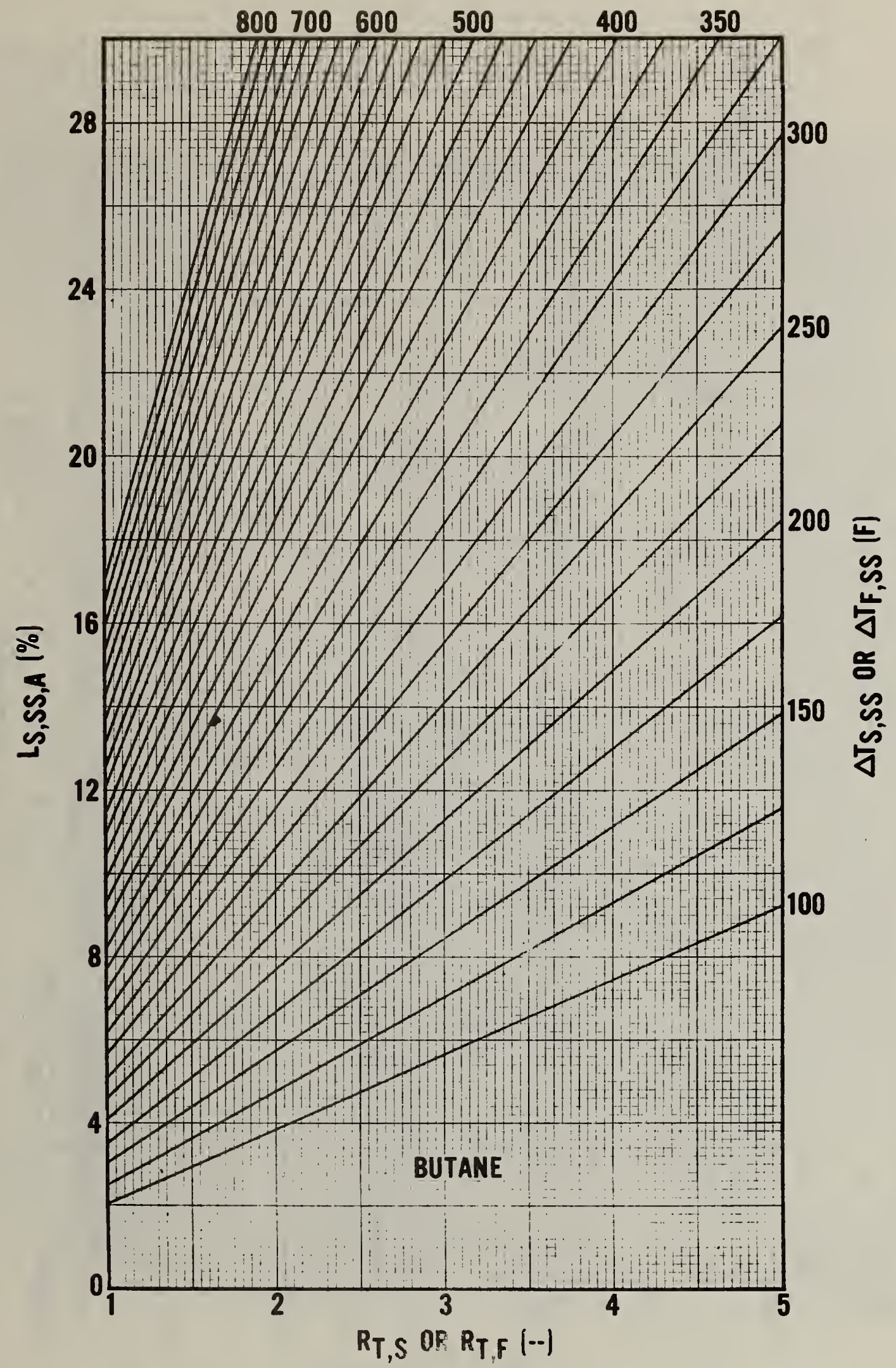

Fig. 2F. Steady-State Sensible Heat Loss Versus Ratio of Total Combustion to Stoichiometric Air (For. Butane) 


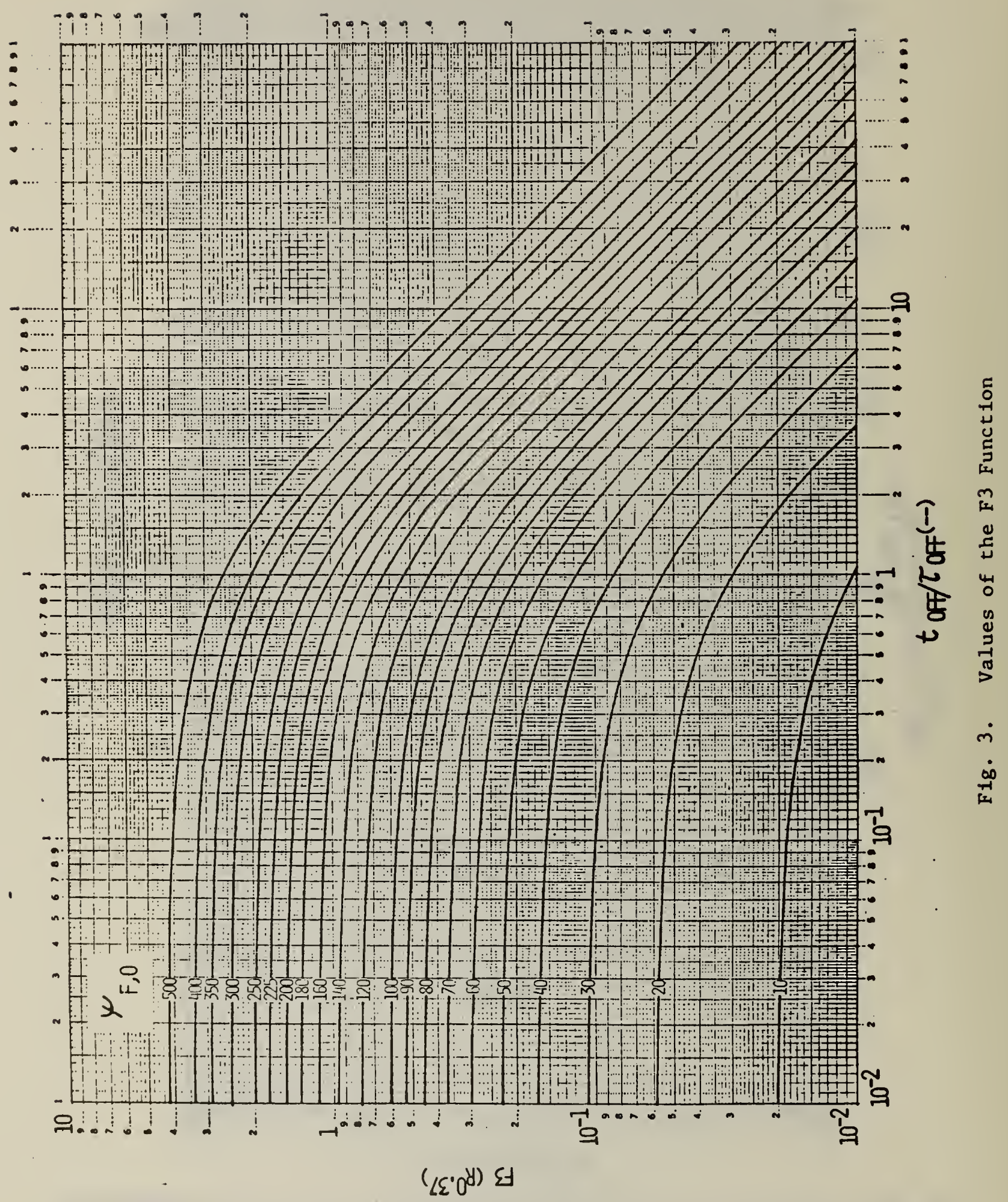




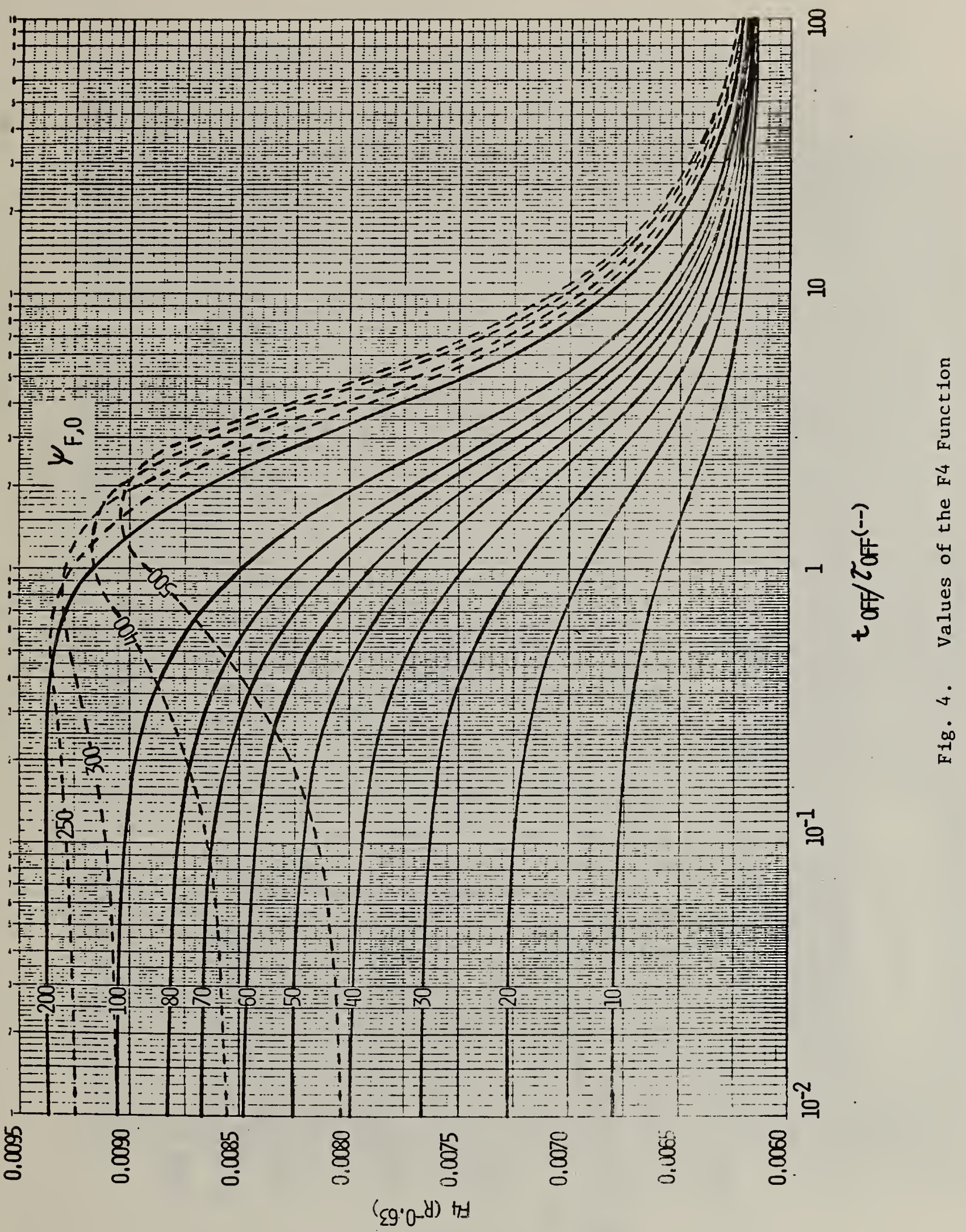




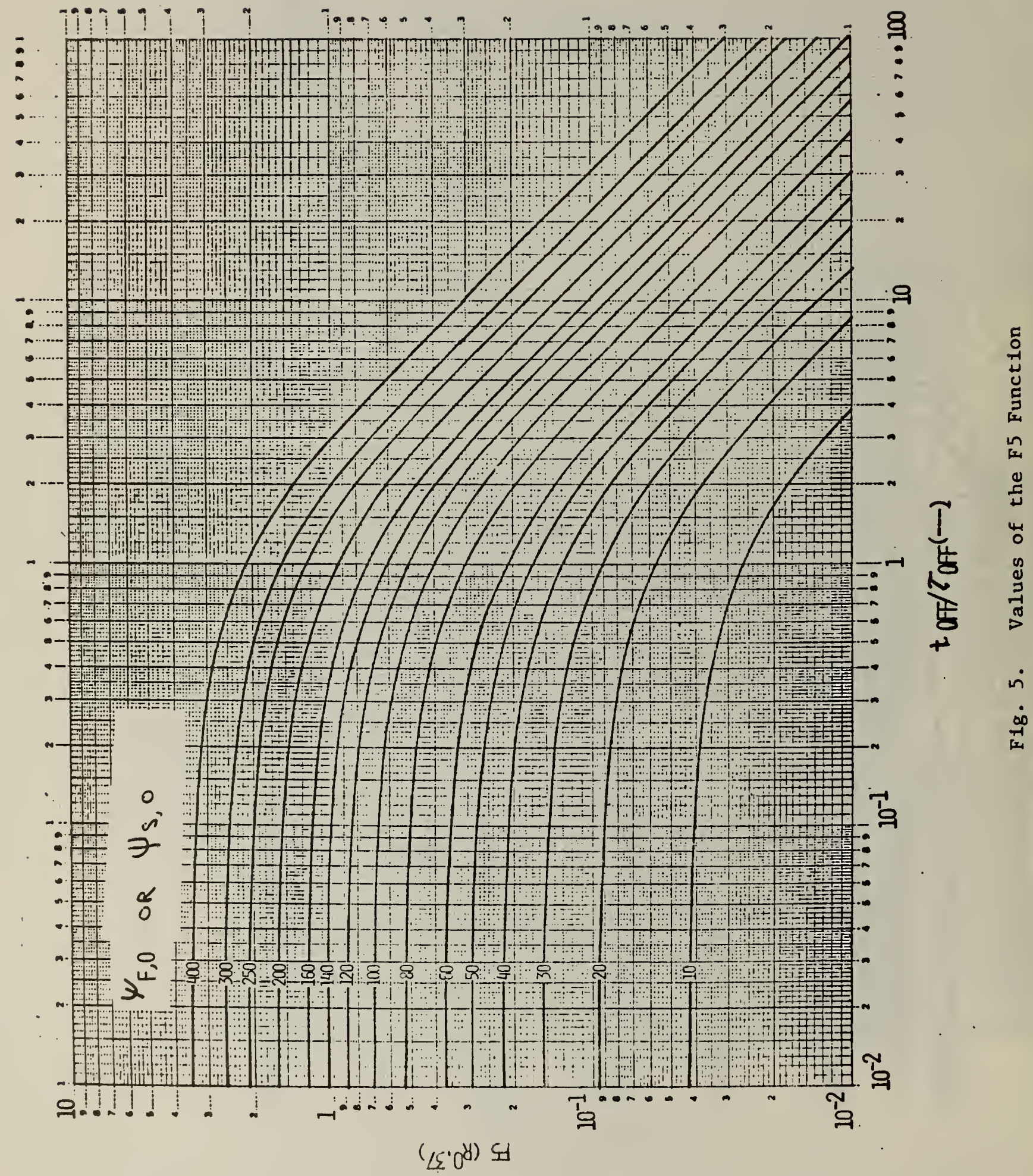


(1)

(1)

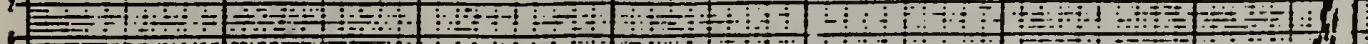
(1)

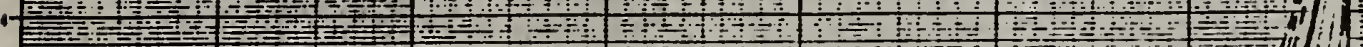

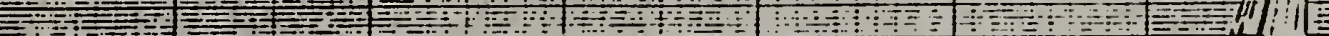

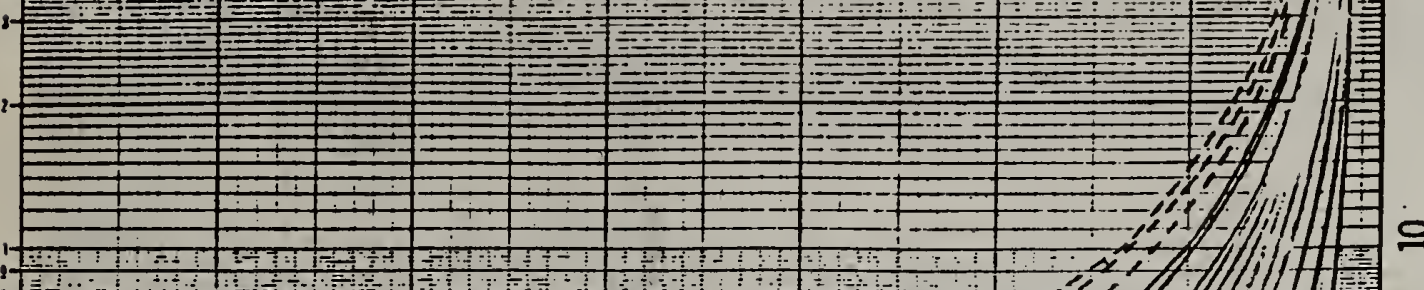

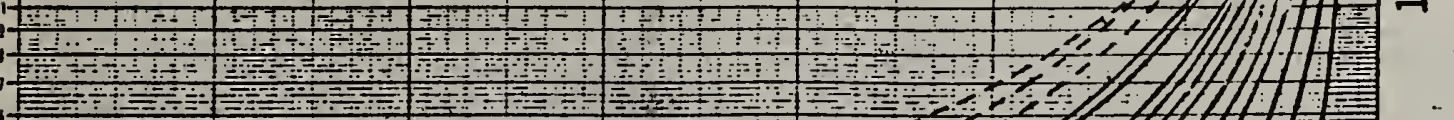

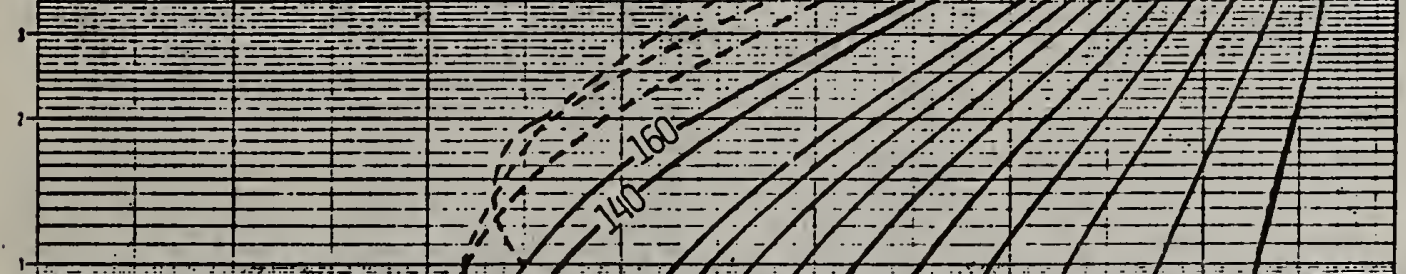

$$
\text { , }
$$

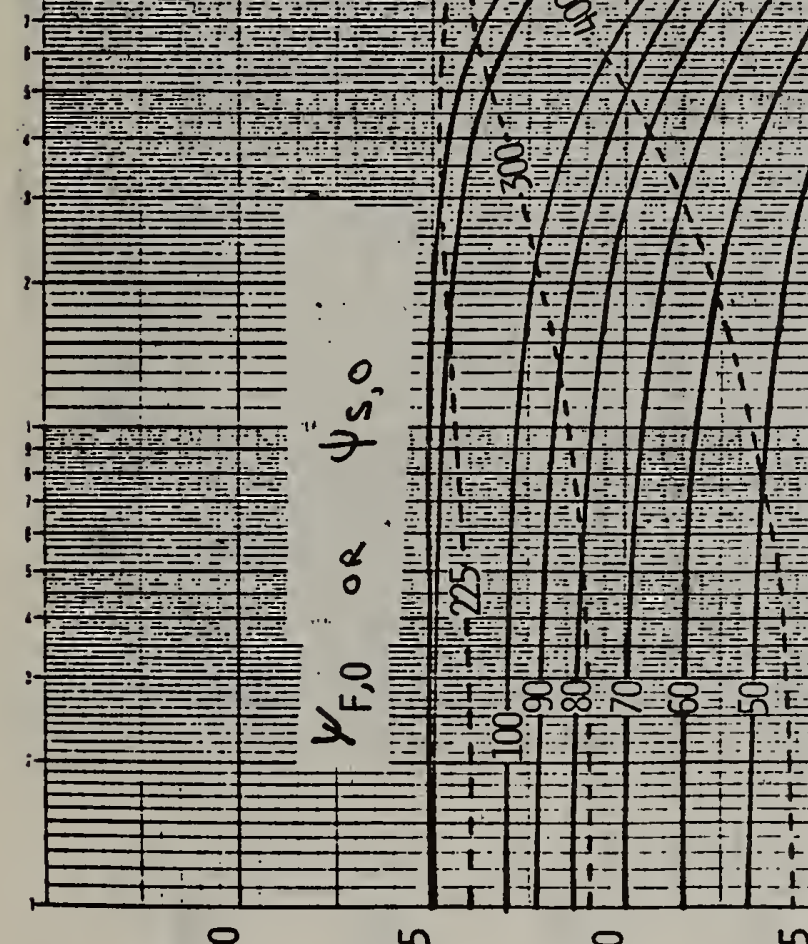

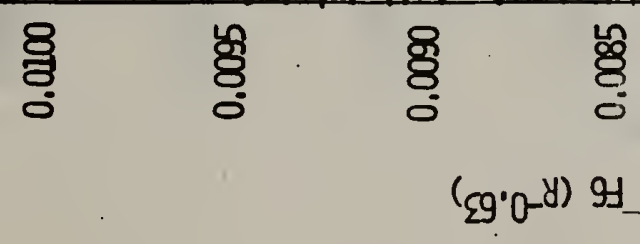

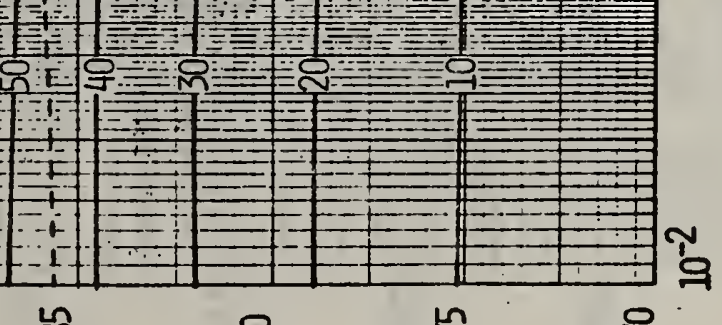

$\begin{array}{llll}8 & 8 & 8 & 0 \\ 0 & 8 & 8 & 8 \\ 0 & 0 & 0\end{array}$ 


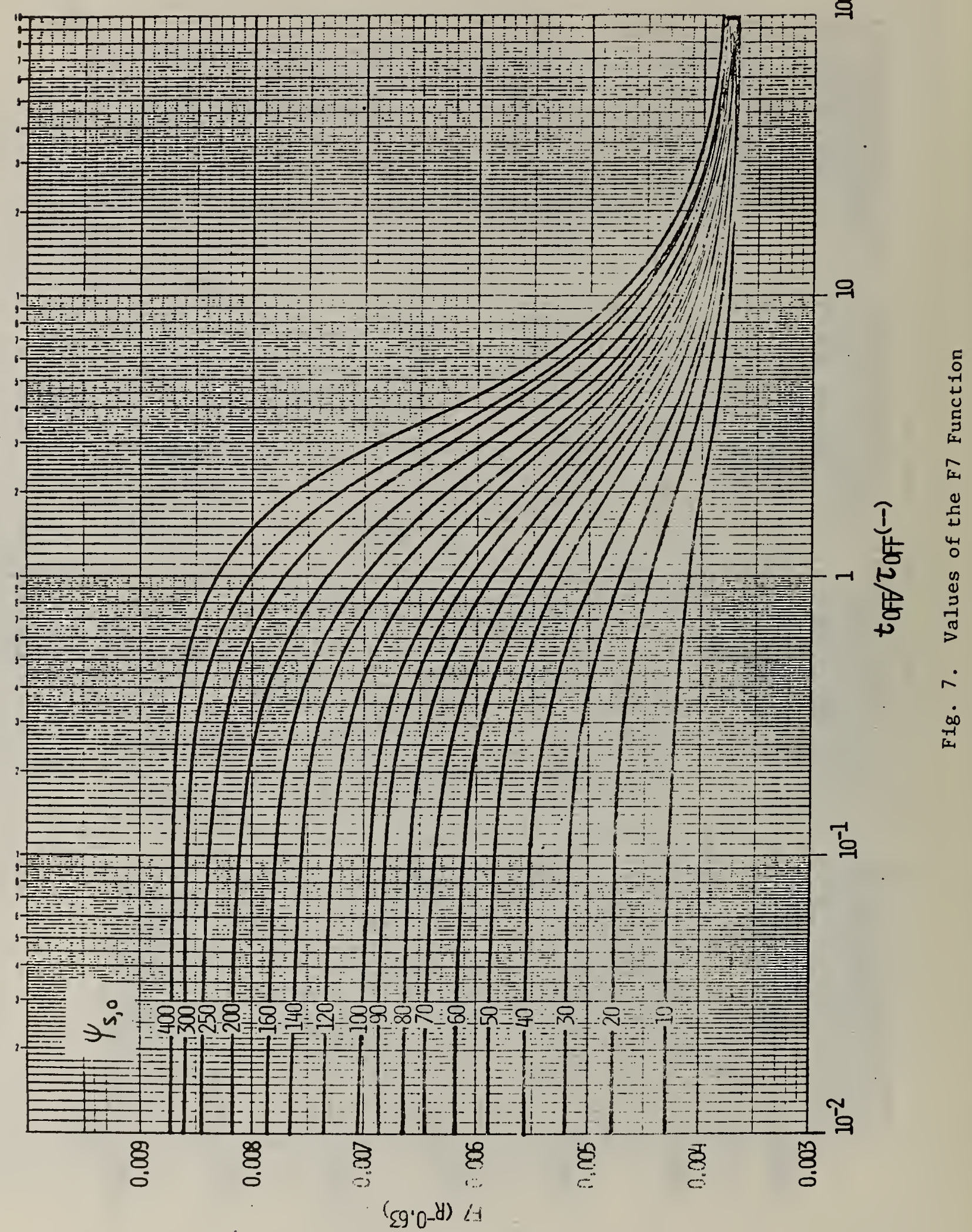




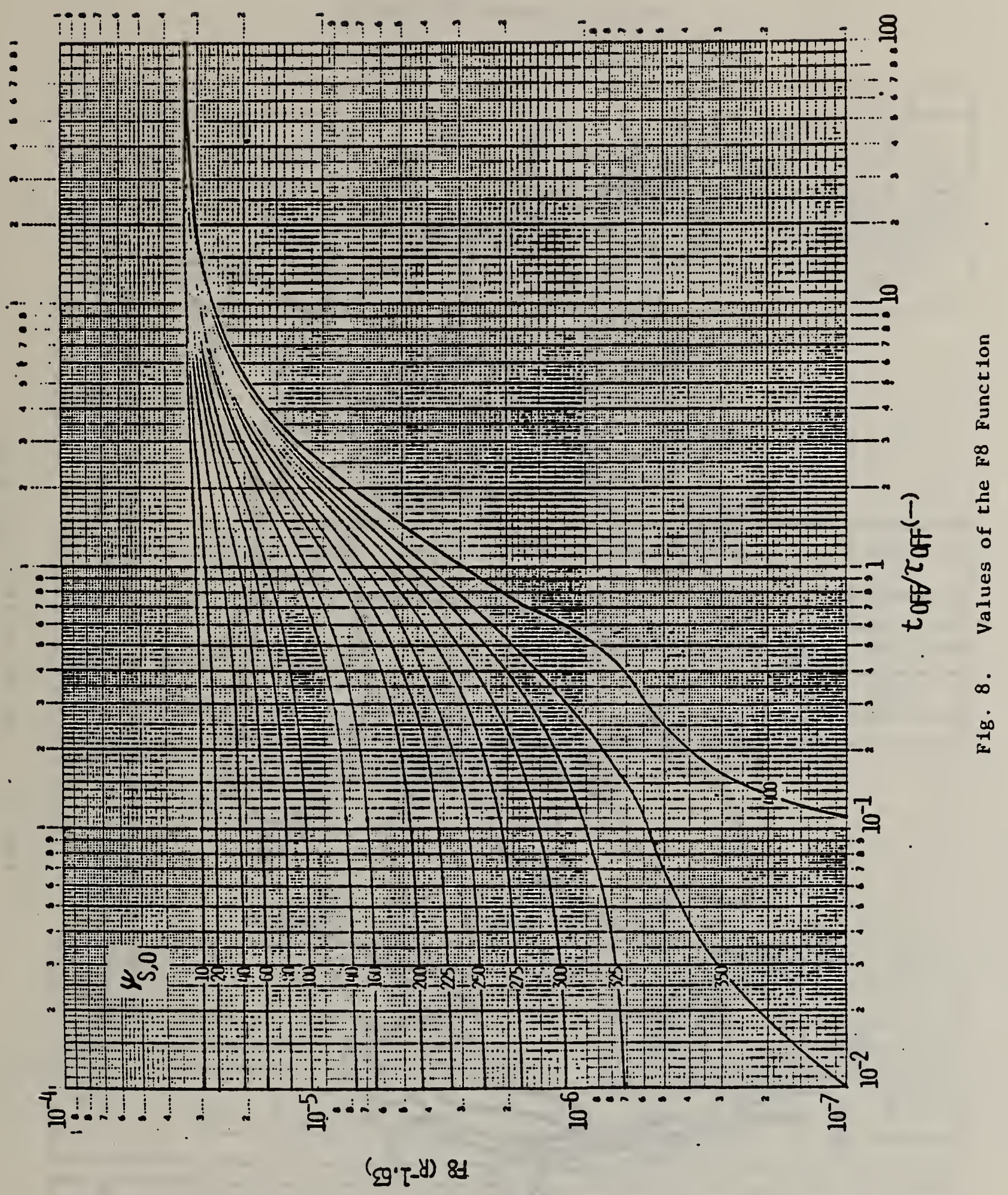




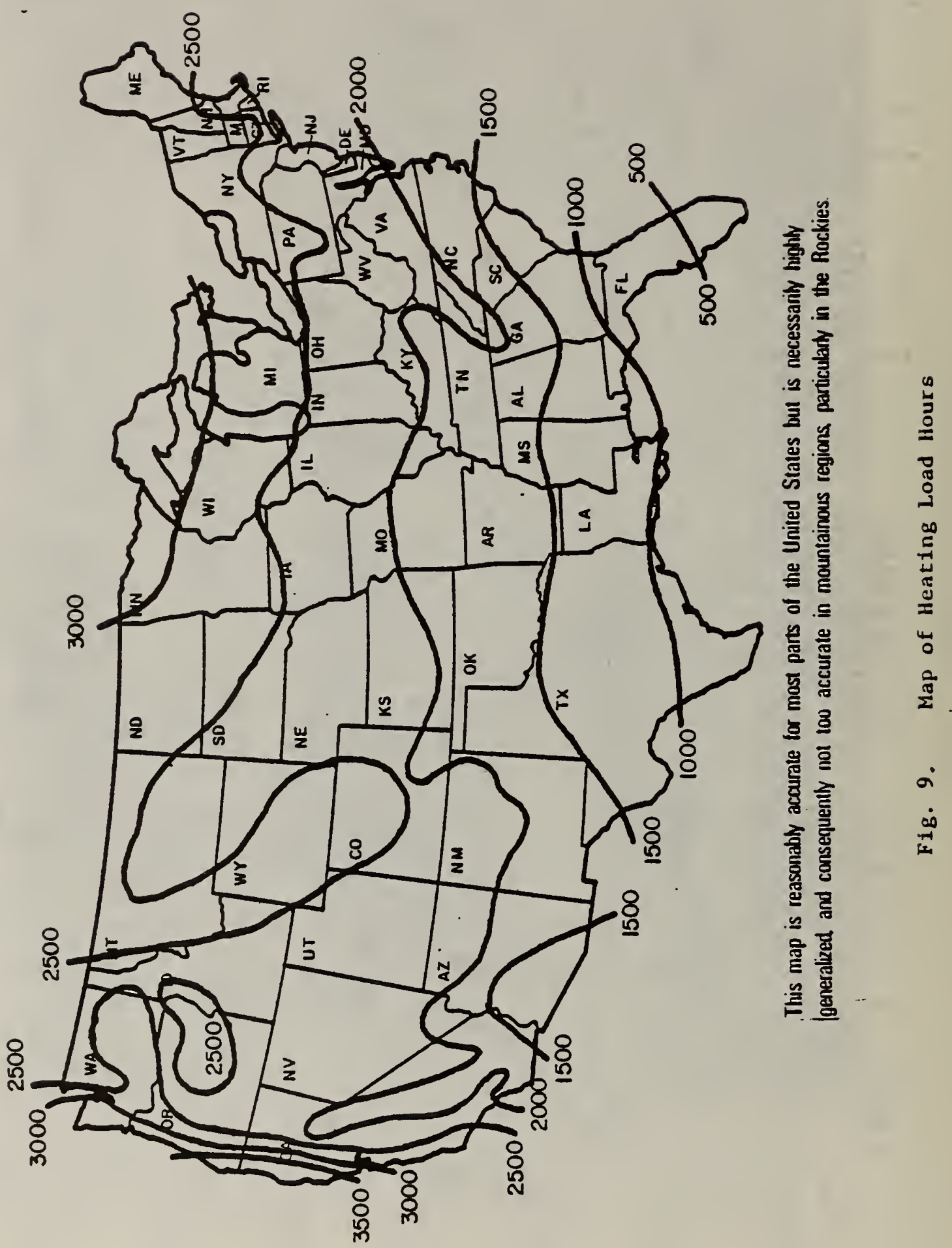


PICURE 10

WOTX SHEEI ROR FURNACE/BOILER STSIEM

Mesaurad Quent1ties and Syatem Characterlstic Conseanto

\begin{tabular}{|c|c|c|c|c|c|c|c|}
\hline 1 & 2 & 3 & 4 & 5 & 6 & 7 & 8 \\
\hline $\begin{array}{l}\text { SISt } \\
(-)\end{array}$ & $\begin{array}{l}\text { Tण्ध } \\
(-)\end{array}$ & $\begin{array}{c}\text { Eav } \\
\text { Btu/ Ib. }\end{array}$ & ${ }_{\text {Beuthr. }}^{Q_{\text {I }}}$ & $\begin{array}{l}Q_{p} \\
B t u / h r .\end{array}$ & $\begin{array}{c}\mathbf{P E} \\
\mathbf{k W}\end{array}$ & $\begin{array}{l}\mathrm{BE} \\
\mathrm{KW}\end{array}$ & ${ }_{z}^{x} \mathrm{CO}_{2}, 5$ \\
\hline & & . & & 21 & & & \\
\hline 9 & 10 & 11 & 12 & 13 & 14 & 15 & 16 \\
\hline $\mathrm{I}_{s, s, x, X}$ & ${ }^{\mathrm{x}_{2} \cdot \mathrm{Z}}$ & $\begin{array}{c}I_{Y, s S} \\
\text { OE }\end{array}$ & 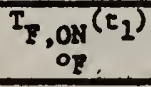 & 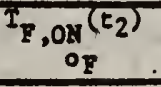 & $T_{\mathrm{F}, \mathrm{OFF}}\left(\tau_{3}\right)$ & $\begin{array}{c}{ }_{\mathrm{F}}^{\mathrm{O}} \mathrm{OFF}_{\mathrm{OF}}\left(\mathrm{E}_{4}\right) \\
\end{array}$ & $\begin{array}{c}\mathrm{T}_{\mathrm{F}, \mathrm{OEF}} \\
\mathrm{OP}\end{array}$ \\
\hline 17 & 18 & 19 & 20 & 21. & 22 & . & \\
\hline $\begin{array}{l}T_{R A} \\
O F\end{array}$ & $\begin{array}{l}\mathrm{L}_{\mathrm{J}} \\
\mathrm{z}\end{array}$ & $\begin{array}{l}S / F \\
(-)\end{array}$ & $\stackrel{D_{E}}{(-)}$ & $(-)$ & $\begin{array}{c}5 \\
(-)\end{array}$ & & \\
\hline
\end{tabular}

Derived System Parameters

\begin{tabular}{|c|c|c|c|c|c|c|c|}
\hline 23 & 24 & 25 & 26 & 27 & 28 & 29 & 30 \\
\hline $\begin{array}{l}P Q \\
(-)\end{array}$ & $\begin{array}{c}\text { Bमv } \\
\text { Bexs/1b. }\end{array}$ & $\begin{array}{l}M / E \\
(-)\end{array}$ & $\begin{array}{l}L_{L}, A \\
\end{array}$ & $\begin{array}{l}C_{J} \\
(-)\end{array}$ & ${ }_{(-)^{R}}^{R^{2}}$ & ${ }^{L} S, S S, A$ & $n_{S S}$ \\
\hline & & & . & & & & \\
\hline 31 & 32 & 33 & 34 & 35 & 36 & 37 & 38 \\
\hline $\begin{array}{c}15,5 S \\
R \\
\end{array}$ & Tox & $8,0, x$ & $\begin{array}{l}\text { ToF: } \\
\text { minutes }\end{array}$ & $\Psi_{\mathrm{F}, 0, x}$ & $\psi_{E, \infty}, \mathrm{X}$ & $\psi_{S_{\partial F}, X}$ & ${ }_{S_{0}, 0, x}$ \\
\hline & & & & $\therefore \quad \cdots$ & 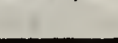 & & \\
\hline
\end{tabular}

\begin{tabular}{|c|c|c|c|c|}
\hline 39 & 40 & 41 & 42 & 43 \\
\hline $\begin{array}{l}C_{S} \\
(-)\end{array}$ & $\begin{array}{l}k_{S, 0 R} \\
(x) / g\end{array}$ & $\begin{array}{l}\bar{K}_{S, O F F_{0}} \\
(\bar{z}) / \mathrm{R} \\
0.37\end{array}$ & $\begin{array}{l}K_{I, O N} \\
(z) / F\end{array}$ & $\begin{array}{l}R_{L}, 0 \% F \\
(z) / R^{0.37}\end{array}$ \\
\hline
\end{tabular}

Calculation of System Loses and Anauel Fuel Vellization Efficlency

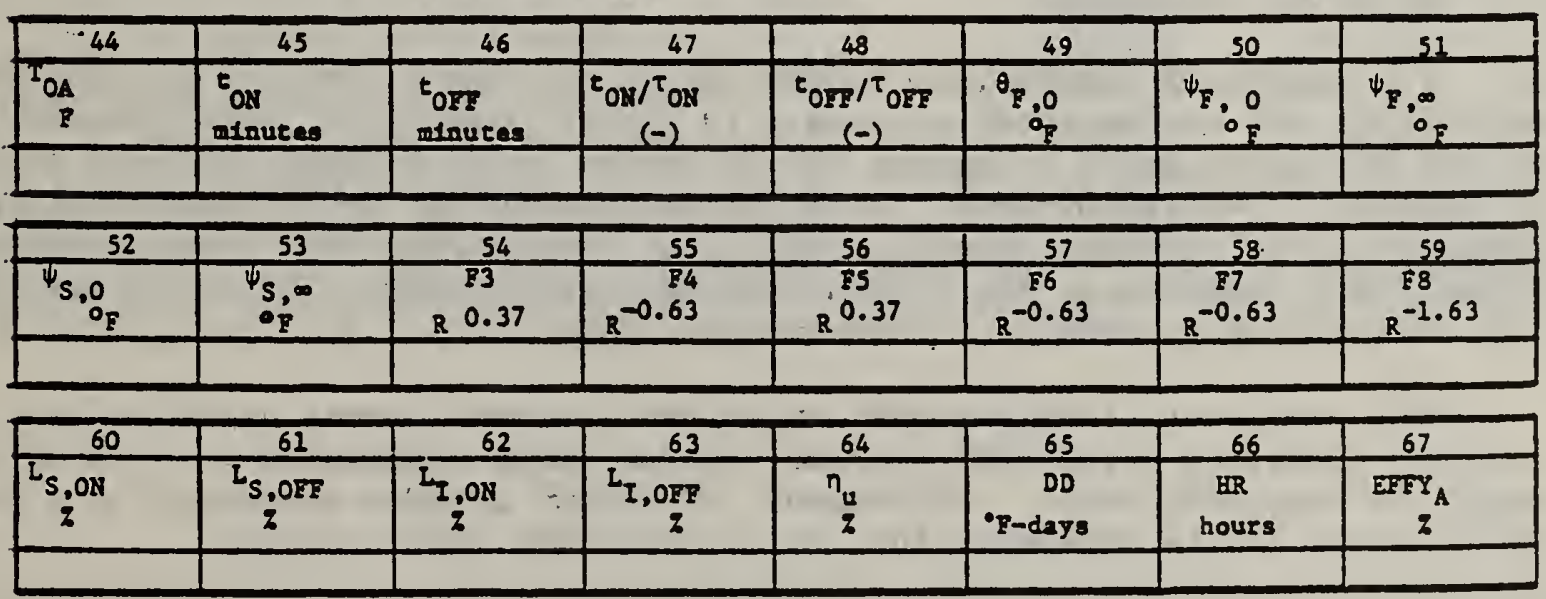




\title{
APPENDIX B
}

\author{
Computerized Calculation Procedure for Condensing \\ and Non-Condensing Furnaces and Boilers
}

The computerized calculation procedure consists of a main program and three subroutines. The fortran program is listed in Figure B-1, and may require modifications when used on some computer systems. The subroutines FUNT 4 and SENLOS5 perform the functions described in Appendix B of NBSIR 7.8-1543 [1]. The newer CLFTR2 subroutine calculates the latent heat loss coefficient, $C_{L}$, and condensate loss correction factor, $L_{\text {, }}$, used in steps 68 and 69 of the calculation procedure for condensing furnaces and boilers.

Three sample sets of data given in Figure B-2 are supplied to exercise the program calculation paths for condensing units. The previous eleven sample sets in reference [1] can also be used to check this program, which is why the three sets are assigned numbers 12 through 14. These three sets of input data are supplied to check the condensing type unit calculation paths, but do not represent specific tests of condensing units. Consequently, these output performances should not be referenced as typical or representative values for condensing heating units.

The program and subroutine flow charts, Figures B-3 through B-6, are provided to assist future users in understanding or revising the program. Numbers in the left column of the flow chart indicate corresponding program statements in Figure $B-1$.

Input to the program must follow the order presented in Figure B-7 entitled Input Data Code Sheet for NBSFBS7. All input values which are listed as zero or blank in the written procedure should have a value of " 0.0 " placed in their input field.

This program uses the implicit scheme for processor recognition of integer and real number input variables. The only integer inputs are IFB, INST, NSYS, and IFUEL. All other input variables are real positive numbers. Although the use of real number inputs greater than zero without the decimal is allowed on many processors, each user will need to check the specific requirements for his or her processor.

The freefield inputs used by NBS on our Fortran V compiler may not be acceptable for use on other systems. It is not possible to anticipate all future alternate input or output format needs, so no attempt has been made to prepare alternate formats. Thus format changes may be necessary for program implementation on other systems. Use of a 72-character-wide output format will require modification to the output formats of the initial 67 quantities which are written for a carriage 132 characters wide.

The fuel cost rates printed out in the regional annual operating cost table are not likely to agree with current Federal Trade Commission fact sheet requirements for specific fuels. Adjustment of CBFBS7 program statements 270 and 313 through 315 is necessary for the desired fuel price ranges. 


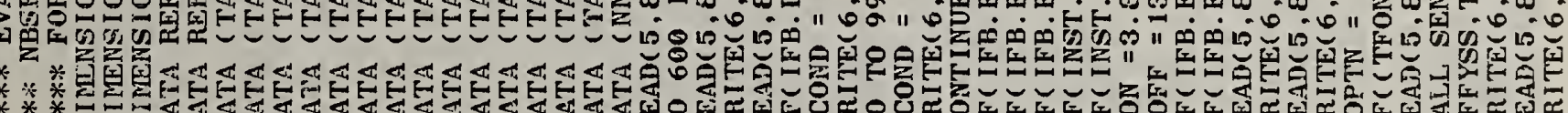

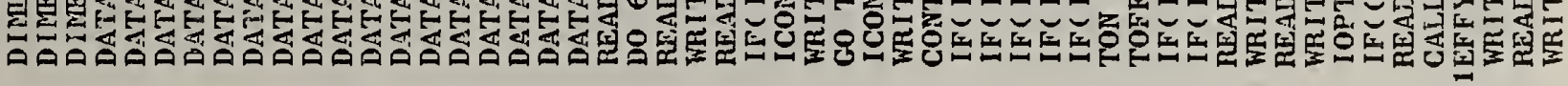

טטט

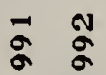

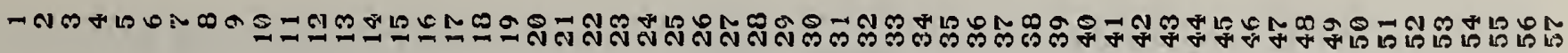




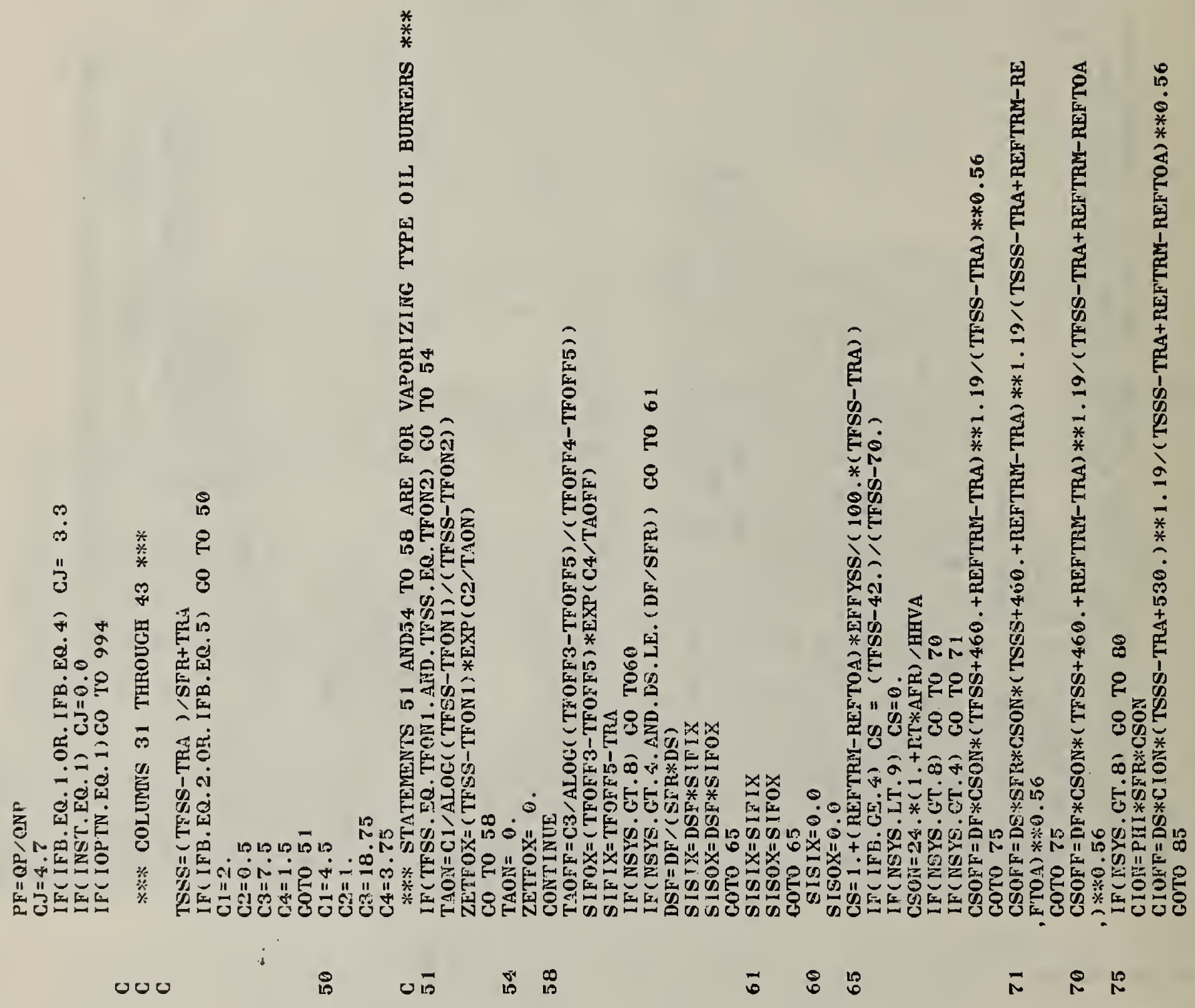

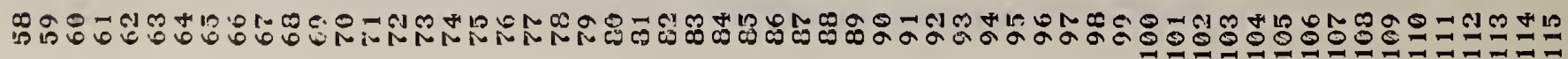




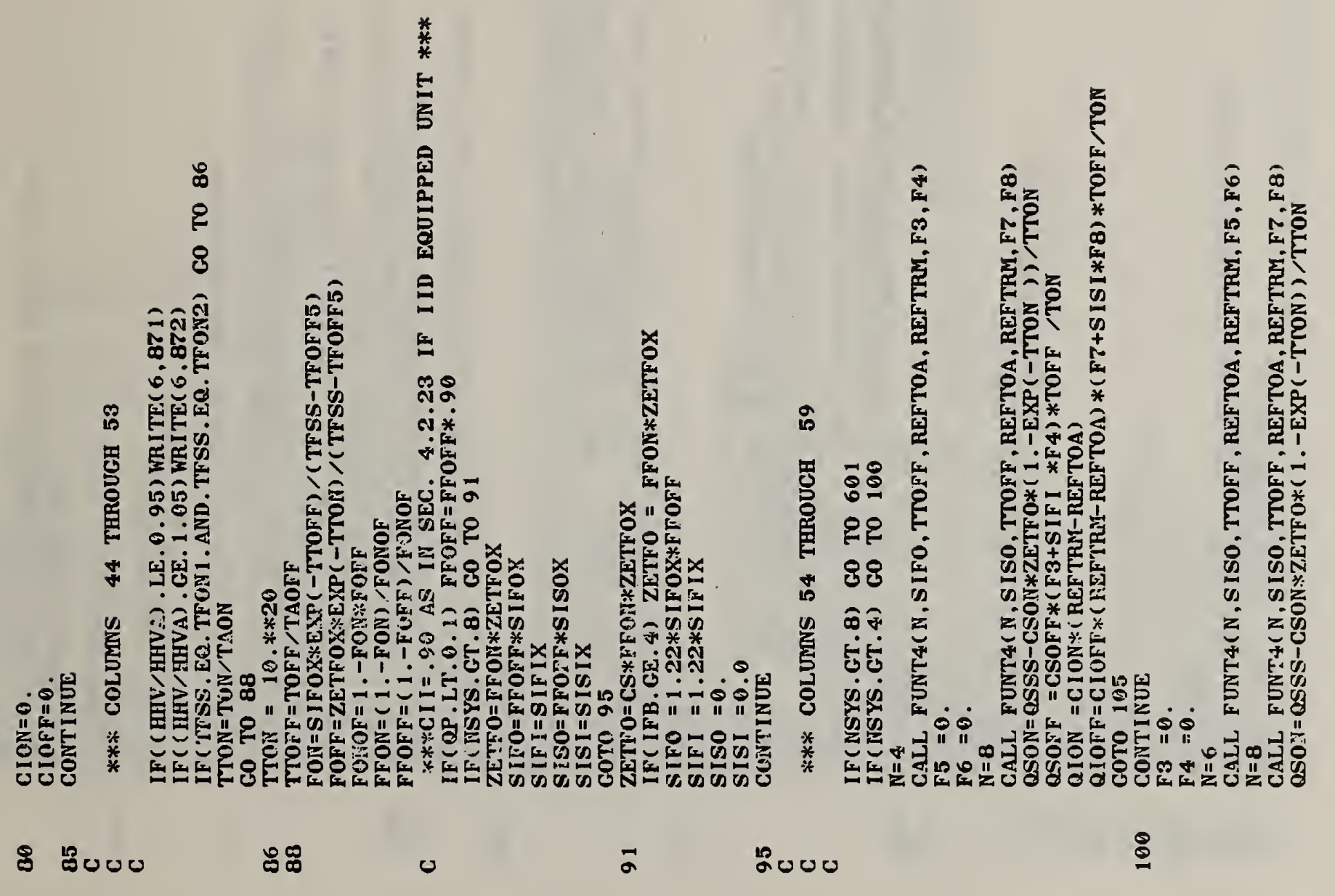

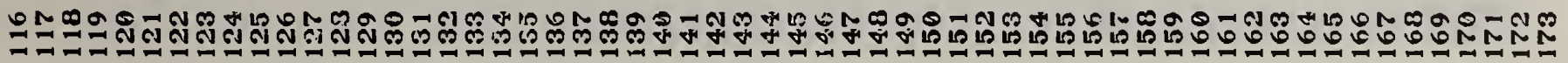



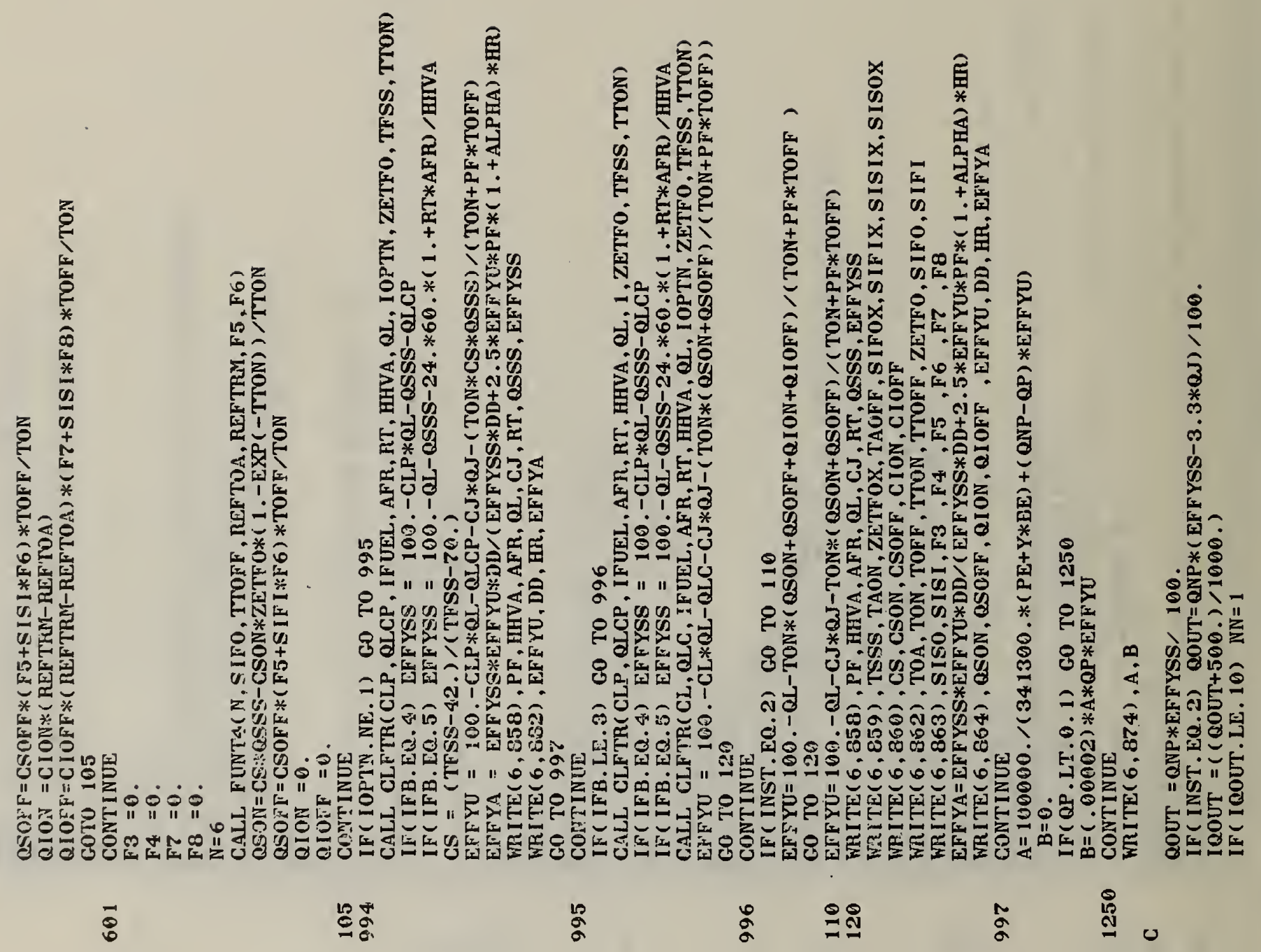

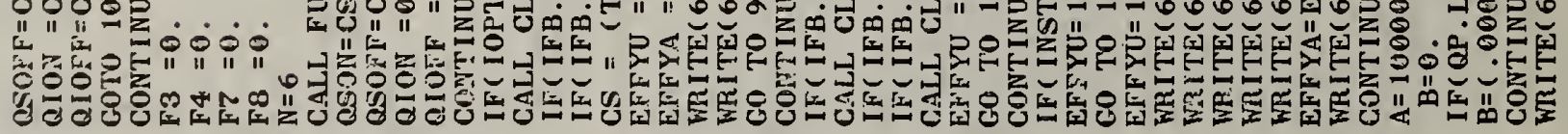

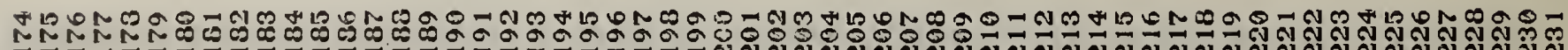




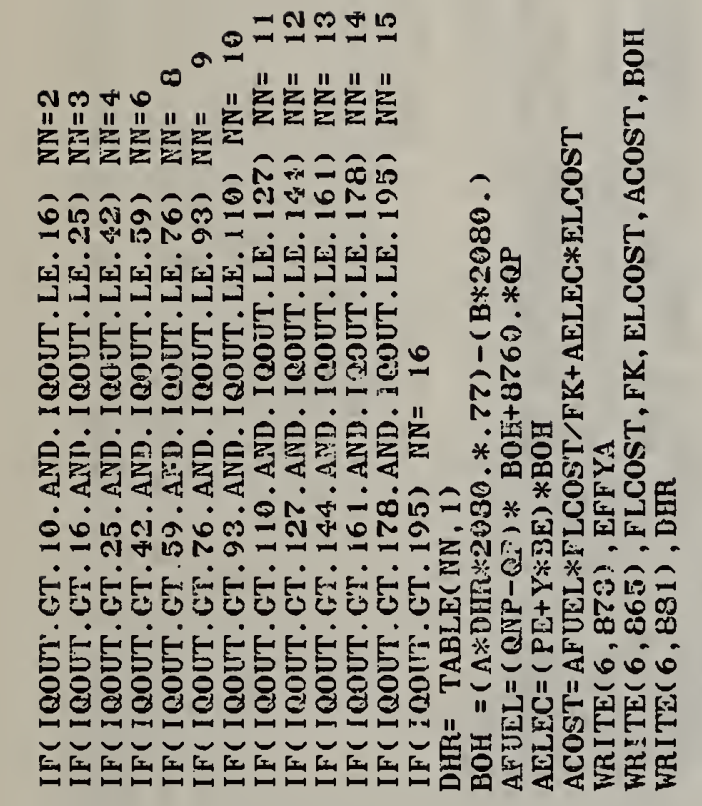

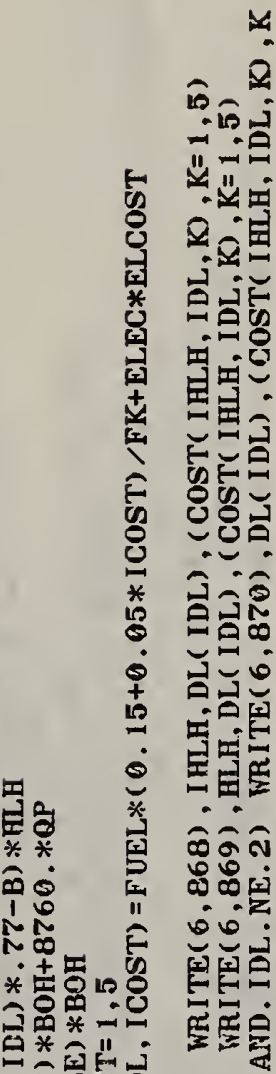

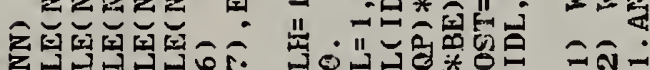

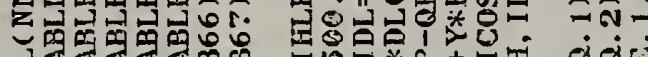
"ล

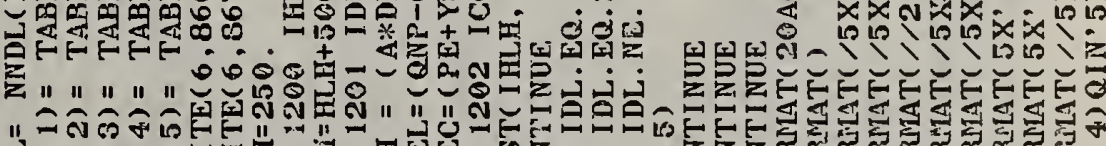

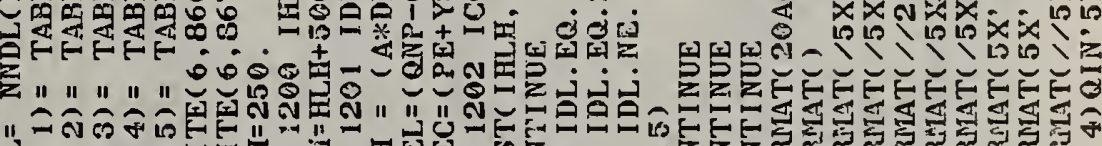

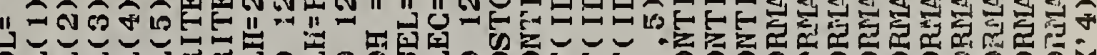

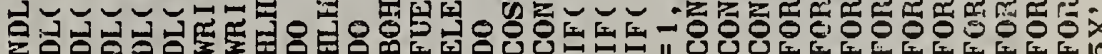

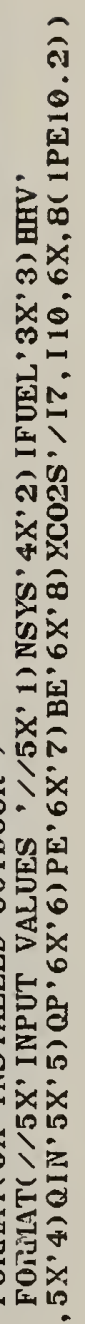

ญิ

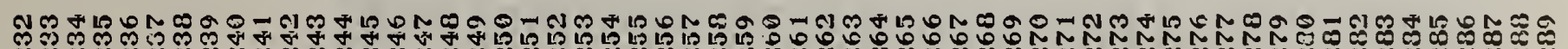

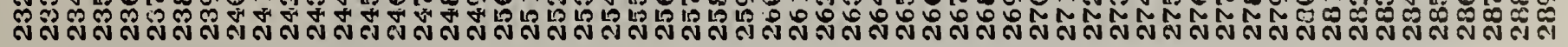




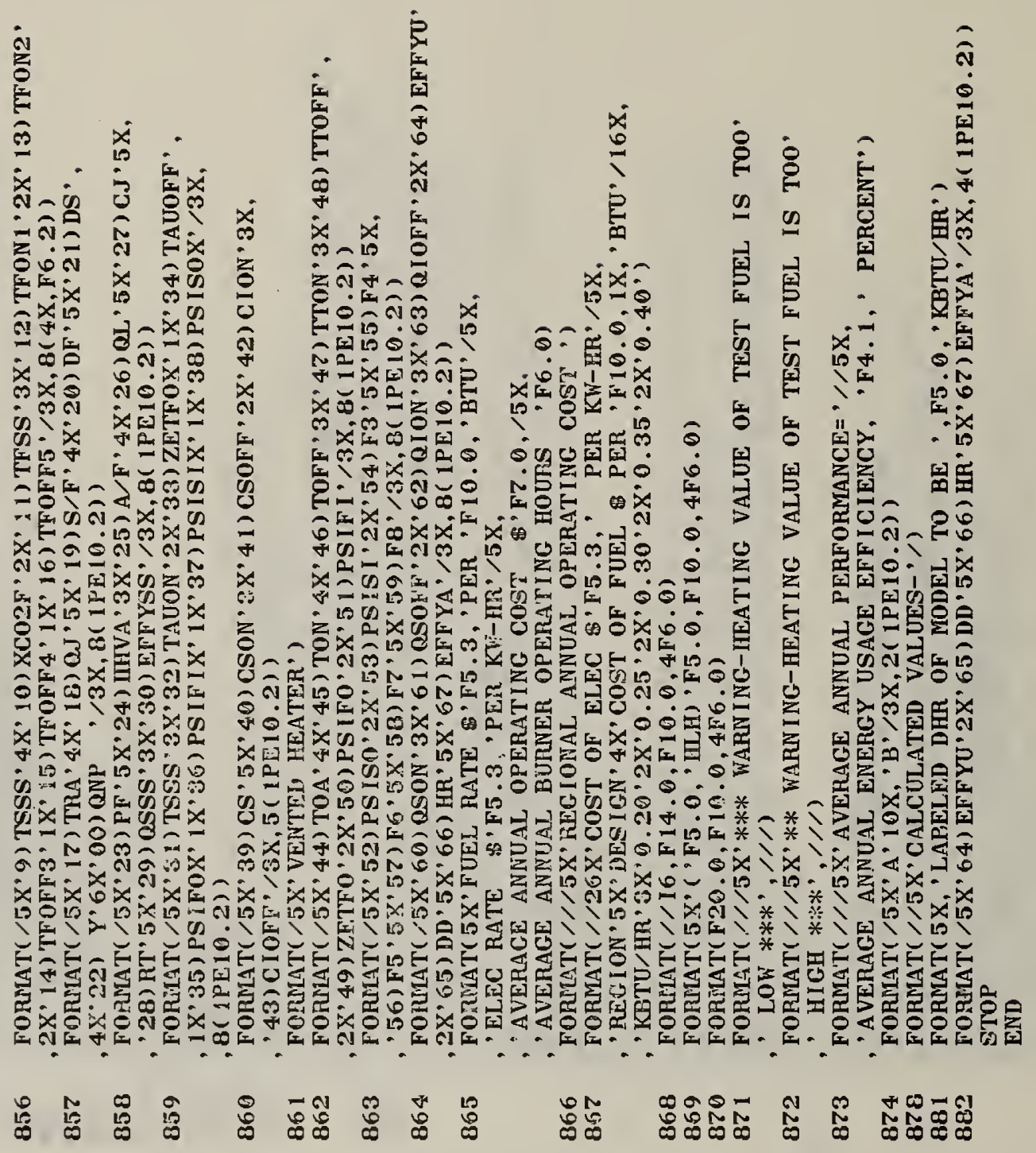

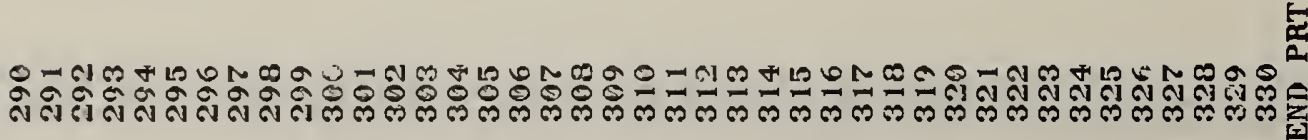




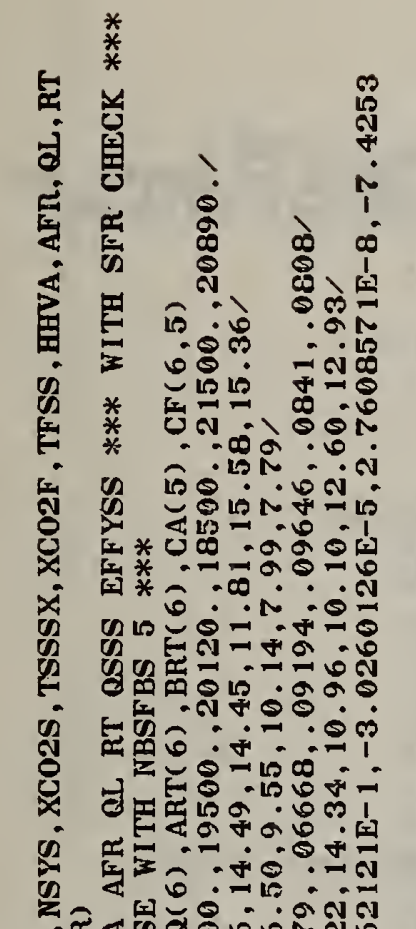

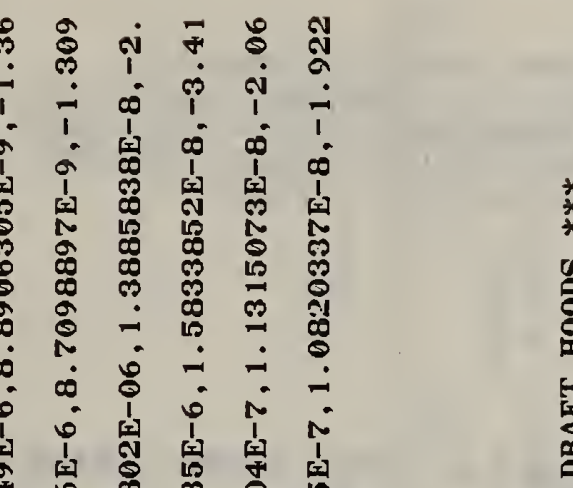

*

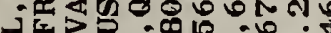

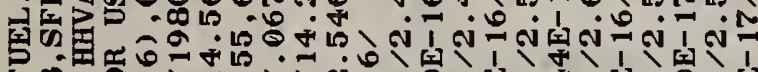

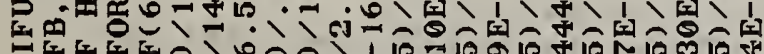

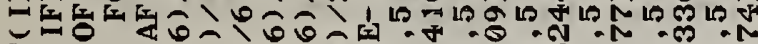

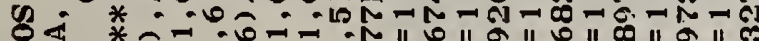

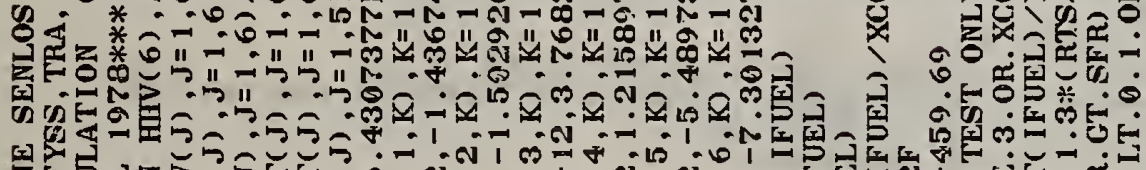

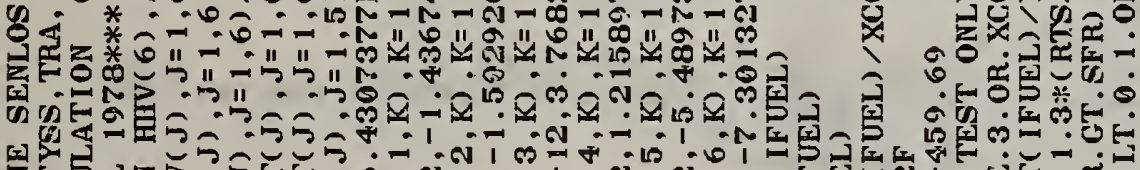

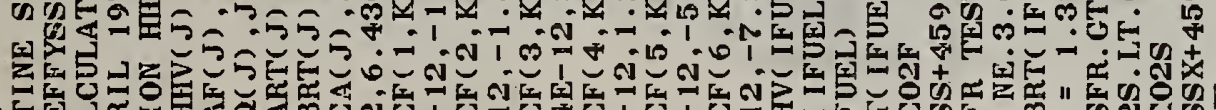

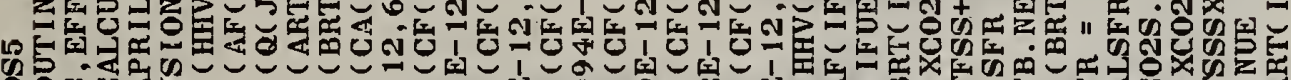

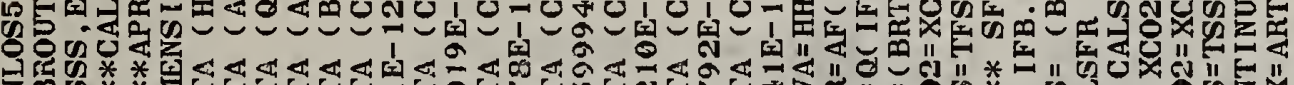

草 番踾

जิ

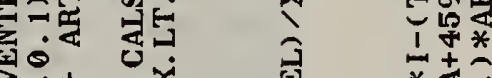
$>$

*

象离

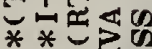
二娄畦8 象实 존 o5* 2 \% 䚾的要 "I

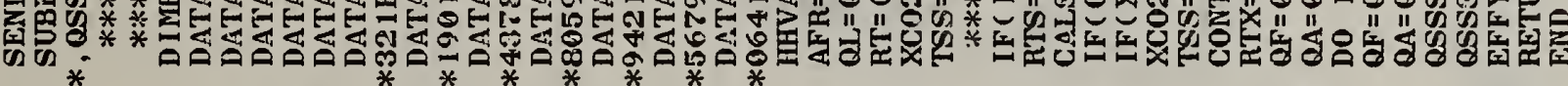
טu
0
ำ ํำ
$\stackrel{\ominus}{ }$

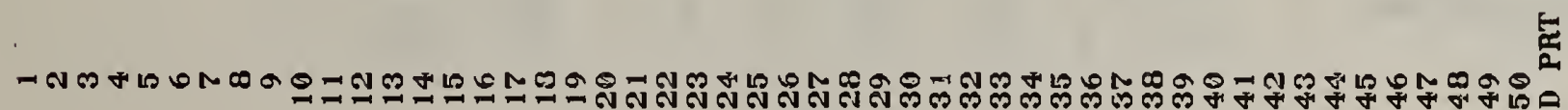


CLFTR2

SUBROUTINE CLFTR( CL, QLC, IFUEL, AFR, RT, HHVA, QL, IOPTN, ZETFO

C
C
C *, TFSS, TTON)

DIMEISION FGMW(6)

DATA (FGMW $J$ ) , J=1,6) $/ 29 ., 29 ., 28 ., 27.5,28.5,28.5 /$

FGM $=1 .+A F R * R T$

$\mathrm{VM}=\mathrm{HHVA} * \mathrm{QL} /(100 . * 1053.3)$

PV $=$ VM*FGMW( IFUEL $) * 14.7 /($ FGM $* 18$.

IF( IOPTN. NE. 1) GO TO 100

AVTFON $=$ TFSS

GO TO 101

AVTFON

IF (PV. GT. PVS) GO TO 110

$\mathrm{CL}=1$

WRITE $(6,990)$

GO TO 120

$\mathrm{CL}=\mathrm{PVS} *(14.7-\mathrm{PV}) /(\mathrm{PV} *(14.7-\mathrm{PVS}))$

OLC $=\operatorname{OL} *(1 .-\mathrm{CL}) *(1 . *(\mathrm{TFSS}-70)-..45 *(\mathrm{TFSS}-42)) /$.

FORMAT $/ / / 15 \mathrm{X} * *$ WARNING**CL= $1 * *, / 5 \mathrm{X}$ ' $* *$ UN IT SHOULD BE TESTED AND , RATED AS A NONCONDENS ING HEATING SYSTEN**'/5X'**ALL CALCULATED , RESTLTS WHICH FOLLOW ARE INVALID**')

RETURN

END

\section{FUNT4}

SUBROUTINE FUNT4(N, S I , TTOFF, REFTOA, REFTRM, F I , FJ)

T1=REFTRI-REFTOA

C1 $1=1$.

T2 $=$ REFTRM +460 .

IF $(N . E Q .4) \quad T 1=0$.

IF (N.EQ.8) C $1=0.0$

$\mathrm{X}=0$.

FI $=0$.

$\mathbf{F} \mathbf{J}=0$

DX $=$ TTOFF $/ 500$.

$\mathrm{FF} 11=(\mathrm{SI}+\mathrm{T} 1) * * 0.56 * \mathrm{SI} * * \mathrm{C} 1 /(\mathrm{SI}+\mathrm{T} 2) * * 1.19$

FF2 $1=(\mathrm{SI}+\mathrm{T} 1+100) * * 0.56 *.(\mathrm{SI}+100) *. * \mathrm{C} 1 /(\mathrm{SI}+\mathrm{T} 2+100) * *$.

Do $150 I=1,250$

$\mathrm{X}=\mathrm{X}+\mathrm{DX}$

$\mathrm{XX}=\mathrm{SI} * \mathrm{EXP}(-\mathrm{X})$

$\mathrm{FF} 12=(\mathrm{XX}+\mathrm{T} 1) * * 0.56 * \mathrm{XX} * * \mathrm{C} 1 /(\mathrm{XX}+\mathrm{T} 2) * * 1.19$

$\mathrm{FF} 22=(\mathrm{XX}+\mathrm{T} 1+100) * * 0.56 *.(\mathrm{XX}+100) *. * \mathrm{C} 1 /(\mathrm{XX}+\mathrm{T} 2+100) * *$.

$\mathrm{X}=\mathrm{X}+\mathrm{DX}$

$\mathrm{XX}=\mathrm{SI} * \operatorname{EXP}(-\mathrm{X})$

$\mathrm{FF} 13=(\mathrm{XX}+\mathrm{T} 1) * * 0.56 *(\mathrm{XX}) * * \mathrm{C} 1 /(\mathrm{XX}+\mathrm{T} 2) * * 1.19$

FF23 $=(\mathrm{XX}+\mathrm{T} 1+100) * * 0.56 *.(\mathrm{XX}+100) *. * \mathrm{C} 1 /(\mathrm{XX}+\mathrm{T} 2+100) * *$.

$F I=F I+(F F 11+4, * F F 12+F F 13)$

$\mathbf{F} \mathbf{J}=\mathrm{F} \mathbf{J}+(\mathrm{FF} 21+4 . * \mathrm{FF} 22+\mathrm{FF} 23)$

FF $11=$ FF 13

$150 \quad$ FF2 $1=$ FI'23

IF ( ( $A B S(F J-F I)) . L E .0 .0000001)$ G0 TO. 110

$F J=(F J-F I) /(100 . *$ TTOFF $)$

$\mathrm{FJ}=\mathrm{DX} * \mathrm{FJ} / 3$.

$$
\text { GOTO } 112
$$

$110 \quad \mathrm{FJ}=0$.

$112 F \mathrm{I}=\mathrm{FI} * \mathrm{DX} /(3 . * \mathrm{TTOFF})$

RETURN

END 


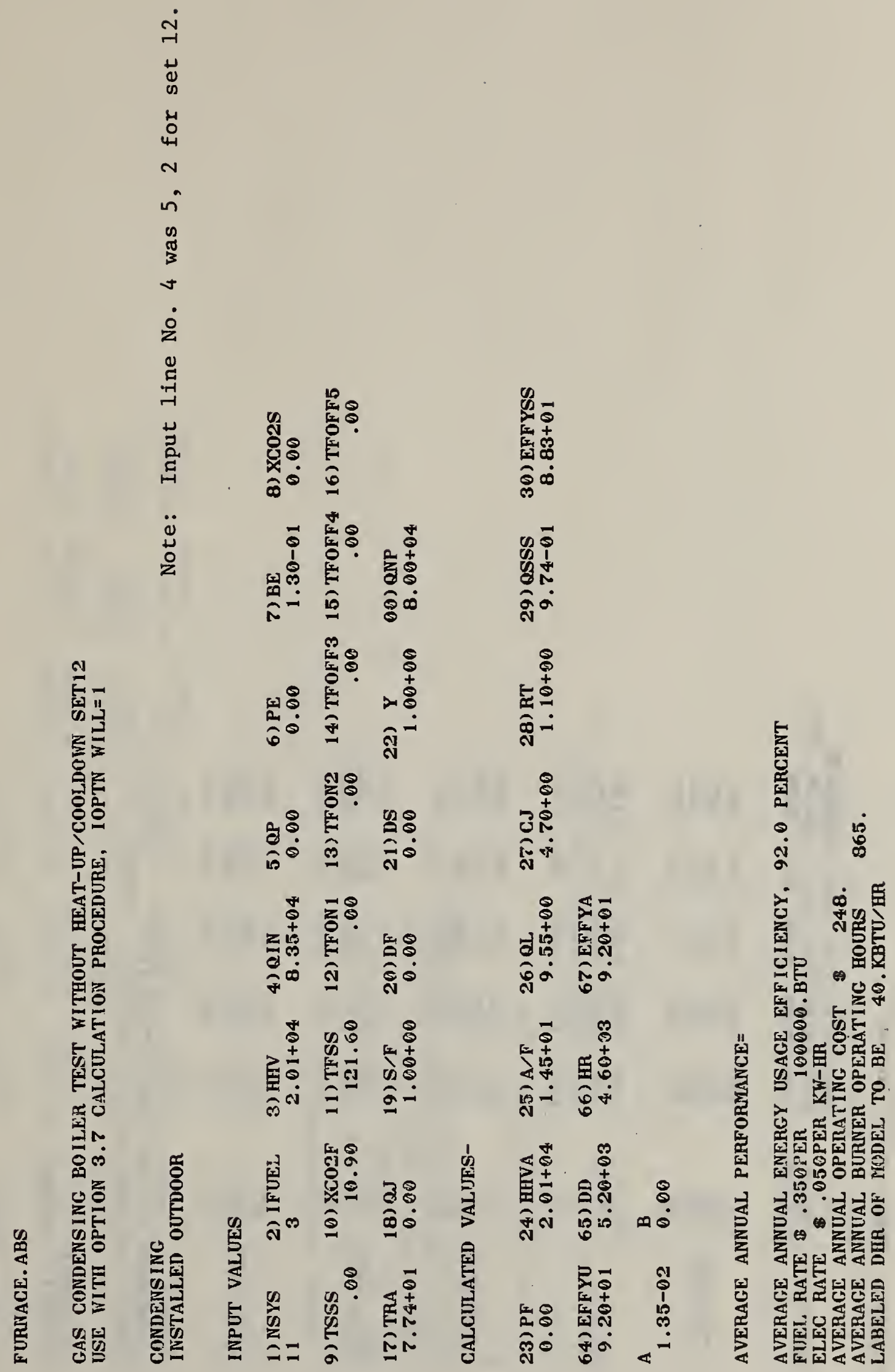


䟞

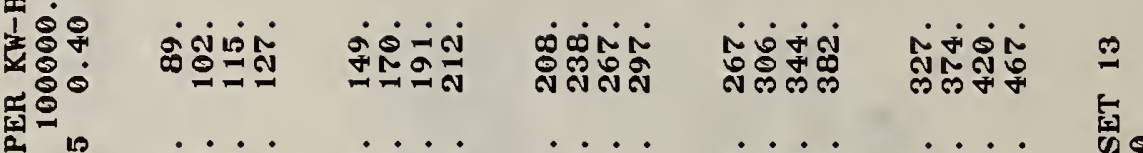

" : ต

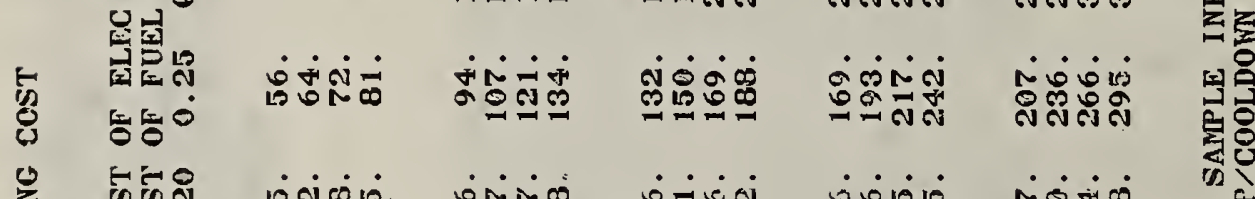

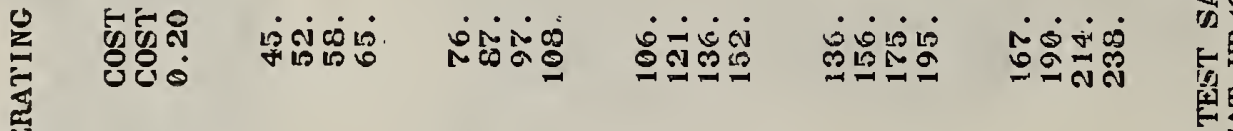

缹

起

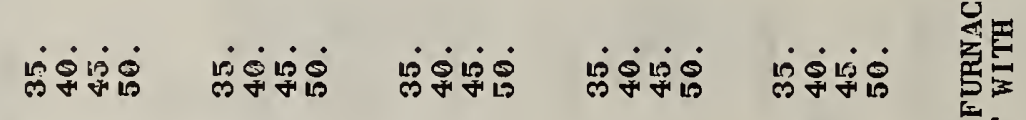

ำ

曐

空

氛

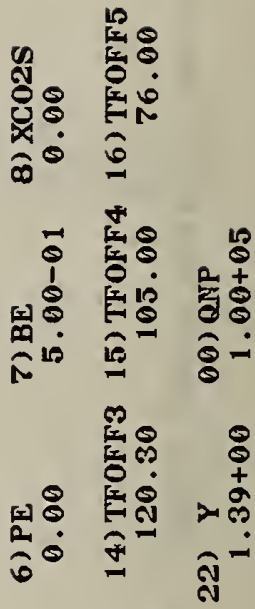

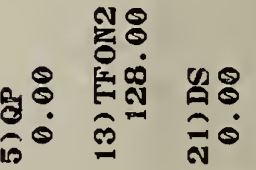

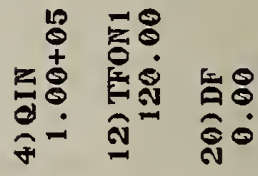

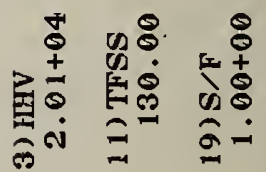

热

举是

音

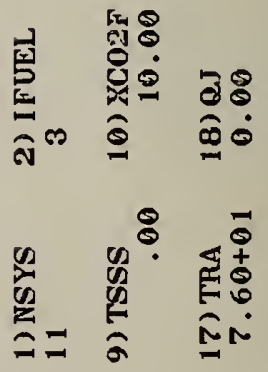




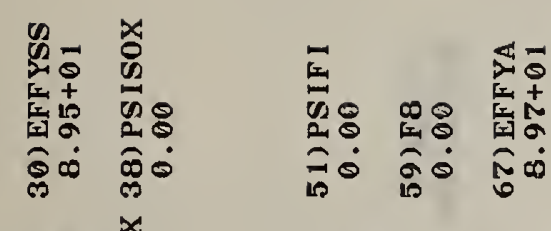

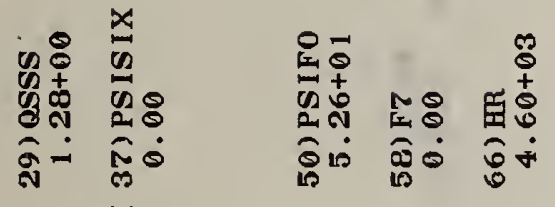

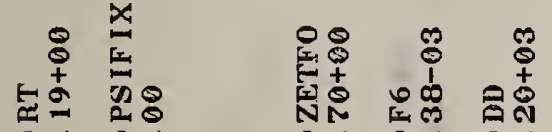

बूं

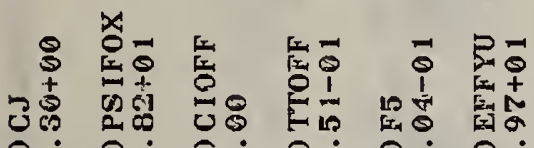

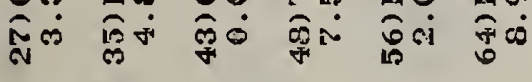

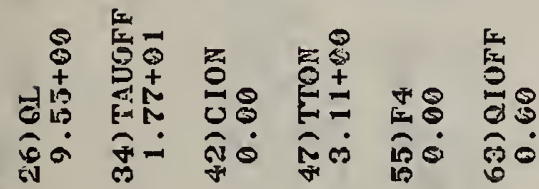

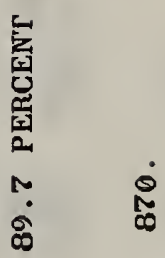

मे

急 施

ज्ञ

育富

这

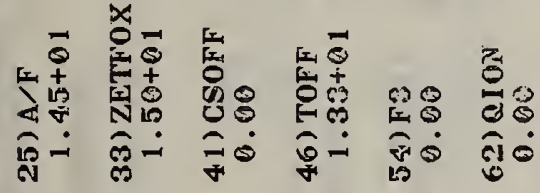

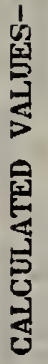

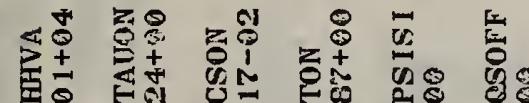

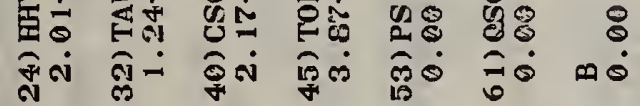

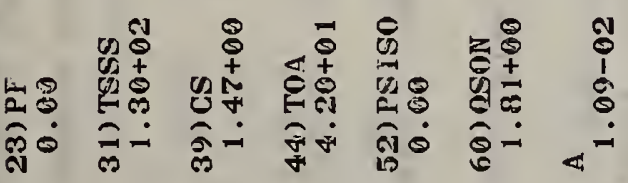

急

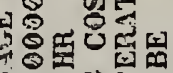
$3-10$

到

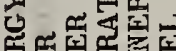

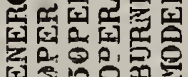

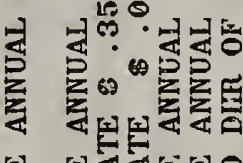

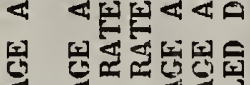

면 면

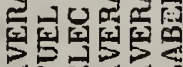

崫

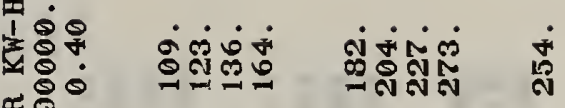

乐

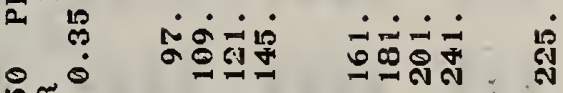
เำำ

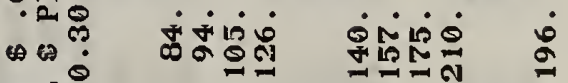

藏最

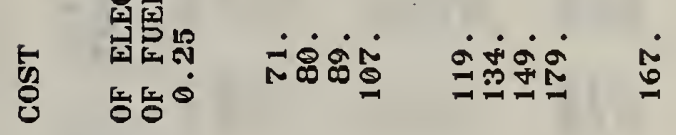

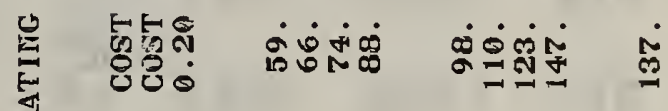

畄

는

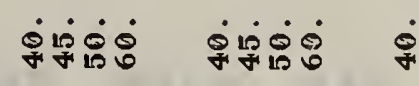

量 


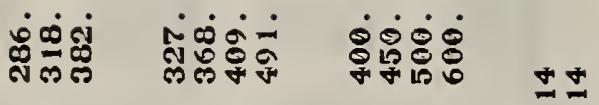

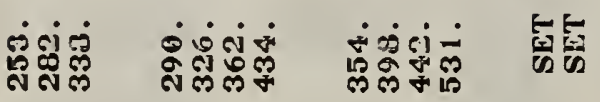

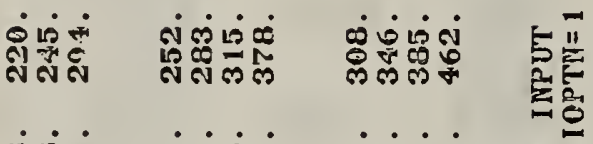

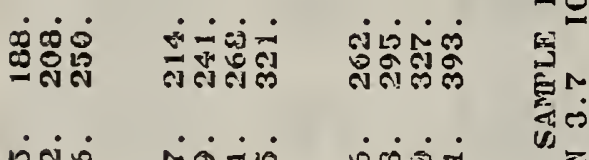

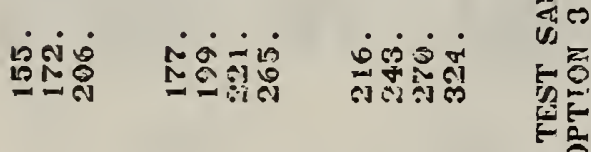

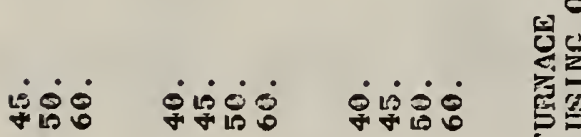

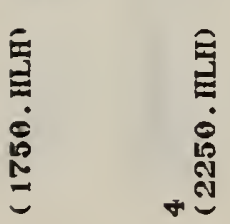

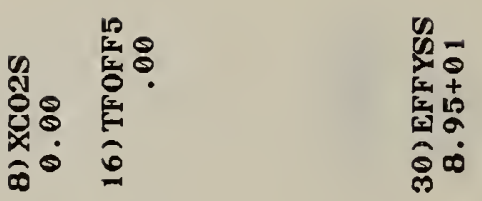

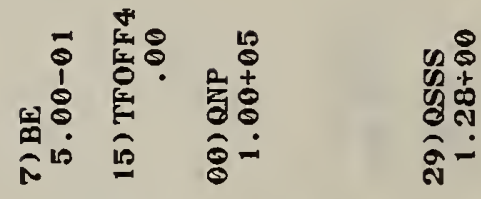

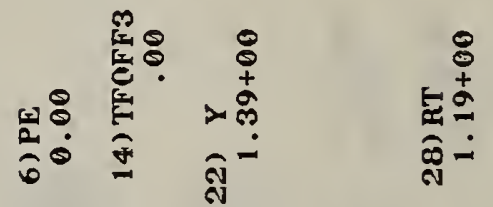

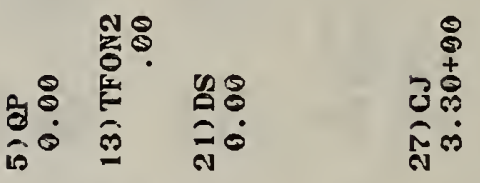

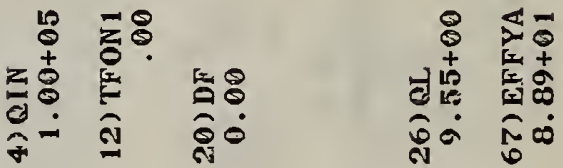

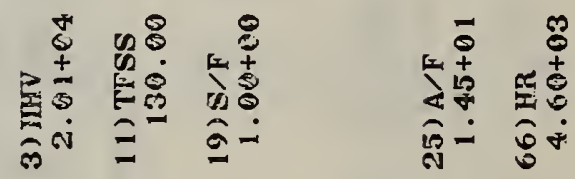

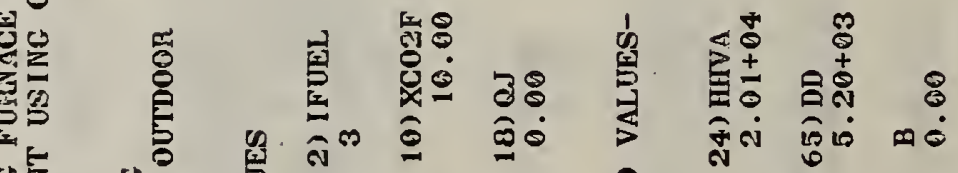

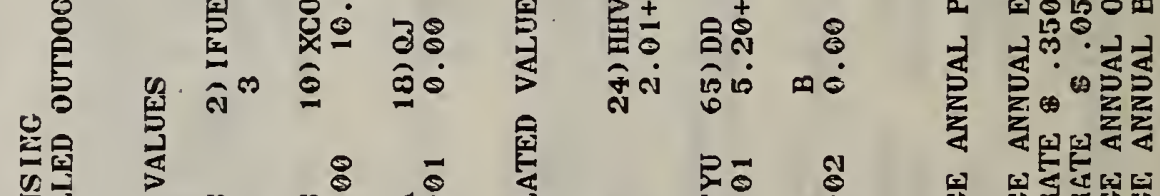

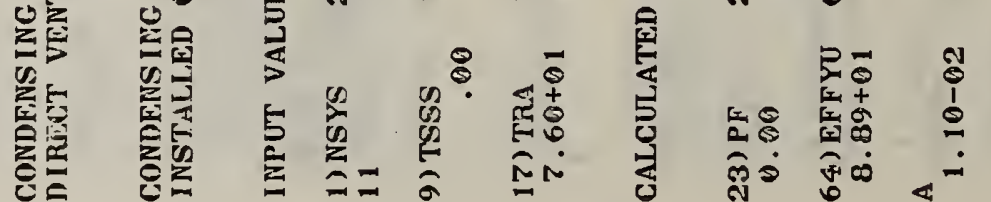

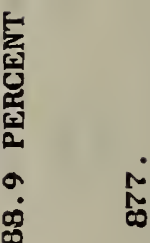

造 은

$\rightarrow$ 둔 똘ㄹㄹ

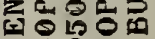

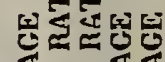

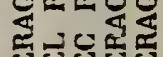
돌돌동 


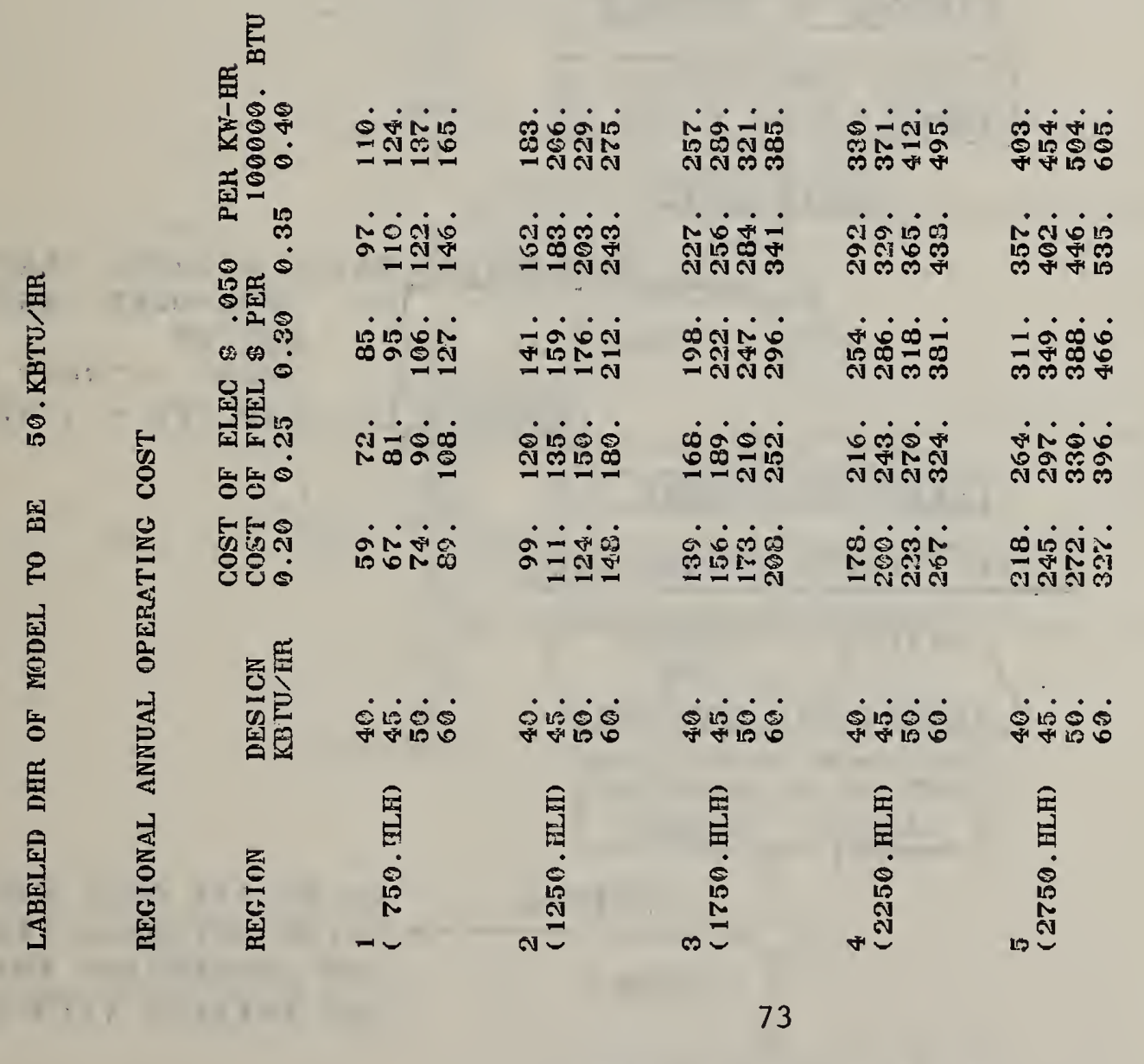




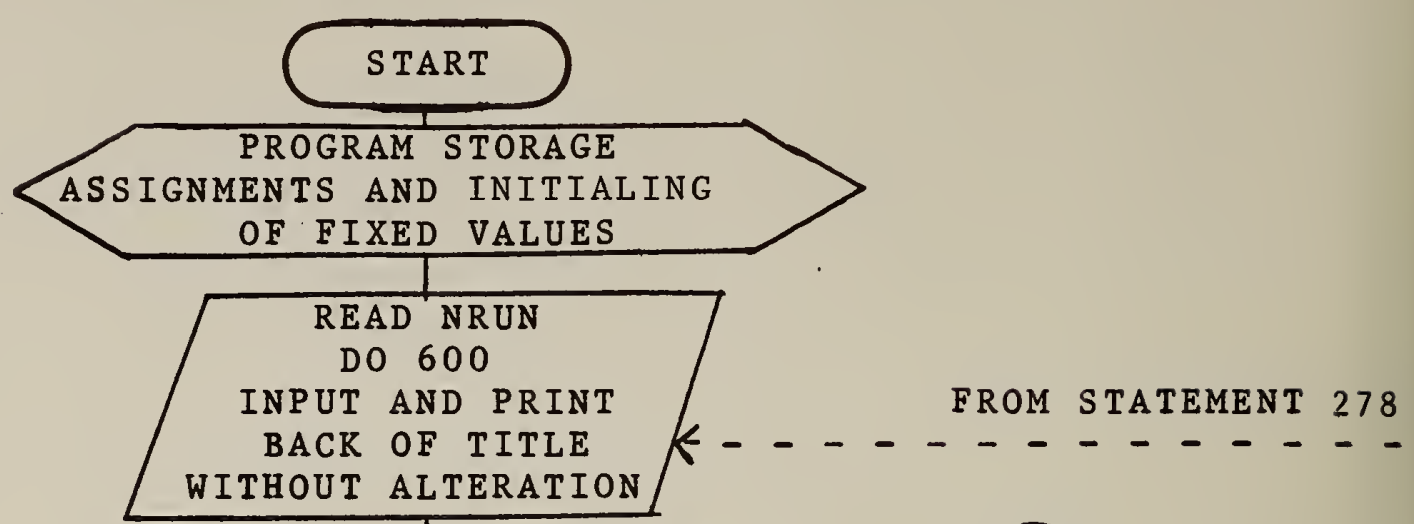

CONDENSING OUTPUT

NONCONDENS ING OUTPUT]

51

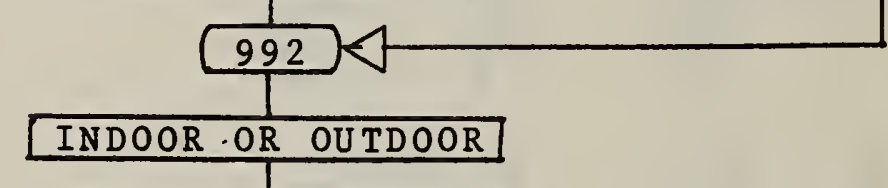

IF $B=4,5$

CONDENSING

EAD AND OUTPUT

INPUT LINES 5 AND 6

$$
\text { IOPTN }=0
$$

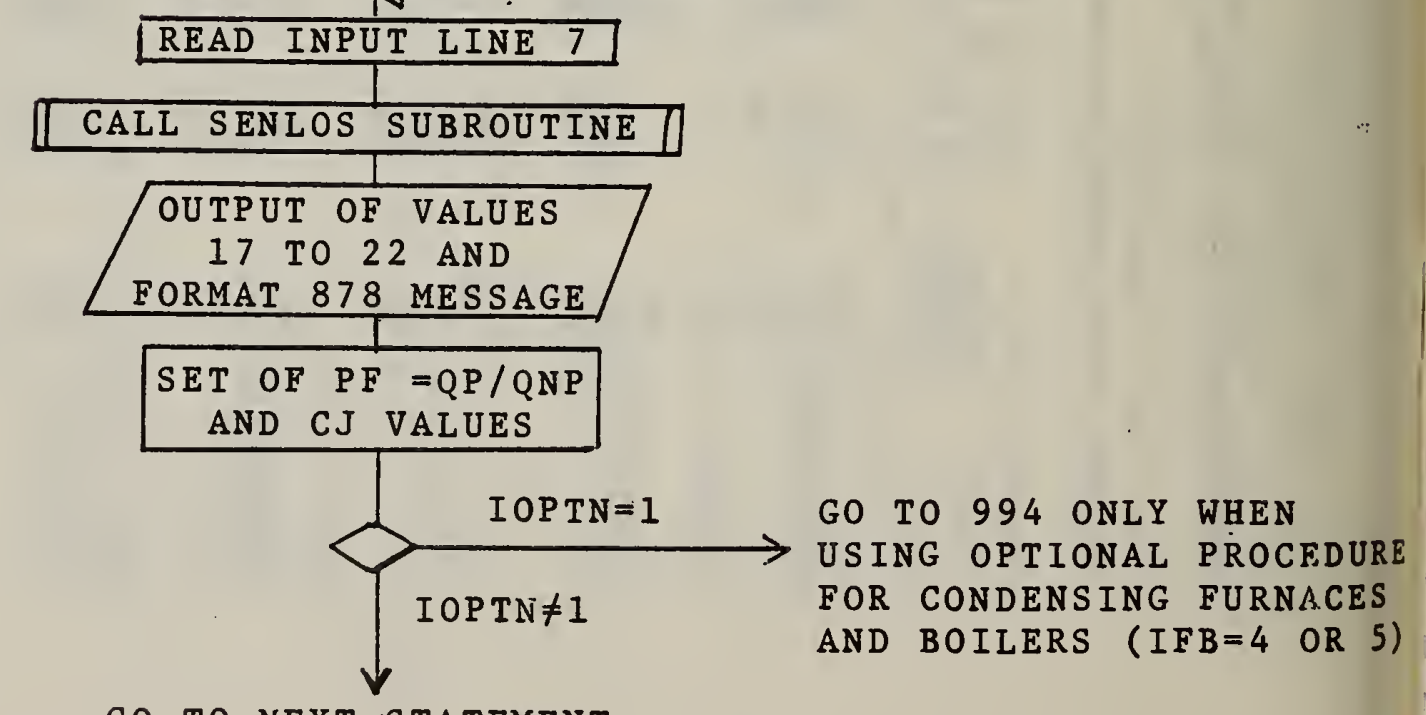

GO TO NEXT STATEMENT

CONDENSING UNITS WITHOUT HEAT-UP/ COOL-DOWN TESTS OPTION IF $B=1,2,3,4,5$ TFON $1=$ TFON $2=0$ AND IFB $=4$ OR 5

3

(1)




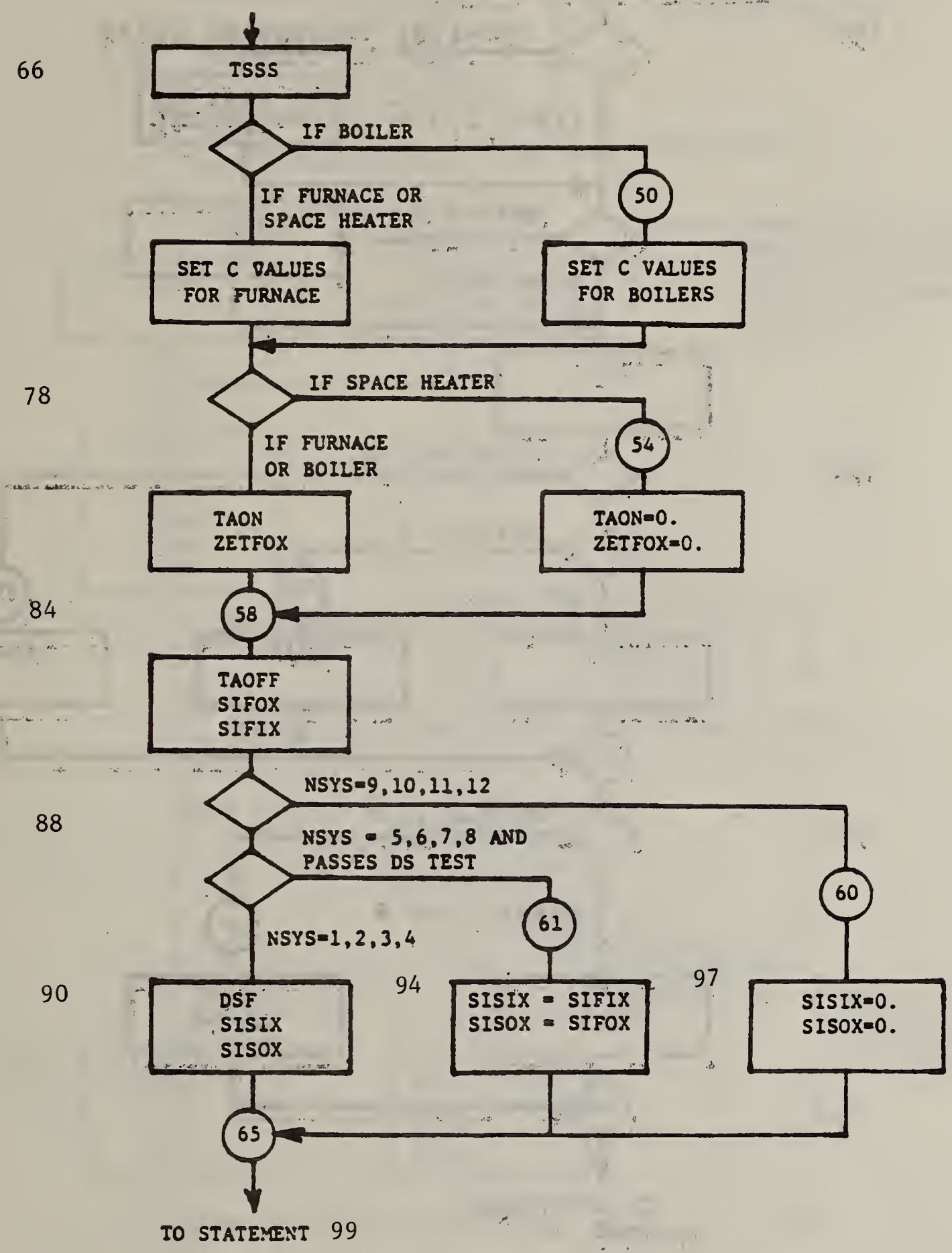




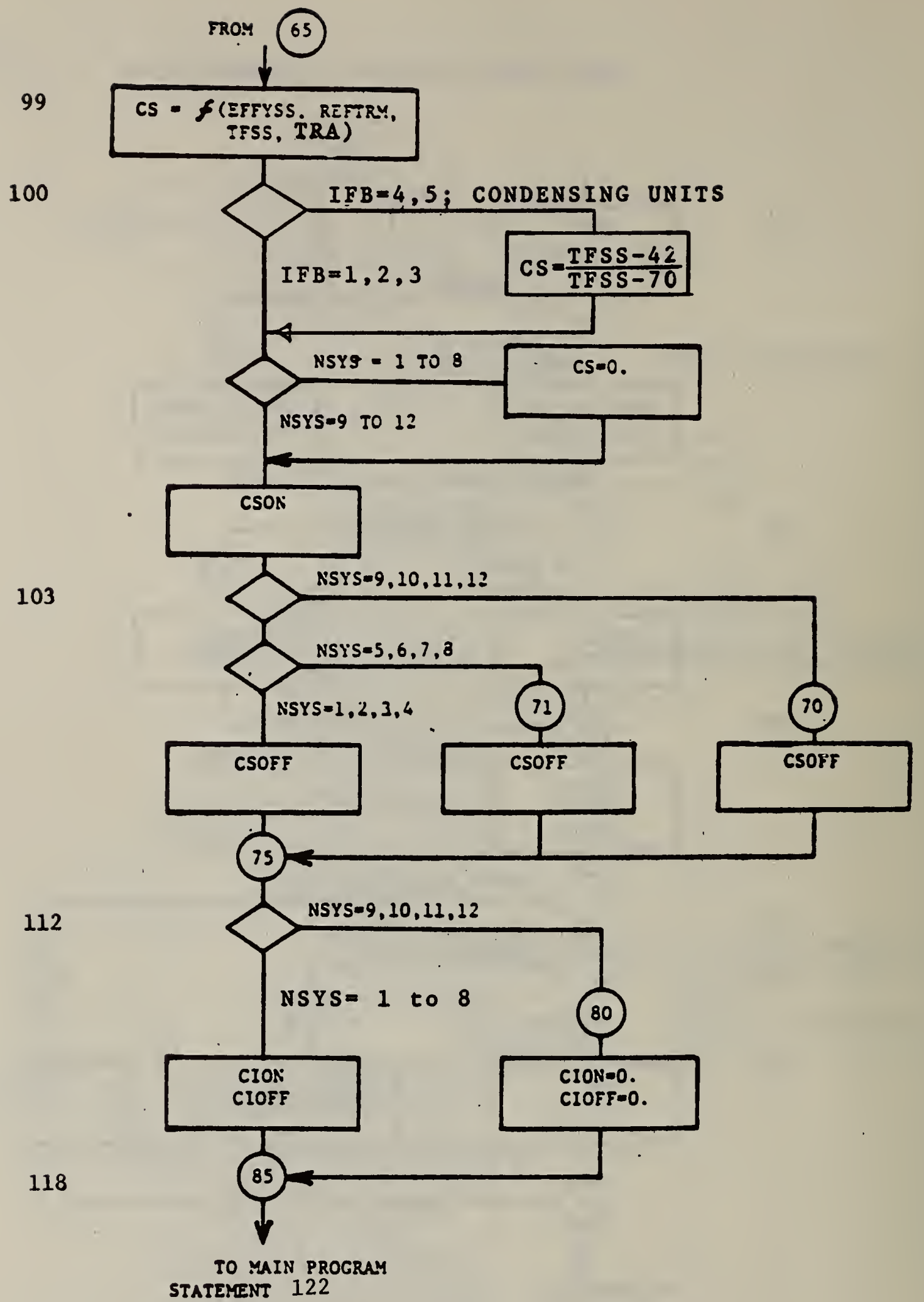




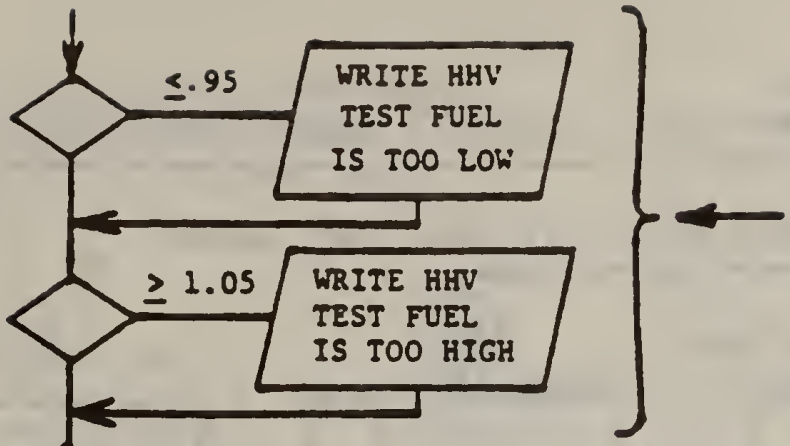

FUEL HEAT VALLE IESTS

BY RATIO HHV/HHVA

128

88

IF UNIT IS FURNACE OR BOILER

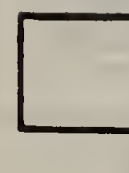

ITON

IION $=10, * \star 20$

SET TO FIXED VALUE TIME CONSTANT RATIO FOR LATER USE IN ON-PERIOD SENSIBLE HEAT LOSS DETERMINATION

RESET OF FFOFF

VALUE BY *. 90.

149

91

NSYS - 1 TO 8

\section{ZETFO w/CS:}

IF $B=1,2,3$

$I F B=4,5$
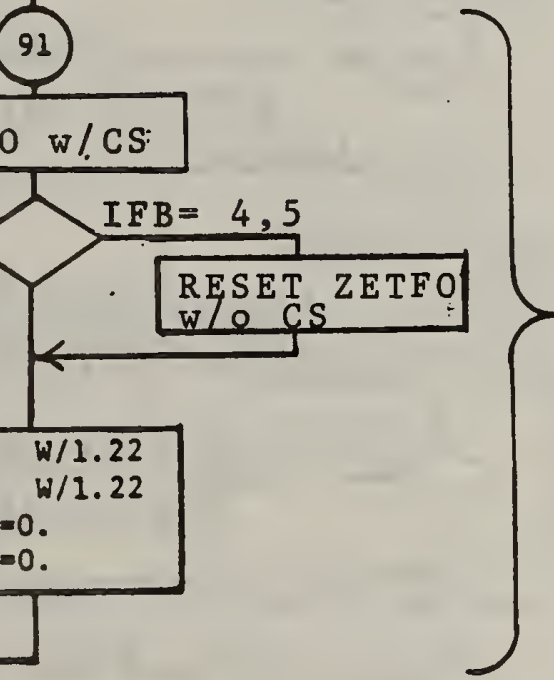

CORRECTION OF HEAT UP AND COOL DOWN TEN. PROFILES FOR THE EFFECT OF CYCLING. 
NSYS $=5$ TO 8 , LNITS WITH STACK DAMPERS

NSYS=1 TO 4

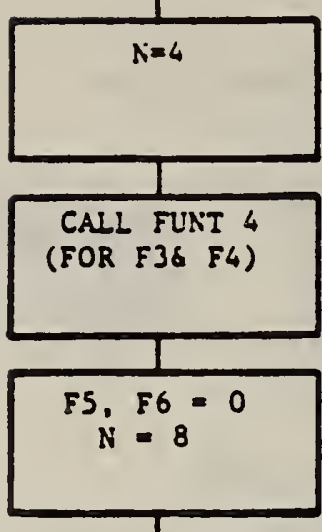

CALL FUNT 4

(FOR F7\& F8)

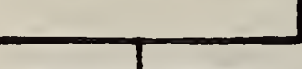

QSON, QSOFF

QION, QIOFF
$53, F 4, F 7, F 6=0$ $N=6$

$N=6$

CALL FUNT 4

(FOR F5\& F6)

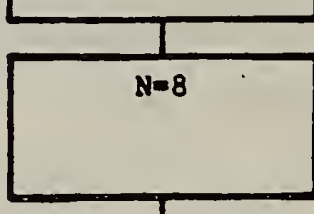

CALL FUNT 4

(FOR F78 F8)

QSON, QSOFF

QION, QIOFF
CALL FUNT 4

(FOR F5\& F6)

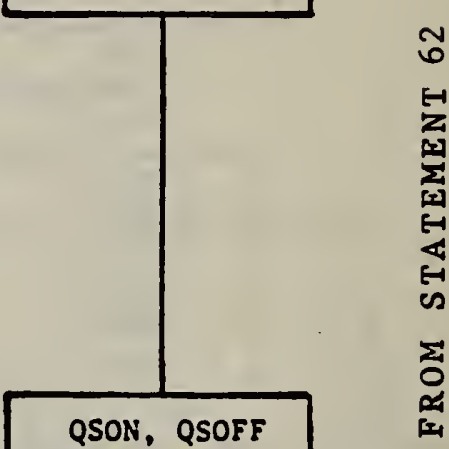

QION=QIOFF $=0$

DENSING UNITS USING OPTIONAL PROCEDURE WHERE NO OFF-CYCLE AIR FLOW PRESENT. TRANSFER BASED

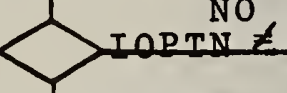

UPON IOPTN $=1$

IOP TN $=1$ $\left.\begin{array}{l}\text { CALL } \\ \text { CLFTR } \\ \text { (IOPTN=1) }\end{array}\right] \begin{aligned} & \text { THIS PATH FOR CONDEN- } \\ & \text { SING UNITS WITHOUT } \\ & \text { HEAT-UP/COOLDOWN TEST. }\end{aligned}$

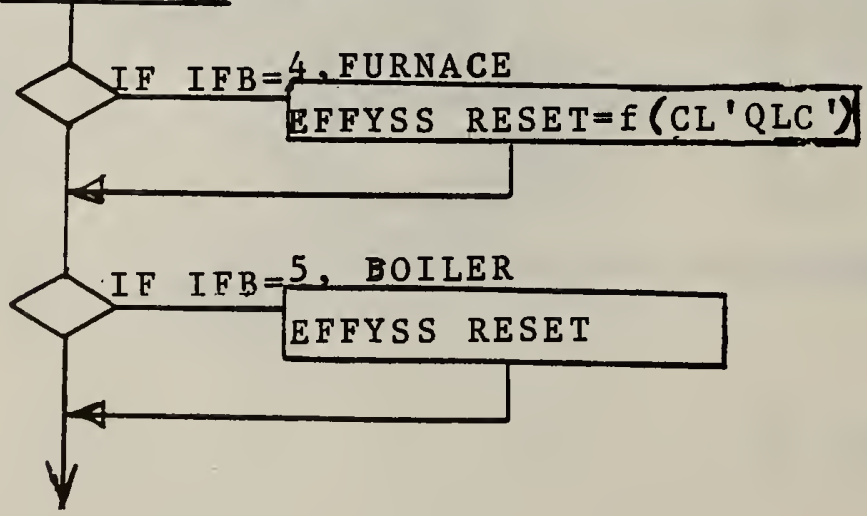

THIS PATH FOR ALL UNITS USING HEATUP / COOLDOWN TESTS .

CONT. ON NEXT PAGE 
FROM EFFYS EVALUATIONS FOR CONDENSING FURNACES AND BOILERS WITHOUT HEAT-UP/COOLDOWN TESTS

194

195

199
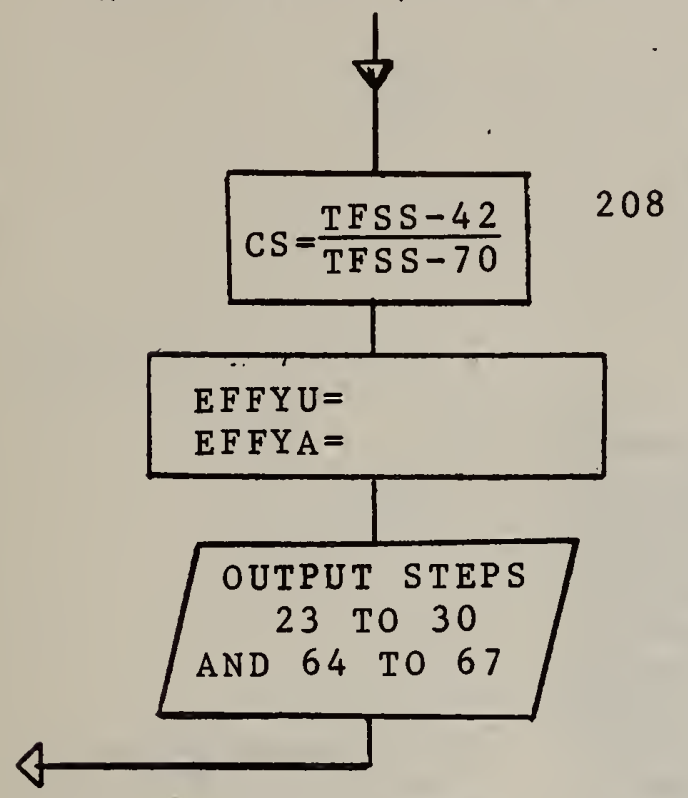

TRANSFER TO 997

ON NEXT

SHEET

NONCONDENSING FURNACES, BOILERS AND VENTED HEATERS

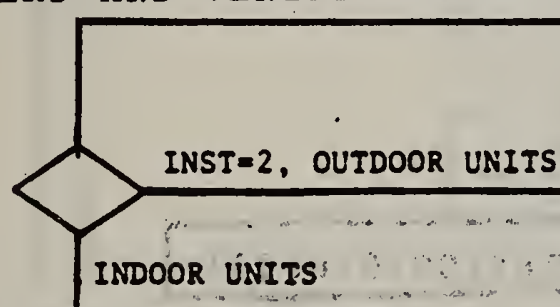

EFFYU INCLUDING INFILTRAIION BUT NOT JACKET LOSSES.

213

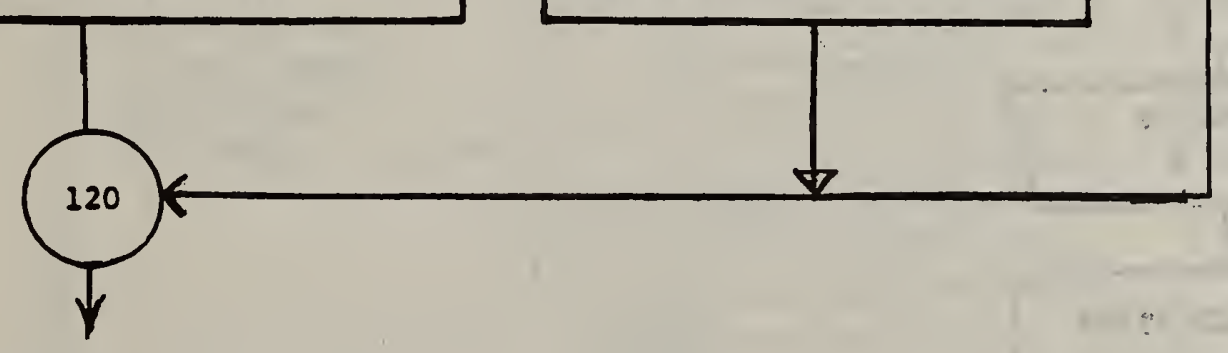

EFFYSS

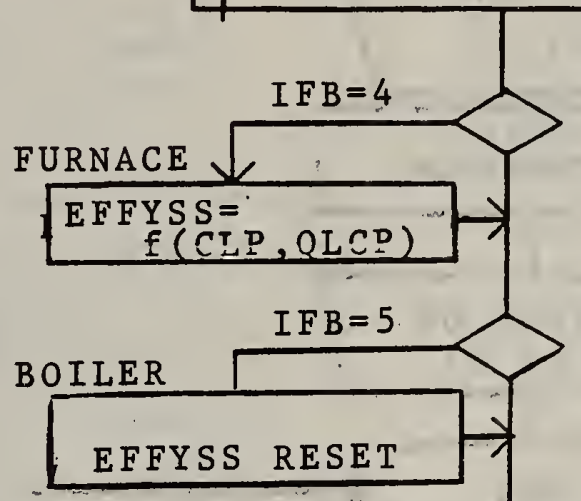

CALL CLFTR , IOPTN,...)
FROM 995 ON

PRECEDING PAGE

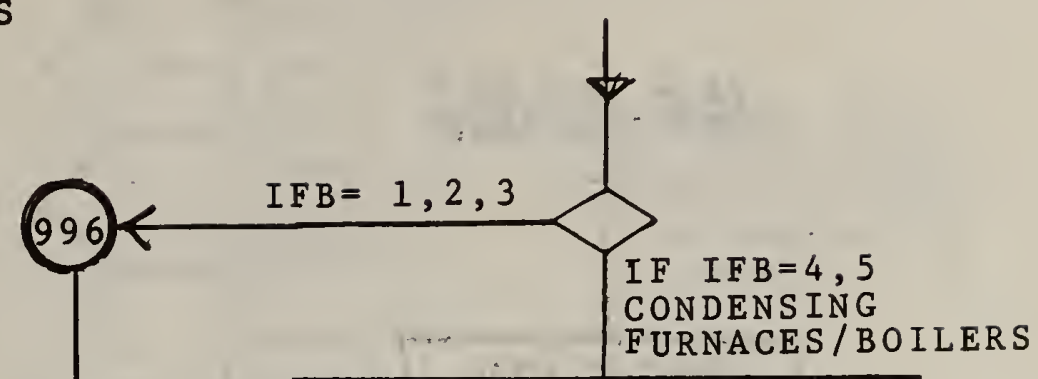

202

CALL CLFTR (CLP, QLCP, IFUEL, AFR, RT, HHVA, QL, 1, ZETFO, TFSS, TTON) (CL, QLC, IFUEL,..

EFFYU INCLUDING JACK - ? ET LOSSES; CL AND QLC FROM SUBROUTINE

CONTINUED ON NEXT PAGE 


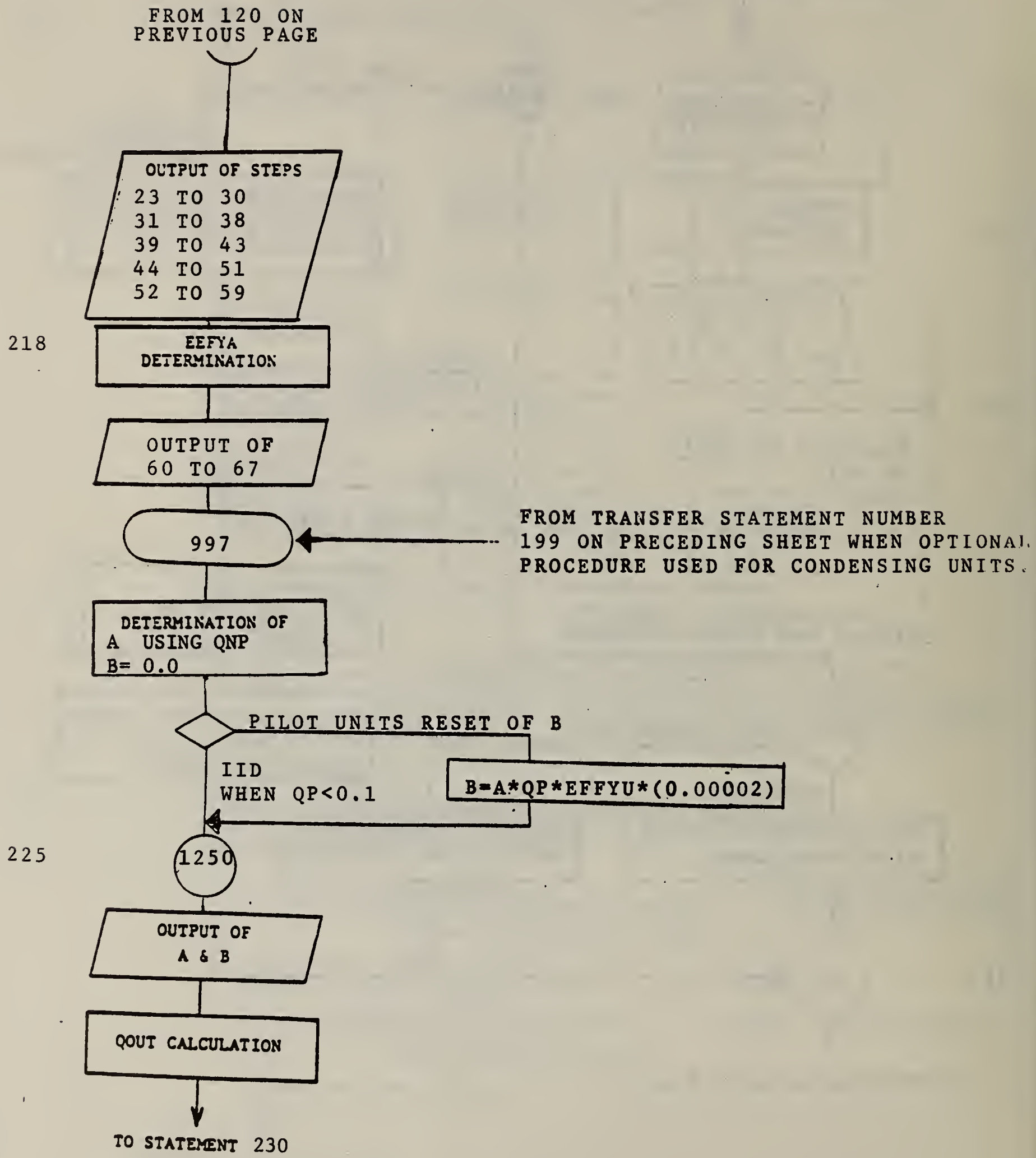




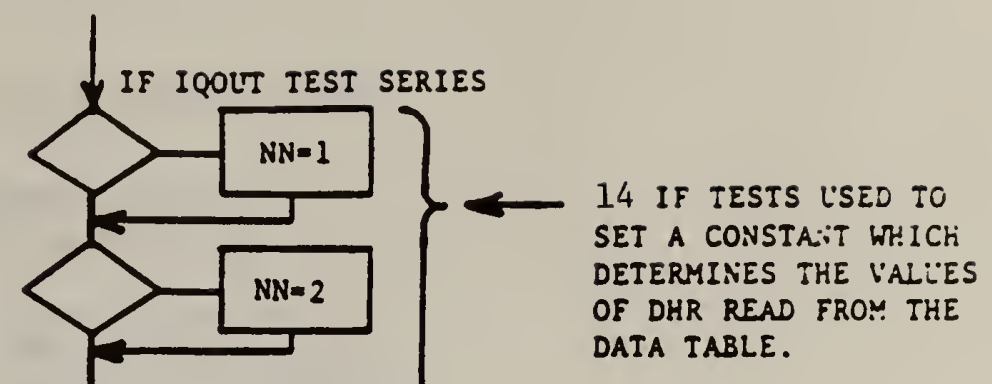

247
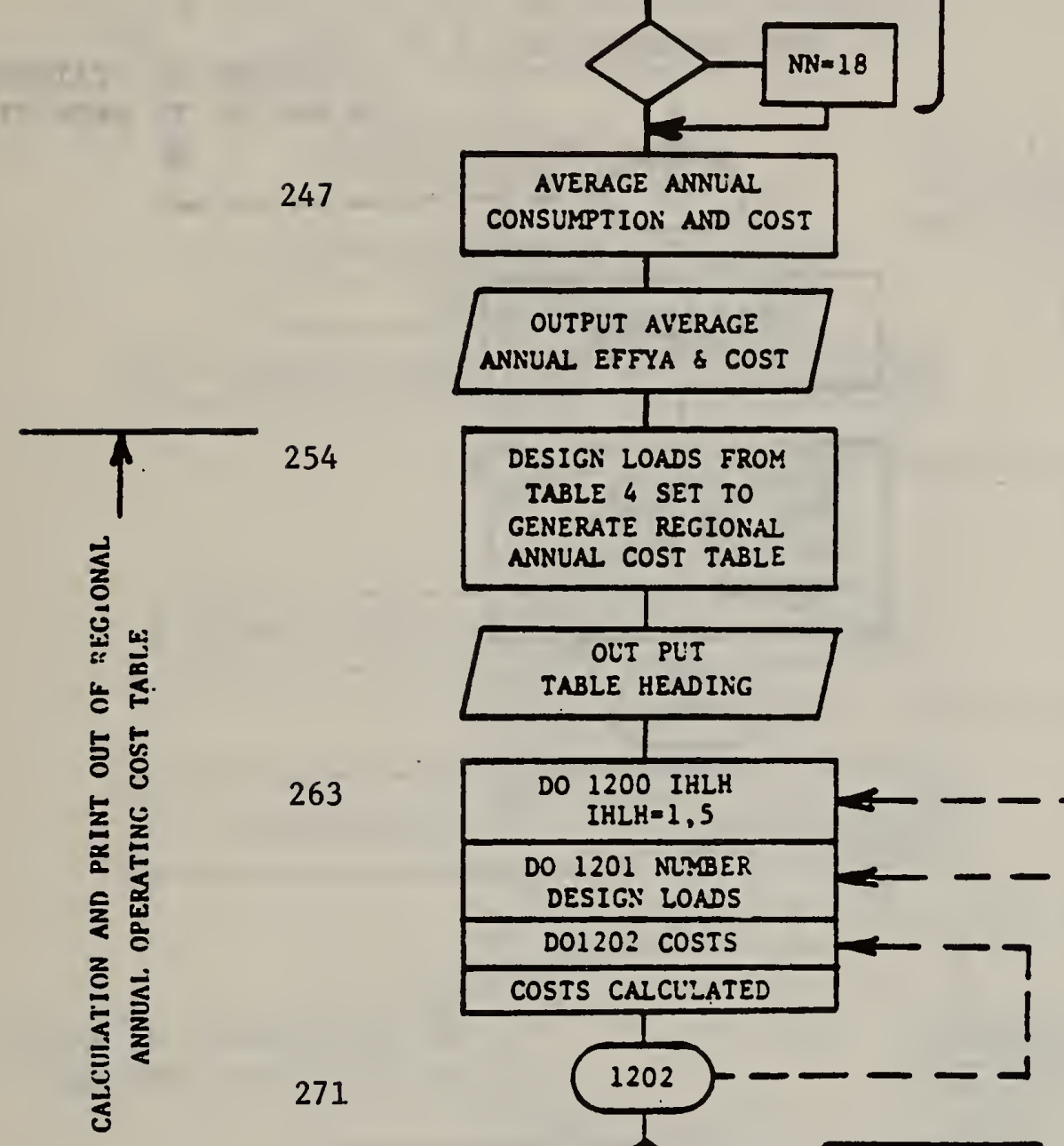
OF DHR READ FROب THE

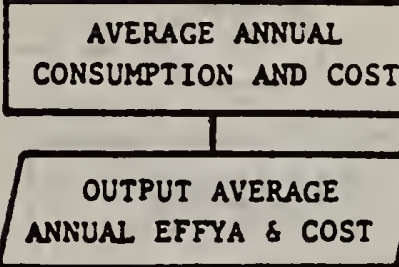

OLTPUT OF COST AT EACH DESIGN LOAD WITHIN EACH REGION

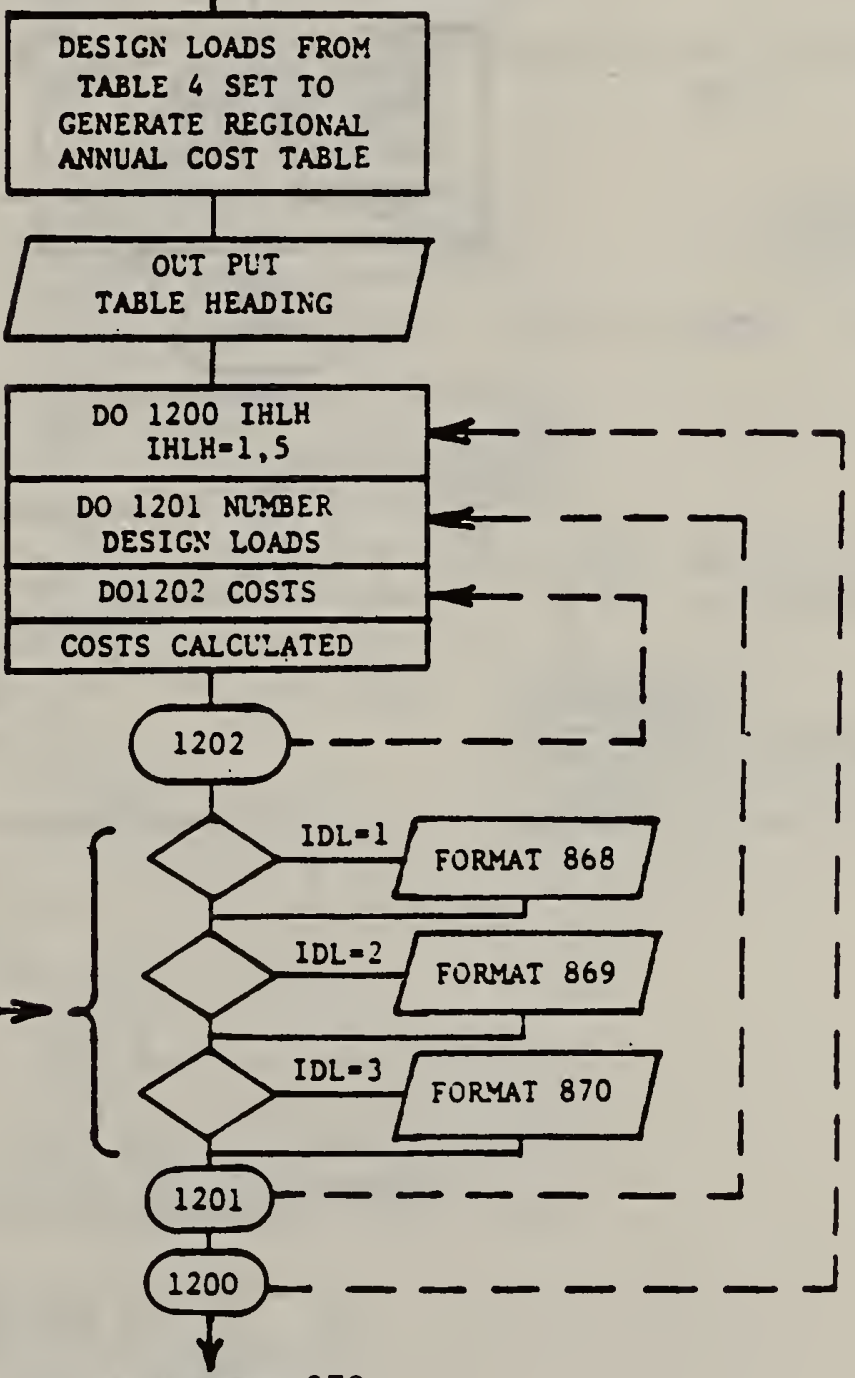

TO STATEMENT 278 
FRON STATE:EST 277

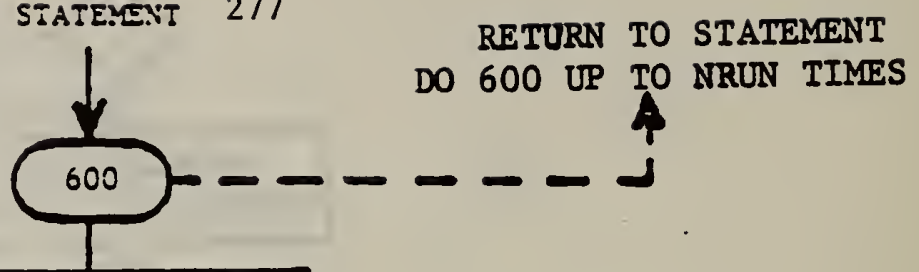

OLTPLT IORMATS

THESE ARE WRITIEN

FOR A 132 CHARACTER

CARRIAGE WIDTH. 
FIG. B-4. SUBROUTINE CLFTR FLOW CHART

1

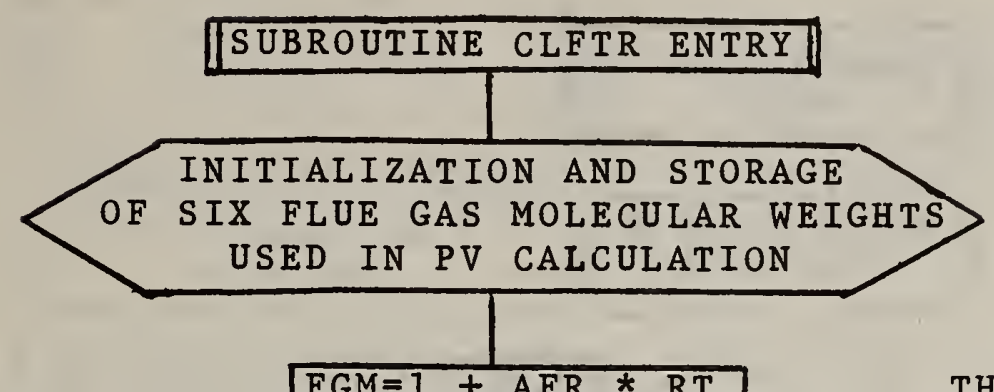

THIS IS THE BEGINNING OF STEP 68 IN THE CONDENSING BOILER CALCUL-

ATION PROCEDURE.

10 PV, PAETIAL PRESSURE OF WATER VAPOR GENERATED

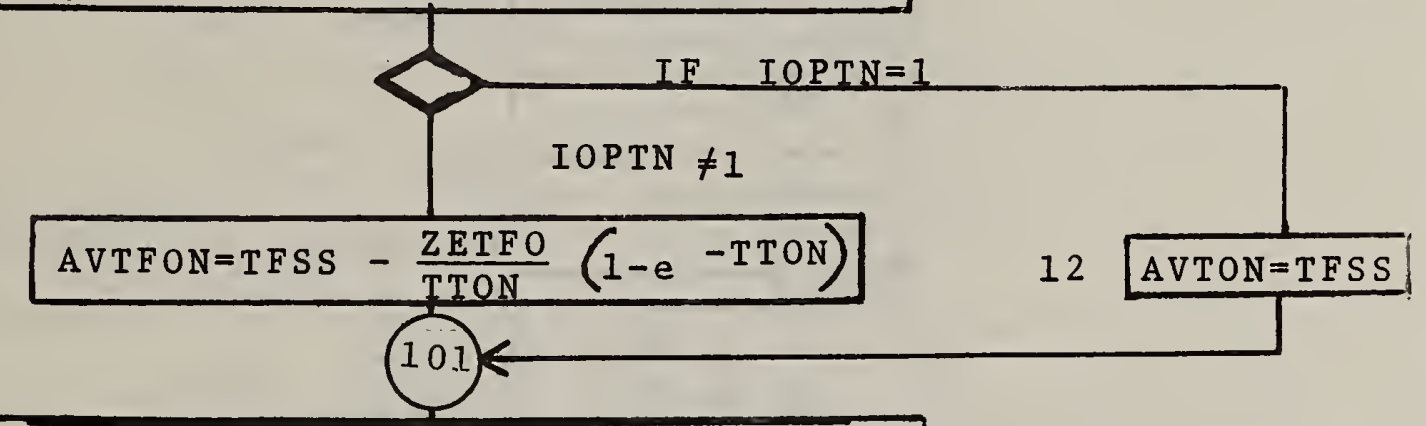

14
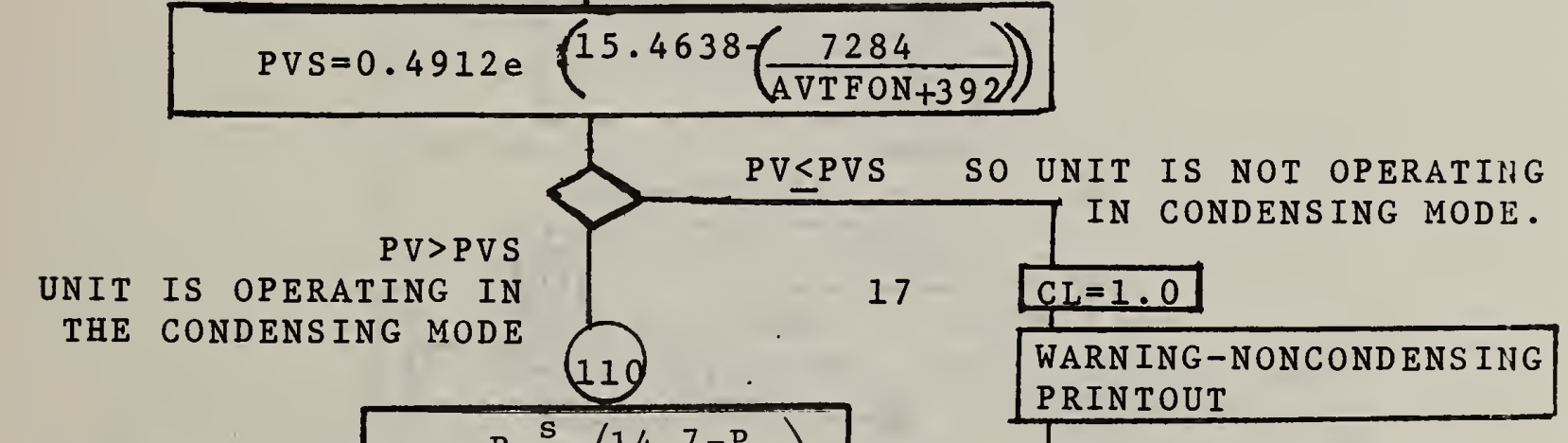

IN CALCULATION

PROCEDURE

$$
C L=\frac{{ }_{V}{ }^{\mathrm{S}}}{\mathrm{V}^{\mathrm{S}}}=\left(\frac{14 \cdot 7-\mathrm{P}_{\mathrm{V}}}{14 \cdot 7-\mathrm{P}_{\mathrm{V}}^{\mathrm{S}}}\right)
$$

QLC WHICH IS STEP 69, L LVALUATION

IN THE CALCULATION PROCEDURE 
FIG. B-5. SUBROUTINE FUNT 4 FLOW CHART

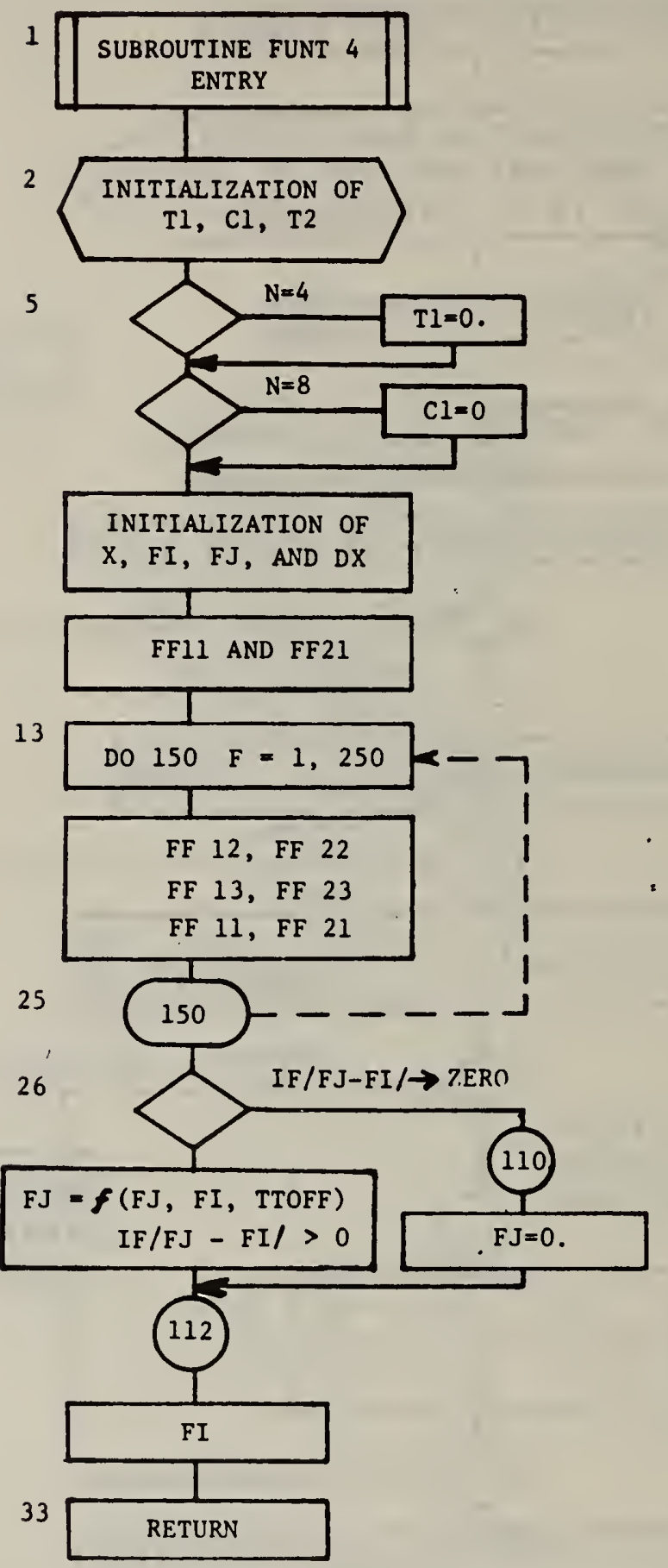




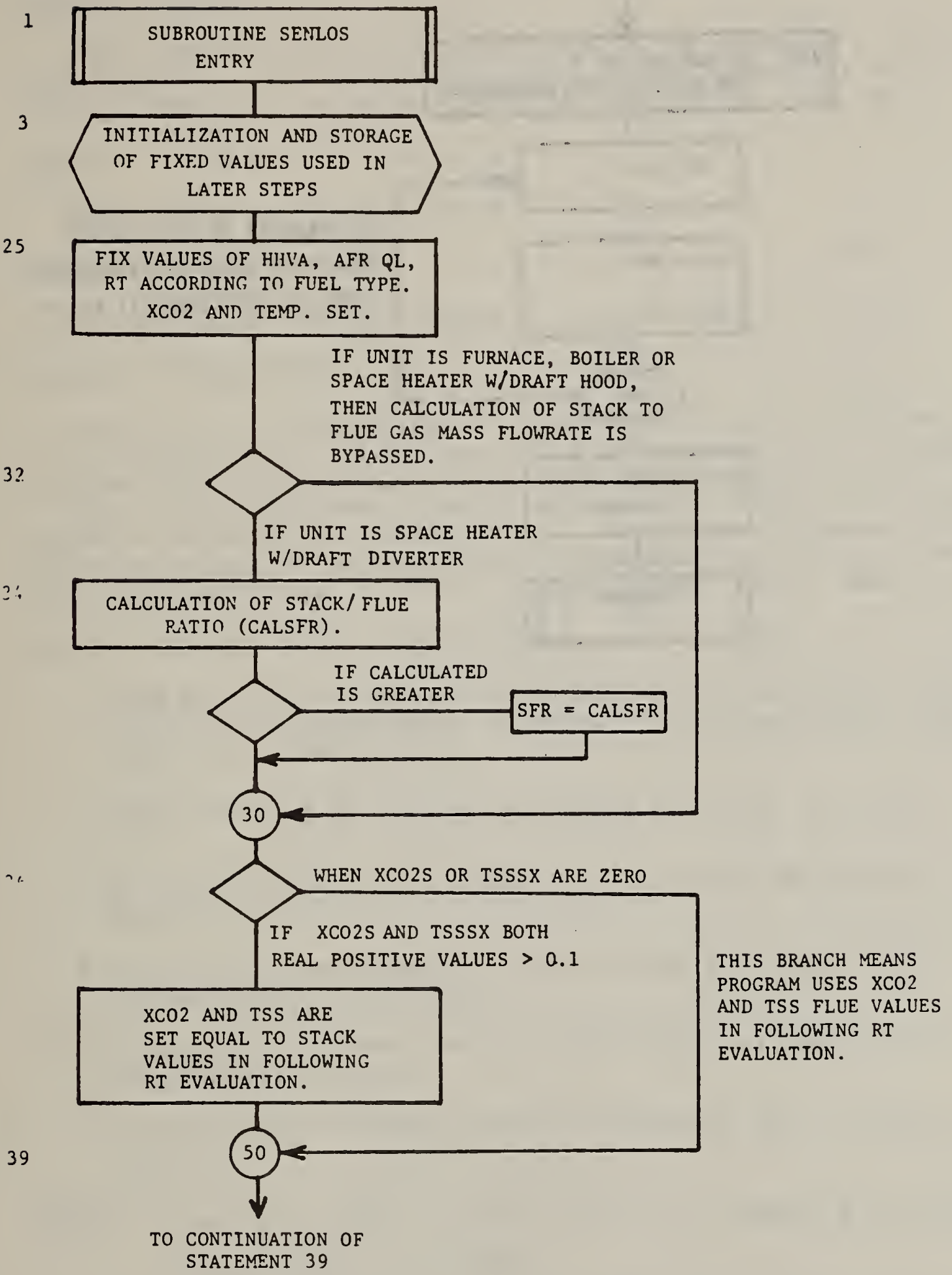




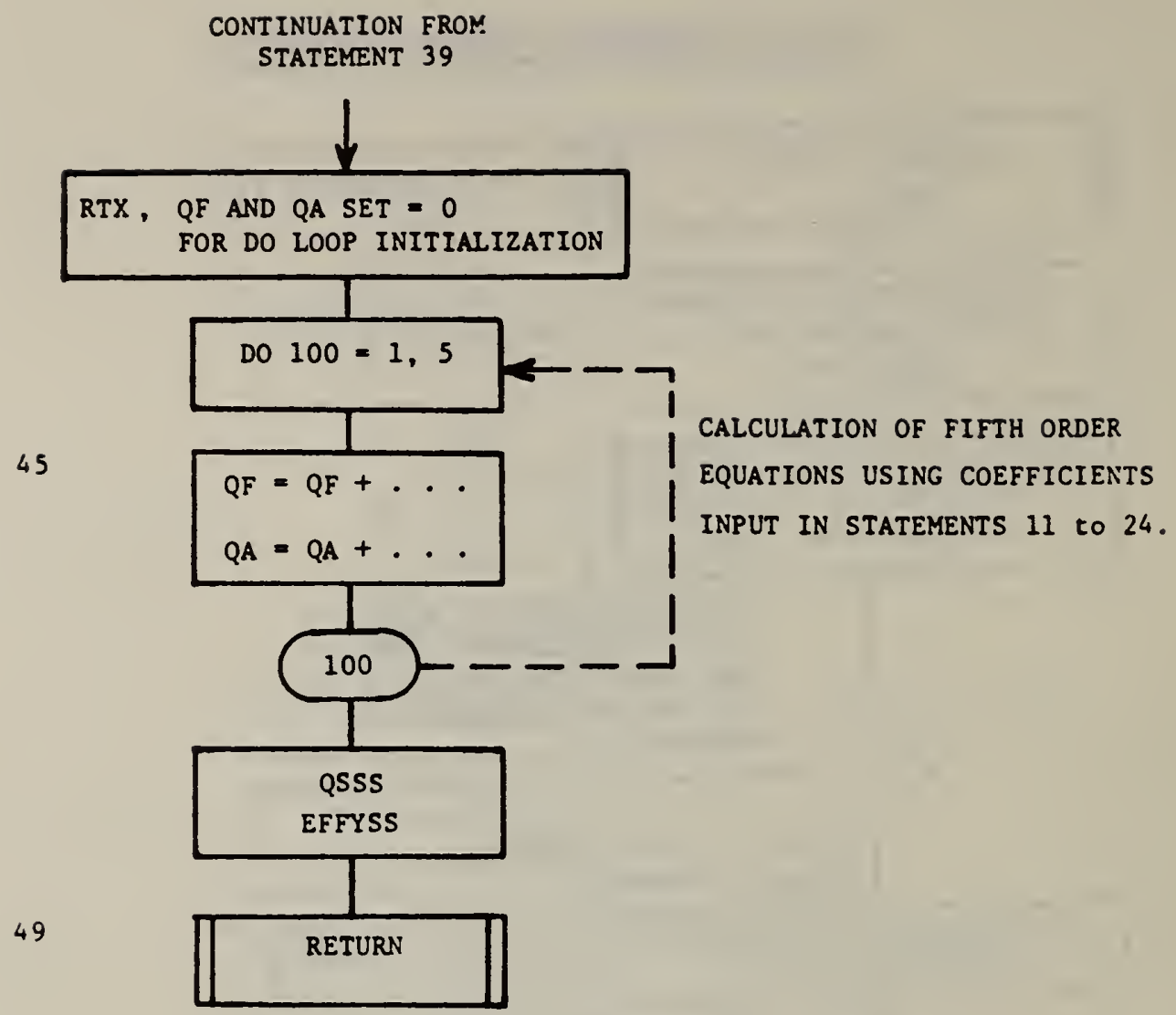




\section{Line 1: NRUN}

Enter number of sets of test data to be analyzed as a left justified integer. Set this value equal to the number of sets of data lines 2 through 8 to be analyzed by the NBSFBS program.

Line 2: TITLE

May be one to 80 characters.

\section{Line 3: SUBTITLE}

May be one to 80 characters.

\section{Line 4: IFB, INST}

Use IFB = 1 if the unit is a furnace, 2 if the unit is a boiler, 3 if the unit is a vented heater, 4 if the unit is a condensing furnace, or 5 if the unit is a condensing boiler.

For central furnaces installed indoors, vented wall furnaces, and vented room heaters, use INST $=1$. For floor furnaces and central furnaces installed outdoors or in unheated spaces, use INST $=2$. When using IFB equal to 4 or 5 , INST should always be set equal to \%.

Line 5: SYS非, IFUEL, $\mathrm{HHV}, \mathrm{Q}_{\mathrm{IN}}, \mathrm{QP}_{\mathrm{P}}, \mathrm{PE}, \mathrm{BE}, \mathrm{X}_{\mathrm{CO}_{2}}, \mathrm{~S}$

* SYS 非 must be an integer as found in tables 1 and 2 for each system being analyzed. Condensing systems should always be input as 9 through 12 .

* IFUEL must be an integer as given as IFUEL in step 2 of section 4.1 .

* HHV is the measured higher heating value of the test fuel, in B tu/ Ib.

* $Q_{I N}$ and $Q_{P}$ are measured steady-state and pilot input rates, respectfully, in Btu/hr.

* $P E$ and $B E$ are power burner and blower (or pump) input powers, respectfully, in $\mathrm{kW}$.

$\mathrm{x}_{\mathrm{CO}_{2} \mathrm{~S}}$ is the concentration by volume of $\mathrm{CO}_{2}$ in dry stack gas,
in Line 6: $T_{S, S S, X}, X_{C_{0}} F, T_{F, S S}, T_{F, O N}\left(t_{1}\right), T_{F, O N}\left(t_{2}\right), T_{F, O F F}\left(t_{3}\right)$,

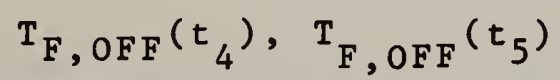

Input values of line six to be given in positive real numbers using units of degree $F$ for temperaturas, and percent (\%) for $\mathrm{X}_{\mathrm{CO}_{2}} \mathrm{~F}$. 
Input values for condensing units tested using optional procedure given in section 3.7 requiring no heat-up/cooldown test must have the values of $T_{F, O N}\left(t_{1}\right)$ through $T_{F, O F F}\left(t_{4}\right)$ equal to zero (0.) and IFB must be 4 or 5 .

Vaporizing type oil burners must have input values of $\mathrm{T}_{\mathrm{F}} \mathrm{SS}$ equal to $T_{F, O N}\left(t_{1}\right)$ and $T_{F, O N}\left(t_{2}\right)$.

Line 7: $T_{\text {RA }}, Q_{J}, S / F, D_{F}, D_{S}, Y, Q N P$

* $T_{\text {RA }}$ is input as a degree $F$ temperature.

* $Q_{J}$ is a percent $(\%)$.

* $S / F, D_{F}$, and $D_{S}$ are positive real numbers using values found in Table 2 .

NOTE: For vented heaters with draft diverters or draft hoods enter value of S/F from Table 2; program automatically calculates $\mathrm{S} / \mathrm{F}=(1.3)\left(\mathrm{R}_{\mathrm{T}, \mathrm{S}} / \mathrm{R}_{\mathrm{T}, \mathrm{F}}\right)$, compares it with the entered value, and uses the larger of the two.

* Y - is a positive real number. See step 22 of calculation procedure for value to be entered.

* QNP is the nameplate input rate in $B t u / h$.

Line 8: FLCOST, ELCOST, $K$

* FLCOST is given in dollars per unit of fuel.

* ELCOST is given as dollars per $\mathrm{kWh}$.

* $K$ is Btu content per unit of fuel.

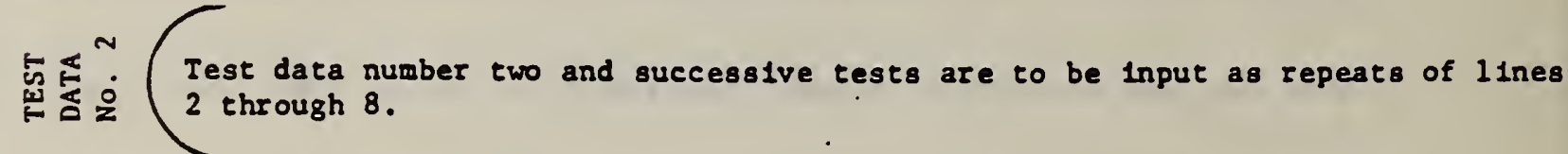
Lines 2 through 8.

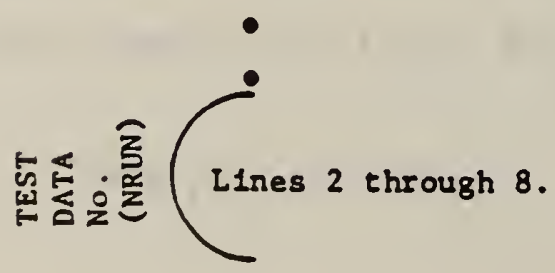

Note: Th1s program is written to use free fleld format Input as given by FORMAT No. 801 . All Input varlables must be separated by cormas or spaces as required by the computer processor syster used. 
Using Condensate Measurement for Calculation

of Annual Fuel Utilization Efficiency of Condensing

Furnaces and Boilers

\section{C1. Background}

An alternative test and calculation procedure to that presented in the main body of this report is discussed within this Appendix. This condensate collection procedure is considered to be a viable evaluation method for distinguishing the relative efficiency of one unit to another only if great care is taken to be consistent in the design and operation of the test setup in which each unit is evaluated. Therefore, it is a procedure that might best be conducted on a single test rig with the same experienced personnel.

Condensate collection can be used in conjunction with the test procedures for non-condensing heating systems to estimate the efficiencies of condensing furnaces and boilers ${ }^{1+}$ The steady-state, cool-down, and heat-up tests are required. Condensate is collected during a cyclic operation test. The quantity of collected condensate is used to determine the latent heat gain due to flue gas water vapor condensation as it is recovered within the confines of the furnace or boiler and not the flue or stack. The percent heat gain is then added to the non-condensing Annual Fuel Utilization Efficiency (AFUE) to estimate the condensing Annual Fuel Utilization. Efficiency. Details of test procedures for condensate collection and evaluation are given in the following sub-sections.

1 Federal Register, Volume 45, No. 252, Wednesday, December 31, 1980, pp. 86526 . 
The test unit shall be installed according to the requirements given in section 2. Control devices shall be installed to allow cyclic operation of the unit and return water or air flows as described in sections 3.2 and 3.3 of this recommended procedure. The test unit shall be leveled prior to test. Operation times and beginning and end of condensate collection shall be determined by a clock or timer with a minimum resolution to one second. Control of on and off operation actions shall be within \pm 6 seconds of the scheduled time. Condensate drain lines shall be attached to the unit as recommended by the manufacturer.

The flue pipe installation must not allow condensate formed in the flue pipe to flow back into the unit. An initial downward slope from the unit's exit, an offset with a drip leg, annular collection rings, or drain holes must be included in the flue pipe installation without disturbing normal flue gas flow (as given in section 2.2), and temperature measurement instrumentation (as given in section 2.6). Flue gases shall not flow out of the drain with the condensate.

Collection-containers must be glass or polished stainless steel, so removal of interior deposits can be easily made. The collection-container shall have a vent opening to the atmosphere.

The scale for measuring the containers and condensate sample mass shall be calibrated with an error no larger than \pm 0.5 percent over the range of interest. 
The condensing furnace or boiler is to have steady-state, cool-down, and heat-up tests conducted by the procedures for non-condensing units given In NBSIR 78-1543 section 3, using the flue gas, air or water flow, and room ambient conditions given in section 2 of the condensing furnace and boiler test procedure. The condensate collection containers shall be dried prior to each use and be at room ambient temperature prior to a sample collection. Tare weight of the collection-container must be measured and recorded prior to each sample collection.

Operating times for on and off cycles at $22.5 \%$ on time schedule shall be 9 minutes 41 seconds on and 33 minutes 16 seconds off for boilers and 3 minutes 52 seconds on and 13 minutes 20 seconds off for furnaces.

The unit should be operated in a cyclic manner until flue gas temperatures at the end of each on-cycle are within $5^{\circ} \mathrm{F}\left(2.8^{\circ} \mathrm{C}\right)$ of each other for two consecutive cycles. Then begin the three test cycles. Return water temperature for boilers or return air temperature for furnaces shall be equal to those required for steady-state test periods, and shall remain within the limits given in sections 2.5 .1 and 2.5 .2 of this procedure. Operation of the furnace blower or boiler pump shall conform to time delay requirements given in sections 3.2 and 3.3 for cool-down and heat-up tests.

Begin condensate collection at one minute before start up of the first test on-period. Three cycles later, the container shall be removed at the end of the cool down cycle one minute prior to the beginning of what would be the fourth cycle period. Condensate mass shall be measured immediately at the end of collection period to prevent evaporation loss from the sample. 
Fuel input shall be recorded during the entire test period starting at the beginning of the on-time of the first cycle to the beginning of the on-time of the second cycle, etc., for each of the three test cycles. Fuel Higher Heating Value (HHV), temperature and pressures necessary for determining fuel energy input, $Q_{c}$, will be observed and recorded. The fuel quantity and HHV shall be measured with errors no greater than one percent.

C4. Recommended Procedure for Calculating Annual Fuel Utilization Efficiency Using Collected Condensate Techniques

Using the conditions for a condensing furnace or boiler, and the procedure for the steady-state, cool-down, heat-up of the non-condensing furnace or boiler; calculations shall be performed to determine the Annual Fuel Utilization Efficiency (AFUE) (Co1. 67). The calculation steps for the non-condensing procedure are presented in section 4 of NBSIR 78-1543 [1] using a direct vent system number.

To determine the AFUE for the condensing units, use the following steps:

(1) Determine the mass of condensate for three cycles, $m_{c}$, by subtracting the tare container weight from the total container and condensate weight at end of three cycles of operation.

(2) Calculate the fuel energy input during the three cycles, $Q_{C}$, in Btu/(3 cycles).

(3) Calculate the heat gain due to condensation, $L_{G}$, in percent by the following equation:

$$
L_{G}=\frac{m_{c:}(1 \mathrm{bm} /(3 \text { cycle })) \times 1053.3(B t u / 1 b m) \times 100}{Q_{c}(B t u /(3 \text { cycle })}
$$

(4) Calculate the loss $\mathrm{L}_{c}$ due to hot condensate going down the drain correcting for the fact that this condensate did not go up the flue as heated vapor. 
$L_{c}=\frac{L_{G}}{1053.3} \times\left(1.0\left(T_{F, S S}(C o 1.11)-70\right)-0.45\left(T_{F, S S}(c o 1.11)-42\right)\right)$

(5) Calculate the condensing AFUE by adding the percent heat gain due to condensation, $\mathrm{L}_{\mathrm{G}}$, to the previously calculated non-condensing AFUE (col. 67), and by subtracting the loss $\mathrm{L}_{\mathrm{c}}$.

Condensing AFUE $=$ non-condensing AFUE $(c 01.67)+L_{G}-L_{c}$. 
NBS-114A (REV. 9-78)

\begin{tabular}{|c|c|c|}
\hline $\begin{array}{l}\text { 1. PUBLICATION OR REPORT NO. } \\
\text { NBSIR } 80-2110\end{array}$ & 2. GovL Accession No & 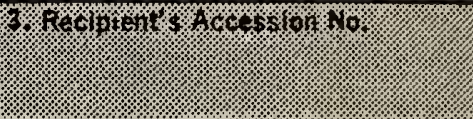 \\
\hline \multirow{2}{*}{\multicolumn{2}{|c|}{$\begin{array}{l}\text { 4. TITLE AND SUBTITLE } \\
\text { RECOMMENDED TESTING AND CALCULATION PROCEDURES FOR } \\
\text { ESTIMATING THE SEASONAL PERFORMANCE OF RESIDENTIAL } \\
\text { CONDENSING FURNACES AND BOILERS }\end{array}$}} & $\begin{array}{l}\text { 5. Publication Date } \\
\text { Apri1 } 1981\end{array}$ \\
\hline & & \\
\hline $\begin{array}{l}\text { 7. AUTHOR(S) } \\
\text { George E. Kelly and Mark E. Kuklewicz }\end{array}$ & & $\begin{array}{l}\text { 8. Performing Organ. Report No. } \\
\text { NBSIR } 80-2110\end{array}$ \\
\hline \multirow{2}{*}{\multicolumn{2}{|c|}{ 9. PERFORMING ORGANIZATION NAME AND ADDRESS }} & 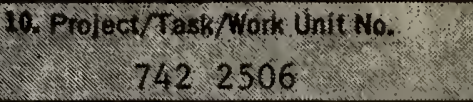 \\
\hline & & 11. Contract/Grant No. \\
\hline \multirow{2}{*}{\multicolumn{2}{|c|}{$\begin{array}{l}\text { 12. SPONSORING ORGANIZATION NAME AND COMPLETE ADDRESS (stroot, City, stato, zIP) } \\
\text { Department of Energy } \\
20 \text { Massachusetts Ave., NW } \\
\text { Washington, DC } 20585\end{array}$}} & $\begin{array}{l}\text { 13. Type of Report \& Period Covered } \\
\text { Final }\end{array}$ \\
\hline & & 11. Sponsoring Agency Code \\
\hline
\end{tabular}

15. SUPPLEMENTARY NOTES

Document describes a computer program; SF-185, FIPS Software Summary, is attached.

16. ABSTRACT (A 200-word or loss tactual summary of most significant information. If document includes a significant bibliography or literature survey, montion it here.)

Procedures are developed for testing and rating the performance of residential central furnaces and boilers of the condensing type. A condensing furnace or boiler is a unit designed to condense part of the water vapor generated by the burning of hydrogen in the fuel and equipped with a means of draining this condensate. The test procedure is similar to one developed by the National Bureau of Standards for the Department of Energy covering noncondensing central heating equipment, except that it requires slightly tighter control of the laboratory temperature, a return water temperature of $120^{\circ} \mathrm{F}$ $\left(48.9^{\circ} \mathrm{C}\right)$ with a 20 degree Fahrenheit (11.1 degree celsius) water temperature rise for hot water boilers, and offers an optional test procedure for condensing units having no off-period losses. The rating procedure provides a method for estimating the steady-state, part-load and annual fuel utilization efficiencies of condensing furnaces and boilers. It accounts for the fact that the latent heat loss for a condensing unit is smaller than for a conventional furnace or boiler, since some of the water vapor generated from burning hydrogen in the fuel is condensed and thereby gives up part of its latent heat to the heat exchanger and jacket.

17. KEY WORDS (six to twelve entries; alphabetical order; capitalize only the first lottor of the first koy word unloss a proper name; separated by semicolons)

Annual fuel utilization efficiency; annual operating costs; central heating equipment; condensing boilers; condensing furnaces; part-load performance; rating procedure; seasonal efficiency.

18. AVAILABILITY [X] Unlimited

For Official Distribution. Do Not Release to NTIS

Order From Sup. of Doc., U.S. Government Printing Office, Washington, DC 20402, SD Stock No. SN003-003-

Order From National Technical Information Service (NTIS), Springfield, VA. 22161

\begin{tabular}{|l|c|}
\hline $\begin{array}{l}\text { 19. SECURITY CLASS } \\
\text { (THIS REPORT) }\end{array}$ & $\begin{array}{c}\text { 21. NO. OF } \\
\text { PRINTED PAGES } \\
\text { UNCLASSIFIED }\end{array}$ \\
\hline $\begin{array}{l}\text { 20. SECURITY CLASS } \\
\text { (THIS PAGE) }\end{array}$ & 93 \\
UNCLASSIFIED & 22. Price \\
\hline
\end{tabular}


1. 